\title{
INFLUÊNCIA DAS TÉCNICAS DE COLETA DE AMOSTRAS NA DETERMINAÇÃO DAS PROPRIEDADES FÍSICAS DO SOLO
}

\author{
RENÉ PORFIRIO CAMPONEZ DO BRASIL \\ Engenheiro Civil
}

Orientador: Prof. Dr. MARCOS VINÍCIUS FOLEGATTI

\begin{abstract}
Dissertação apresentada à Escola Superior de Agricultura "Luiz de Queiroz", Universidade de São Paulo, para a obtenção do título de Mestre em Agronomia, Área de Concentração: Irrigação e Drenagem
\end{abstract}

P I R A C I C A B A

Estado de São Paulo - Brasil

Maio - 2000 


\section{Dados Internacionais de Catalogação na Publicação (CIP) DIVISĀO DE BIBLIOTECA E DOCUMENTAÇĀO - Campus "Luiz de Queiroz"/USP}

\section{Camponez Do Brasil, René Porfirio}

Influência das técnicas de coleta de amostras na determinação das propriedades fisicas do solo / René Porfirio Camponez Do Brasil. - - Piracicaba, 2000.

102 p. : il.

Dissertação (mestrado) - Escola Superior de Agricultura Luiz de Queiroz, 2000. Bibliografia.

1. Amostragem 2. Densidade do solo 3. Equipamento agricola 4. Fisica do solo 5. Propriedade fisico-quimica I. Titulo

$\operatorname{CDD} 631.43$ 


\section{À minha esposa Sely \\ Aos meus filhos Mariana e Afonso}

Aos meus pais Moacyr $\boldsymbol{e}$ Therezinha (in memoriam)

Dedico. 


\section{AGRADECIMENTOS}

Meus sinceros agradecimentos a todas as pessoas e instituições que, de forma direta ou indireta, contribuíram para a consecução desse trabalho. Em especial, agradeço:

Ao Prof. Dr. Marcos Vinícius Folegatti, pela confiança depositada, amizade e sempre presente orientação.

Aos professores do Departamento de Engenharia Rural, pela oportunidade concedida para a realização do curso de Pós-Graduação e pelos ensinamentos ao longo do mesmo.

Ao prof. Dr. Sérgio de Oliveira Morais, pelos ensinamentos e sugestões durante a realização deste trabalho.

Ao prof. Dr. Álvaro Pires da Silva, pela amizade e discussões sobre o tema do trabalho.

Ao prof. Dr. Antônio Carlos A. Gonçalves, pelos ensinamentos e orientação durante a instalação deste trabalho.

Ao prof. Dr. Sérgio Nascimento Duarte, pelas sugestões e apoio para a realização deste trabalho.

Ao prof. Dr. José Carlos Chitolina e ao Dr. José Antônio Quaggio, pelo estímulo e encorajamento no início do trabalho.

A Prof. Dra. Sônia Maria De Stefano Piedade, pelo apoio no planejamento e execução da análise estatística do ensaio.

A CAPES, pela concessão da bolsa de estudo.

Aos colegas de curso, Carmelo, Caroline, Edivaldo, Enio, Flávio, Leonardo, Maurício, Ronaldo, e Valdemício, pelo apoio e sugestões durante a implantação e condução do ensaio.

Ao funcionário do Laboratório de Solos e Manejo de Irrigação, Gilmar Grigolon, pela ajuda prestada nas análises físicas do solo. 


\section{SUMÁRIO}

Página

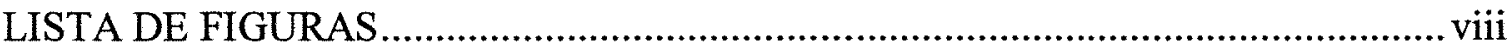

LISTA DE TABELAS .......................................................................... xiii

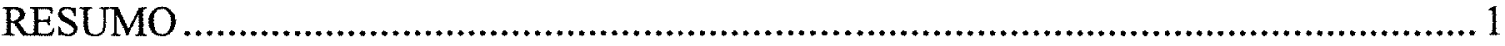

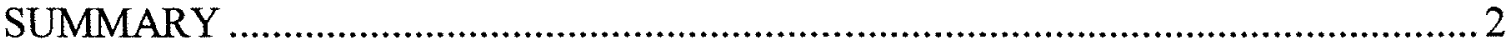

1 INTRODUÇÃ

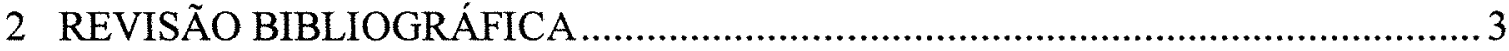

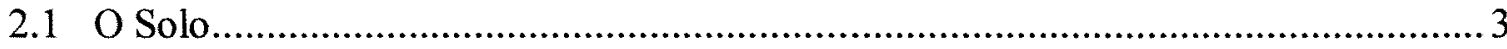

2.2 Variabilidade espacial das propriedades físico-hídricas do solo .......................... 4

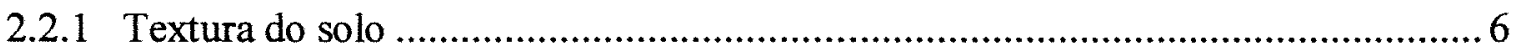

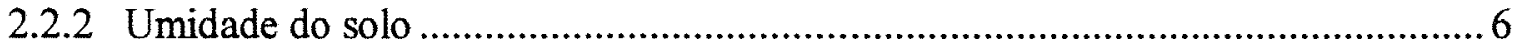

2.2.3 Porosidade total, macroporosidade e microporosidade ................................ 8

2.2.4 Densidade do solo e de partículas ......................................................

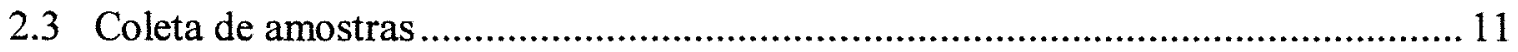

2.3.1 Número de amostras necessárias ........................................................ 11

2.3.2 Métodos para análise física dos solos ............................................. 12

2.3.3 Equipamentos utilizados na coleta de amostras......................................... 13

2.3.4 Comparação de diferentes tamanhos de cilindros................................... 16

2.4 Métodos estatísticos para estudo da variabilidade ........................................ 17

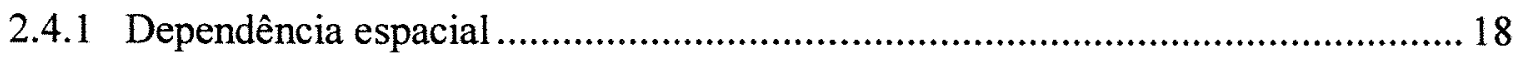

2.4.2 Delineamento em quadrados latinos ..................................................... 19

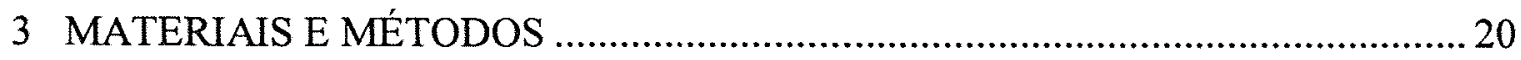


Página

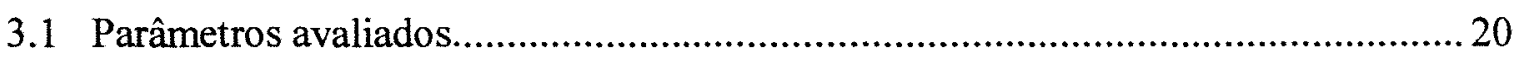

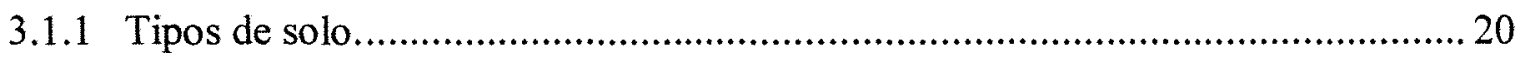

3.1.2 Equipamentos e tamanho de anéis volumétricos.................................22

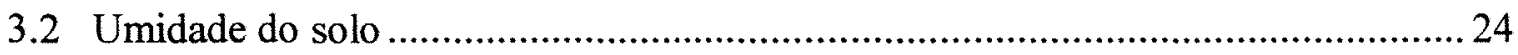

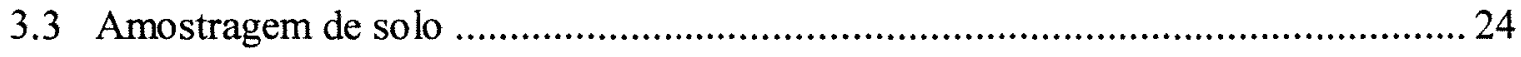

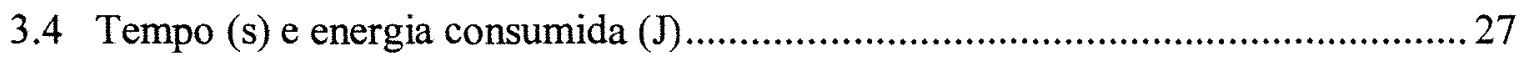

3.5 Porosidade total, macroporosidade e microporosidade ................................. 27

3.6 Textura, umidade gravimétrica, densidade do solo e de partículas. .....................29

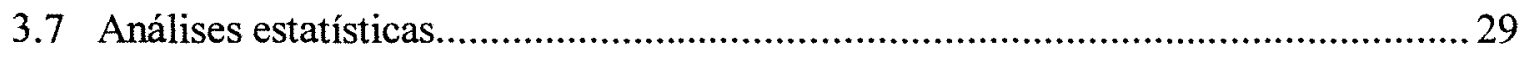

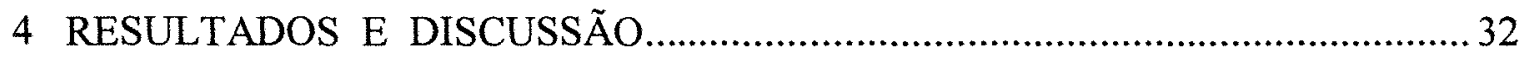

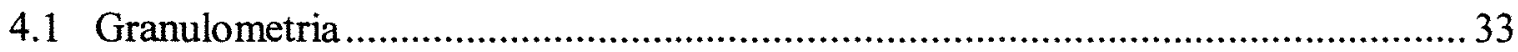

4.1.1 Amostras coletadas no solo argiloso da Fazenda Areão ................................. 33

4.1.2 Amostras coletadas no solo arenoso da Fazenda Sertãozinho....................... 33

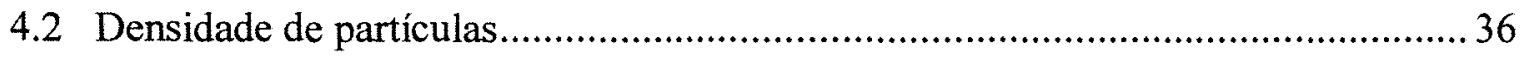

4.2.1 Solos argilosos amostrados na fazenda Areão ....................................... 36

4.2.2 Solos arenosos amostrados na fazenda Sertãozinho .................................. 36

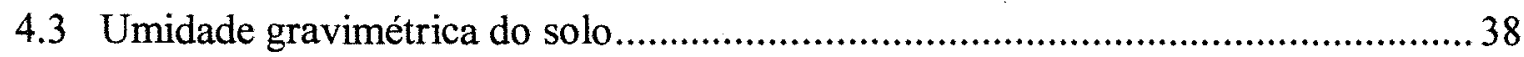

4.3.1 Solos argilosos amostrados na fazenda Areão.......................................... 38

4.3.2 Amostras coletadas no solo arenoso da Fazenda Sertãozinho .........................41

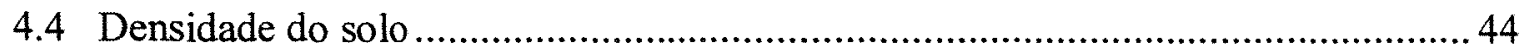

4.4.1 Solos argilosos amostrados na fazenda Areão...................................... 44

4.4.2 Amostras coletadas no solo arenoso da Fazenda Sertãozinho........................... 48 
Página

4.5 Correlação entre umidade e densidade do solo ............................................51

4.5.1 Solos argilosos amostrados na fazenda Areão.......................................... 51

4.5.2 Amostras coletadas no solo arenoso da Fazenda Sertãozinho...........................52

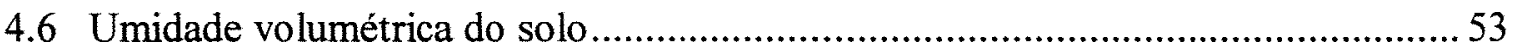

4.6.1 Solos argilosos amostrados na fazenda Areão ..........................................53

4.6.2 Amostras coletadas no solo arenoso da Fazenda Sertãozinho..........................56

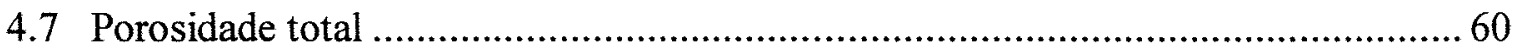

4.7.1 Porosidade total determinado pelo método indireto. ................................ 60

4.7.1.1 Solos argilosos amostrados na fazenda Areão ........................................ 60

4.7.1.2 Amostras coletadas no solo arenoso da fazenda Sertãozinho........................ 63

4.7.2 Porosidade total determinada pelo método direto......................................66

4.7.2.1 Solos argilosos amostrados na fazenda Areão....................................... 66

4.7.2.2 Amostras coletadas no solo arenoso da Fazenda Sertãozinho .........................69

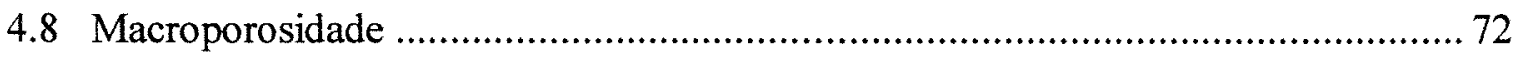

4.8.1 Solos argilosos amostrados na fazenda Areão ......................................... 72

4.8.2 Amostras coletadas no solo arenoso da Fazenda Sertãozinho......................... 75

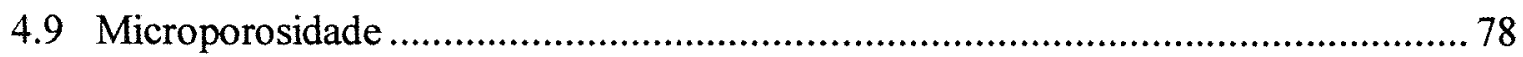

4.9.1 Solos argilosos amostrados na fazenda Areão ......................................... 78

4.9.2 Amostras coletadas no solo arenoso da Fazenda Sertãozinho....................... 81

4.10 Energia consumida na operação de coleta de amostras. .................................. 84

4.10.1 Solos argilosos amostrados na fazenda Areão .................................... 85

4.10.2 Amostras coletadas no solo arenoso da Fazenda Sertãozinho.........................86 
Página

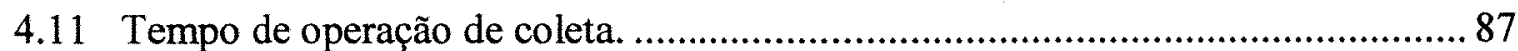

4.11.1 Solos argilosos amostrados na fazenda Areão............................................ 88

4.11.2 Amostras coletadas no solo arenoso da Fazenda Sertãozinho........................ 89

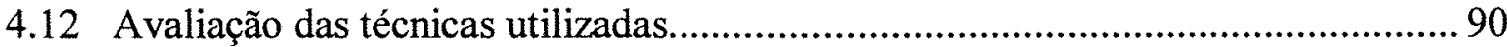

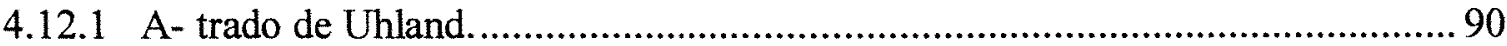

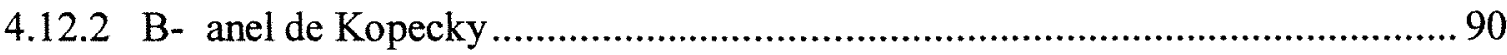

4.12 .3 C- trado modelo Soil Moisture ….......................................................... 91

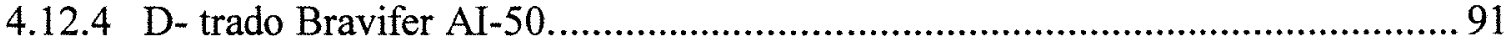

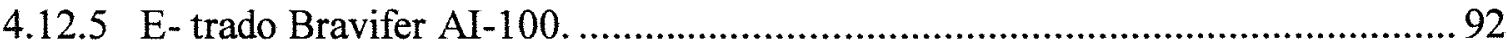

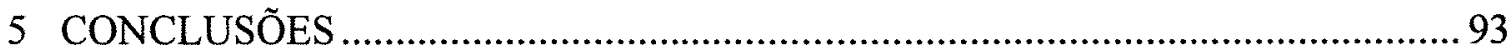

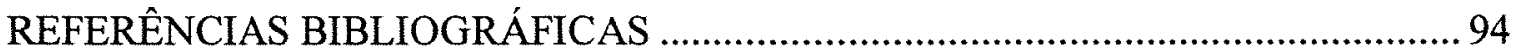




\section{LISTA DE FIGURAS}

Página

1 a) Área irrigada por pivô central no solo argiloso da fazenda Areão;

b) plantação de laranjas no solo arenoso da fazenda Sertãozinho.

2 Equipamentos: a) trado de Uhland (TU); b) Anel de Kopecky (AK); c) trado Soil Moisture (TSM); d) trado Bravifer AI-50 (TB50) e e) trado Bravifer AI100 (TB100).

3 Quadro de saturação do solo com os tensiômetros instalados. 24

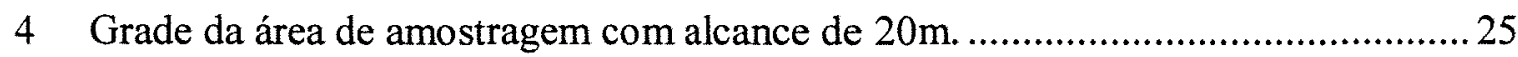

5 Grade de coleta de amostras, com as posições das ferramentas...............................25

6 Quadro de coleta com os orifícios para retirada das amostras. ................................26

7 Médias da umidade gravimétrica do solo (U\%), determinadas com as ferramentas de coleta A, B, C, D, E, e a geral, nas quatro grades coletadas no solo argiloso da fazenda Areão.

8 Mapas de contorno, com a distribuição espacial da umidade do solo U\%, nas quatro grades de amostragem, do solo argiloso da fazenda Areão: a) grade 1, b) grade2, c) grade 3 e d) grade 4 .

9 Médias da umidade gravimétrica do solo (U\%), determinadas com as ferramentas de coleta A, B, C, D, E, e a geral, nas quatro grades coletadas no solo arenosos da fazenda Sertãozinho.

10 Mapas de contorno, com a distribuição espacial da umidade do solo U\%(g/g), nas quatro grades de amostragem do solo arenoso da fazenda Sertãozinho: a) grade 1, b) grade 2 , c) grade 3 e d) grade 4

11 Médias da densidade do solo $\left(\mathrm{g} . \mathrm{cm}^{-3}\right)$, determinadas com as ferramentas de coleta A, B, C, D, E, e a geral, nas quatro grades de amostragem no solo argiloso da fazenda Areão. 
12 Mapas de contorno, com a distribuição espacial das densidades do solo $\left(\mathrm{g}^{\mathrm{c}} \mathrm{cm}^{-3}\right)$ nas quatro grades de amostragem do solo argiloso da fazenda Areão: a) grade 1, b) grade 2, c) grade3 e d) grade 4.

13 Médias da densidade do solo $\left(\mathrm{g}_{\mathrm{cm}} \mathrm{cm}^{-3}\right)$, determinadas com as ferramentas de coleta A, B, C, D, E, e a geral, nas quatro grades de amostragem no solo arenoso da fazenda Sertãozinho.

14 Mapas de contorno, da distribuição espacial das densidades do solo $\left(\mathrm{g} \cdot \mathrm{cm}^{-3}\right)$ nas quatro grades de amostragem do solo arenoso da fazenda Sertãozinho: a) grade 1, b) grade 2, c) grade3 e d) grade 4.

15 Correlação entre as médias de U\%(g/g) e $\operatorname{Ds}\left(\mathrm{g} . \mathrm{cm}^{-3}\right)$, obtidas com as diferentes ferramentas no solo argiloso da fazenda Areão, num total de 100 amostras, separadas em classes: $\mathrm{U}(\%)<17 \% ; 17,1$ a $18,5 \%$; 18,6 a $20 \% ; 20,1$ a $21 \%$ e $U(\%)>21 \%$.

16 Correlação entre as médias de $\mathrm{U} \%(\mathrm{~g} / \mathrm{g})$ e $\mathrm{Ds}\left(\mathrm{g} \cdot \mathrm{cm}^{-3}\right)$, obtidas com as diferentes ferramentas no solo arenoso da fazenda Sertãozinho, num total de 100 amostras, separadas em classes: $U(\%)<9,5 \% ; 9,6$ a $10,5 \% ; 10,6$ a $11,5 \% ; 11,6$ a $12,5 \%$ e $U(\%)>12,6 \%$. 52

17 Mapas de contorno, com a distribuição espacial das umidades volumétricas $\theta_{\mathrm{s}} \%\left(\mathrm{~cm}^{-3} \cdot \mathrm{cm}^{-3}\right)$ nas quatro grades de amostragem do solo argiloso da fazenda Areão: a) grade 1, b) grade2, c) grade3 e d) grade4.

18 Médias da umidade volumétrica do solo $\theta_{\mathrm{s}} \%\left(\mathrm{~cm}^{3} \cdot \mathrm{cm}^{-3}\right)$, determinadas com as ferramentas A, B, C, D, E, e a geral, nas quatro grades amostradas no solo argiloso da fazenda Areão.

19 Mapas de contorno das quatro grades de amostragem, com a distribuição espacial da umidade volumétrica do solo $\theta_{\mathrm{s}} \%\left(\mathrm{~cm}^{3} / \mathrm{cm}^{3}\right)$, no solo arenoso da fazenda Sertãozinho: a) grade 1, b) grade2, c) grade3 e d) grade4. 
20 Médias da umidade volumétrica do solo $\theta_{\mathrm{s}} \%\left(\mathrm{~cm}^{3} \cdot \mathrm{cm}^{-3}\right)$, determinadas com as ferramentas A, B, C, D, E, e a geral, nas quatro grades amostradas no solo arenoso da fazenda Sertãozinho.

21 Mapas de contorno das quatro grades de amostragem, com a distribuição espacial da porosidade total determinada pelo método indireto no solo argiloso da fazenda Areão: a) grade 1, b) grade2, c) grade3 e d) grade4.

22 Médias da porosidade total do solo, determinadas pelo método indireto, com as ferramentas A, B, C, D, E, e a geral nas quatro grades de coletadas no solo argiloso da fazenda Areão.

23 Mapas de contorno, da distribuição espacial da porosidade total do solo determinada pelo método indireto, nas quatro grades de amostragem do solo arenoso da fazenda Sertãozinho: a) grade1, b) grade2, c) grade3 e d) grade4..... 65

24 Médias da porosidade total do solo, determinadas pelo método indireto com as ferramentas A, B, C, D, E, e a geral, nas quatro grades amostradas no solo arenoso da fazenda Sertãozinho.

25 Mapas de contorno, da distribuição espacial da porosidade total do solo determinada pelo método direto, nas quatro grades de amostragem do solo argiloso da fazenda Areão: a) grade 1, b) grade2, c) grade3 e d) grade4.

26 Médias da porosidade total do solo, determinadas pelo método direto com as ferramentas A, B, C, D, E, e a geral, nas quatro grades amostradas no solo argiloso da fazenda Areão.

27 Mapas de contorno, da distribuição espacial da porosidade total do solo determinada pelo método direto, nas quatro grades de amostragem do solo arenoso da fazenda Sertãozinho: a) grade1, b) grade2, c) grade3 e d) grade4..... 71 
28 Médias da porosidade total do solo, determinadas pelo método direto com as ferramentas A, B, C, D, E, e a geral, nas quatro grades amostradas no solo arenoso da fazenda Sertãozinho.

29 Mapas de contorno, da distribuição espacial da macroporosidade do solo, nas quatro grades de amostragem do solo argiloso da fazenda Areão: a) grade1, b) grade2, c) grade 3 e d) grade4.

30 Médias da macroporosidade do solo, determinadas com as ferramentas A, B, C, $\mathrm{D}, \mathrm{E}$, e a geral, nas quatro grades amostradas no solo argiloso da fazenda Areão

31 Mapas de contorno, da distribuição espacial da macroporosidade, nas quatro grades de amostragem do solo arenoso da fazenda Sertãozinho: a) grade1, b) grade2, c) grade3 e d) grade4.

32 Médias da macroporosidade do solo, determinadas com as ferramentas A, B, C, D, E, e a geral, nas quatro grades amostradas no solo arenoso da fazenda Sertãozinho

33 Mapas de contorno das quatro grades de amostragem, com a distribuição espacial da microporosidade do solo argiloso na fazenda Areão: a) grade1, b) grade 2, c) grade3 e d) grade4.

34 Médias da microporosidade do solo, determinadas com as ferramentas A, B, C, D, E, e a geral, nas quatro grades amostradas no solo argiloso da fazenda Areão.

35 Mapas de contorno das quatro grades de amostragem, com a distribuição espacial da microporosidade do solo arenoso na fazenda Sertãozinho: a) grade1, b) grade 2, c) grade 3 e d) grade 4. 
36 Médias da microporosidade do solo, determinadas com as ferramentas A, B, C, $\mathrm{D}, \mathrm{E}$, e a geral, nas quatro grades amostradas no solo arenoso da fazenda Sertãozinho.

37 Médias da energia potencial gravitacional consumida na operação de coleta de amostras, com as ferramentas, no solo argiloso da fazenda Areão e no solo arenoso da fazenda Sertãozinho, num total de 20 amostras para cada ferramenta.

38 Médias do tempo de operação das coletas de amostras, obtidas com as ferramentas no solo argiloso da fazenda Areão e no solo arenoso da fazenda Sertãozinho, num total de 20 amostras para cada ferramenta em cada tipo de solo. 87 


\section{LISTA DE TABELAS}

Página

1 Análise granulométrica com percentagens de areia, silte e argila na fazenda Areão, e as respectivas classificações do solo, para as grades de amostragem número 1 (a), grade2 (b), grade3 (c), grade4 (d) e para média geral (e).................. 34

2 Análise granulométrica com percentagens de areia, silte e argila na fazenda Sertãozinho, e as respectivas classificações do solo, para as grades de amostragem número 1 (a), grade 2 (b), grade3 (c), grade4 (d) e para média geral (e).

3 Densidades de partículas do solo, obtidas com as ferramentas de coleta no solo argiloso, à profundidade média de $20 \mathrm{~cm}$. Valores médios de 5 repetições.

4 Densidades de partículas do solo, obtidas com as ferramentas de coleta no solo arenoso, à profundidade média de $20 \mathrm{~cm}$. Valores médios de 5 repetições.

5 Umidades gravimétricas do solo (U\%) obtidas com as ferramentas de coleta no solo argiloso da fazenda Areão, à profundidade média de $20 \mathrm{~cm}$. Valores médios de 5 repetições.

6 Umidade gravimétrica do solo (U\%), obtidas com as ferramentas de coleta no solo arenoso da fazenda Sertãozinho, à profundidade média de $20 \mathrm{~cm}$. Valores médios de 5 repetições.

7 Densidades do solo $\left(\mathrm{g} . \mathrm{cm}^{-3}\right)$, obtidas com ferramentas de coleta no solo argiloso da fazenda Areão, à profundidade média de $20 \mathrm{~cm}$. Valores médios de 5 repetições.

8 Densidade do solo $\left(\mathrm{g}_{\mathrm{cm}} \mathrm{cm}^{-3}\right)$, obtidas com as ferramentas de coleta no solo arenoso da fazenda Sertãozinho, à profundidade média de $20 \mathrm{~cm}$. Valores médios de 5 repetições. 
9 Umidades volumétricas do solo (U\%), obtidas pelas ferramentas de coleta no solo argiloso da fazenda Areão, à profundidade média de $20 \mathrm{~cm}$. Valores médios de 5 repetições. ................................................................ 53

10 Umidades volumétricas do solo (U\%), obtidas com as ferramentas de coleta no solo arenoso da fazenda Sertãozinho, à profundidade média de $20 \mathrm{~cm}$. Valores médios de 5 repetições.

11 Porosidade total do solo (\%), determinada pelo método indireto, através dos dados obtidos com as ferramentas no solo argiloso da fazenda Areão, à profundidade média de $20 \mathrm{~cm}$. Valores médios de 5 repetições.

12 Porosidade total do solo (\%), determinada pelo método indireto, através dos dados obtidos com as ferramentas no solo arenoso da fazenda Sertãozinho, à profundidade média de $20 \mathrm{~cm}$. Valores médios de 5 repetições.

13 Porosidade total do solo (\%), determinada pelo método direto, através dos dados obtidos com as ferramentas no solo argiloso da fazenda Areão, à profundidade média de $20 \mathrm{~cm}$. Valores médios de 5 repetições.

14 Porosidade total do solo (\%) obtida pelo método direto, com as amostras coletadas pelas ferramentas no solo argiloso da fazenda Sertãozinho, à profundidade média de $20 \mathrm{~cm}$. Valores médios de 5 repetições.

15 Macroporosidades do solo (\%), obtidas com as amostras coletadas pelas ferramentas no solo argiloso da fazenda Areão, à profundidade média de $20 \mathrm{~cm}$. Valores médios de 5 repetições.

16 Macroporosidades do solo (\%), obtidas com as amostras coletadas pelas ferramentas no solo arenoso da fazenda Sertãozinho, à profundidade média de $20 \mathrm{~cm}$. Valores médios de 5 repetições. 
17 Microporosidades do solo (\%), obtidas com as amostras coletadas pelas ferramentas no solo argiloso da fazenda Areão, à profundidade média de $20 \mathrm{~cm}$. Valores médios de 5 repetições.

18 Microporosidades do solo (\%), obtidas com as amostras coletadas pelas ferramentas no solo arenoso da fazenda Sertãozinho, à profundidade média de $20 \mathrm{~cm}$. Valores médios de 5 repetições.

19 Energia potencial gravitacional consumida pelas ferramentas, para coletar as amostras, em cada grade de amostragem no solo argiloso da fazenda Areão, à profundidade média de $20 \mathrm{~cm}$. Valores médios de 5 repetições.

20 Energia potencial gravitacional consumida pelas ferramentas, para coletar as amostras em cada grade de amostragem no solo arenoso da fazenda Sertãozinho, à profundidade média de $20 \mathrm{~cm}$. Valores médios de 5 repetições. .......86

21 Tempos médios consumidos pelas ferramentas, para coletar as amostras em cada grade de amostragem no solo argiloso da fazenda Areão à profundidade média de $20 \mathrm{~cm}$. Valores médios de 5 repetições.

22 Tempos médios consumidos pelas ferramentas, para coletar as amostras em cada grade de amostragem no solo arenoso da fazenda Sertãozinho à profundidade média de $20 \mathrm{~cm}$. Valores médios de 5 repetições. 


\title{
INFLUÊNCIA DAS TÉCNICAS DE COLETA DE AMOSTRAS NA DETERMINAÇÃO DAS PROPRIEDADES FÍSICAS DO SOLO
}

\author{
Autor: RENÉ PORFIRIO CAMPONEZ DO BRASIL \\ Orientador: Prof. Dr. MARCOS VINÍCIUS FOLEGATTI
}

\section{RESUMO}

Com o objetivo de avaliar os efeitos de cinco diferentes equipamentos de amostragem para determinação das propriedades físicas do solo, em dois solos na região de Piracicaba, SP, utilizou-se os equipamentos para coleta de amostras de solo indeformadas: (i) Trado de Uhland; (ii) Anel de Kopecky; (iii) Trado modelo Soil Moisture; (iv) Trado Bravifer AI-50; (v) Trado Bravifer AI-100. A amostragem foi realizada de forma sistematizada em 4 grades de $1 \mathrm{~m}^{2}$, cada uma com 25 pontos coletados, de forma a termos 5 repetições por ferramenta, totalizando 100 amostras para cada solo. Com os resultados obtidos nas análises, concluiu-se que: a) as técnicas de amostragem influem nas propriedades fisico-hídricas do solo, densidade do solo, umidade volumétrica, porosidade total, macroporosidade e microporosidade; b) $\mathrm{O}$ efeito conjunto da umidade do solo no momento da coleta e o equipamento/tamanho do cilindro, interferem nos resultados das propriedades fisico-hídricas do solo, com maior intensidade nos solos argilosos; c) As ferramentas que apresentaram menores tempos e energia consumida durante o processo de coleta de amostras, para os dois solos estudados, foram na seguinte ordem: trado Bravifer AI-50, trado Bravifer AI-100, trado Soil Moisture, anel de Kopecky e trado Uhland; d) As ferramentas que afetaram menos a estrutura do solo no interior do cilindro e que consumiram menos tempo e energia na operação de coleta, foram o trado Bravifer AI-50, Trado Bravifer AI-100 e trado Soil Moisture; e e) A ferramenta anel de Kopecky, superestimou as propriedades: densidade do solo, umidade volumétrica e microporosidade, e subestimou as propriedades: porosidade total calculada, porosidade total determinada e a macroporosidade do solo, caracterizando estar compactando a amostra no interior do cilindro. 


\title{
INFLUENCE OF SOIL SAMPLE TECHNICHES ON SOIL PHYSICAL PROPERTIES DETERMINATION.
}

\author{
Author: RENÉ PORFIRIO CAMPONEZ DO BRASIL \\ Adviser: Prof. Dr. MARCOS VINÍCIUS FOLEGATTI
}

\section{SUMMARY}

In order to evaluate the effects of five different soil sampling equipments for soil physical properties determination, in two soils of Piracicaba, SP, region, the following samplers for undisturbed soil sampling were used: (i) Uhland; (ii) Kopecky's ring; (iii) Soil Moisture sampler ring kit, type 200A; (iv) Bravifer AI-50 and (v) Bravifer AI-100. Sampling was made in a systematic scheme in four grids of $1 \mathrm{~m}^{2}$, with 25 sampling points each, given five replications and 100 samples for each soil. The physical analysis results allowed us to conclude that: (a) the sampling techniques can influence on soil physical properties, like soil bulk density; moisture; total, macro and micro porosity; (b) the combined effect of soil moisture at sampling time and the relation sampler/ring size influences on the results of soil physical properties mainly in clayey soils; (c) samplers which required lesser time and power consumption during sampling process, for both soils, were: Bravifer AI-50, Bravifer AI-100, Soil Moisture, Kopecky's ring and Uhland; (d) samplers which had lesser effects on soil structure inside the samples and that required a lesser time and power in the sampling process were Bravifer AI-50, Bravifer AI-100 and Soil Moisture; (e) Kopecky's ring overestimated the soil bulk density, soil moisture and microporosity and underestimated the calculated total porosity, measured total porosity and macroporosity, letting us to conclude that sample was compacted inside the soil core. 


\section{INTRODUÇÃO}

A agricultura nos dias de hoje, na busca de alta produtividade, tem utilizado avançadas tecnologias, como o GPS (Global Position System) na Agricultura de Precisão, uso de modernos sistemas de irrigação e fertirrigação, além do desenvolvimento de variedades de plantas geneticamente modificadas.

Porém, a eficiência da utilização dessas técnicas, esbarra na grande variabilidade das propriedades fisico-hídricas e fisico-químicas existentes nos solos em geral, como, textura, estrutura, densidade e retenção de água, decorrentes da variabilidade existente no seu material de origem e de outros fatores formadores destes solos, e que podem ainda, ser incrementadas pelas diversas operações e usos da atividade agrícola.

Estudos sobre variabilidade, têm revelado que mesmo em um solo considerado homogêneo, as suas propriedades físicas podem variar entre pontos relativamente próximos de uma mesma área, de forma significativa e sem causa visual aparente. Esta variabilidade pode também aumentar significativamente com o tamanho da área, tornando desaconselhavel, conduzir-se experimentos em áreas muito extensas com pontos amostrais muito distantes uns dos outros.

Através da utilização de métodos da estatística clássica, que admite a independência e aleatoriedade dos pontos amostrais, é possível determinar o número de amostras adequado para se calcular um valor médio representativo, e assim, contornar em parte, o problema da variabilidade espacial do solo.

A geoestatística é baseada nos conceitos das funções aleatórias, variáveis regionalizadas e estacionaridade. Essa técnica, considera a existência da dependência espacial entre os pontos amostrados, isto é, leva em consideração a distribuição espacial 
das medidas, o que permite definir o raio de correlação espacial entre as amostras. As análises estatísticas, tanto na clássica, quanto na geoestatística, se baseiam nos valores das propriedades físicas do solo, determinadas através das amostras que foram coletadas no campo, porém, o fator que não tem sido considerado nos estudos da variabilidade espacial dessas propriedades, é a influência da utilização de diferentes ferramentas para coleta das amostras do solo, nos resultados dessas determinações.

O trabalho teve como objetivo, utilizar os diferentes métodos de coleta de amostras de solo indeformadas, com cilindros de tamanho variáveis, avaliando o tempo e a energia consumida na coleta, e comparar a influência desses métodos nos resultados obtidos de propriedades fisico-hídricas do solo. 


\section{REVISÃO BIBLIOGRÁFICA}

\subsection{O Solo}

O solo é um corpo natural, de constituintes minerais e orgânicos, diferenciados em horizontes de profundidade variável, formando uma superfície inconsolidada que recobre as rochas e mantém a vida animal e vegetal da terra. É constituído de camadas que diferem pela natureza física, química, mineralógica e biológica, que se desenvolveram com o tempo sob a influencia do clima e da própria atividade biológica (Vieira, 1975).

O solo é constituído de um sistema composto de três fases: sólida, liquida e gasosa. A fase sólida é formada por matéria inorgânica e orgânica. Estes dois componentes formam o chamado "mátrix" do solo. A porção mineral consiste de partículas de vários tamanhos, resultantes da decomposição das rochas que deram origem ao solo. A fração orgânica tem sua origem no acumulo de resíduos vegetais e animais, que ocorrem no solo em diferentes estágios de decomposição, e por organismos vivos em atividade. A fase liquida é constituída pela solução do solo, que é composta por água, sais em dissolução e matéria coloidal em suspensão. A fase gasosa é o ar do solo, assim denominado pelo fato de sua composição diferir do ar atmosférico quanto a proporção percentual de seus elementos (Buckman \& Brady,1966).

Um solo considerado ideal para agricultura, deveria ter a proporção de cerca de $50 \%$ de porosidade total e $50 \%$ de volume de sólidos. Os sólidos devem estar assim divididos, $45 \%$ de matéria mineral (primário e secundário), e 5\% de matéria orgânica em 
peso, e a porosidade total em $33,5 \%$ de água (micropóros) e 16,5\% de ar (macropóros) (Kiehl, 1979).

A classificação dos solos é feita de acordo com sua textura e estrutura das partículas, e a determinação de sua classe textural, se baseia no tamanho das partículas, dividindo-se em três frações: Areia $(2,0 \mathrm{~mm}$ a $0,02 \mathrm{~mm})$, Silte $(0,02$ a $0,002 \mathrm{~mm})$ e Argila $(<0,002 \mathrm{~mm})$, que pode ser visualizada no diagrama triangular que descreve as misturas das frações, de acordo com a escala proposta pelo Departamento de Agricultura dos Estados Unidos (USDA) e adotado pela Sociedade Brasileira de Ciência do Solo (Prevedello, 1996).

A Estrutura do solo é determinada pelo arranjamento dessas partículas na constituição do solo, e este arranjamento é um dos principais responsáveis pela grande variabilidade das propriedades físicas do solo (Kiehl, 1979).

\subsection{Variabilidade espacial das propriedades físico-hídricas do solo}

O estudo da variabilidade espacial de solos não é um estudo recente, tendo sido analisada sob vários ângulos, desde o início do século. Recentemente, tem despertado uma atenção especial pelo fato de ser possível tirar proveito dela e, pela aplicação de técnicas de análise estatística (geoestatística) que visam compreender melhor os processos físico-químicos que ocorrem no solo (Reichardt et al., 1986).

A análise de dados obtidos em condições de campo tem apresentado dificuldade nas diversas áreas da ciência, devido a variabilidade espacial. Quando se trata da ciência do solo, as dificuldades tornam-se maiores porque, sendo a formação do solo resultante de uma série de fatores, o produto final é bastante heterogêneo em relação às suas características e propriedades (Silva at al, 1989).

Tormena (1998), trabalhando com o intervalo hídrico ótimo (IHO), verificou que os sistemas de plantio direto e preparo convencional promovem diferentes alterações na estrutura do solo, que foram traduzidas pelas diferenças nos valores do IHO. O preparo excessivo e a ausência de cobertura podem expor estes solos a elevadas taxas de secamento e aumentar bruscamente a resistência, enquanto que sob plantio direto, a 
presença de resíduos mantém maiores conteúdos de água no solo, contribuindo para manter as propriedades fisicas numa faixa ótima para a cultura.

A importância da variabilidade do solo em experimentação agrícola e no manejo de água na agricultura irrigada, é indiscutível. Os primeiros estudos sobre a variabilidade, tiveram como objetivo, caracterizar e verificar o seu efeito no rendimento das culturas.

Posteriormente, a casualização, a repetição, e um maior conhecimento da função de distribuição, levou a adoção da amostragem ao acaso, desprezando as coordenadas geográficas dos pontos amostrados. Esse procedimento estatístico, que visa contornar o problema da variabilidade espacial, é utilizado para garantir a independência entre as amostras, requisito básico em ensaios com delineamentos experimentais.

A hipótese de aleatoriedade não é garantida somente com a distribuição normal, e só pode ser verificada com uma descrição da estrutura de dependência da variável, obtida apenas quando a mesma é associada às coordenadas geográficas (Vieira,).

Nas ultimas décadas, muitos estudos retomaram a preocupação original do conhecimento da variabilidade, com a ferramenta geoestatística, que vem demonstrando que, independente da unidade experimental estudada, as variáveis do solo tem apresentado em sua maioria, dependência espacial (Burgess \& Webster, 1980).

Apesar do grande numero de trabalhos voltados a estudos específicos da variabilidade das propriedades do solo, é insipiente o conhecimento sobre o efeito das ferramentas utilizadas na coleta de amostras indeformadas, seja este provocado pelo tamanho da amostra, tipo de equipamento, umidade adequada no processo de sua remoção em cada tipo de solo e facilidade de operação. Essas informações, são importantes a fim de se trabalhar com ferramentas e condições adequadas para cada tipo de solo, padronizando o equipamento, tornando comparáveis, amostras de procedências distintas. 


\subsubsection{Textura do solo}

Babalola (1978), afirma que alta variabilidade em propriedades físicas do solo tais como teores de areia, silte e argila além da densidade do solo, causam uma alta variabilidade na retenção de água.

As glebas estudadas por Berg \& Klamt (1997), apresentaram grande homogeneidade de textura, mas grande variabilidade entre glebas, indicando influência de material de origem na formação dos solos. Uma amostragem sistemática em grade com pontos distanciados de 600 metros, foi suficiente para estudar as características mais estáveis dos solos, no entanto, deve ser entendido que grande variância de propriedades químicas e físicas relacionadas ao manejo, podem estar presentes à distâncias menores que 50 metros.

Macedo et al (1995), estudando em solo podzólico vermelho amarelo, as propriedades, percentagens de argila, areia total, areia grossa, silte, matéria orgânica, macro, micro e total porosidades, e densidades aparente e real, concluíram que para determinar as propriedades de densidades aparente e real, apenas uma amostra seria suficiente. Já o comportamento da porosidade total foi uma variável, o que acarretou a necessidade de se coletar 3 amostras. Concluíram ainda que a menor variabilidade espacial correspondeu a fração areia total, seguida pelas frações areia grossa, silte e argila, e que de modo geral, a variabilidade espacial cresceu com o aumento da distância entre os pontos amostrais.

\subsubsection{Umidade do solo}

A caracterização da variabilidade espacial da umidade do solo, pode ser obtida, não necessariamente, pela estatística clássica, dada a alteração da distribuição pelo afastamento da normal, durante o ciclo da cultura. A escolha de um único parâmetro para avaliação da variabilidade pode levar a resultados errôneos (Libardi et al, 1996).

A principal causa da dispersão dos pontos nas curvas de calibração de Sondas de Neutrons e, consequentemente, de seus baixos coeficientes de correlação, é a variabilidade espacial dos parâmetros, umidade e densidade do solo. Como as leituras da 
Sonda de Neutrons são sensíveis ao volume de água presente ao redor do ponto de medida (umidade a base de volume), estas são afetadas pela densidade global do solo, propriedade essa que pode variar significativamente ao longo de pequenas distâncias, da ordem de centímetros. Essas características do método, o tornam muito dependente da variabilidade espacial do solo, sobretudo da variabilidade da densidade global, porosidade e umidade (Turatti et al, 1990).

Folegatti (1996), avaliando o armazenamento hídrico de um solo siltoso, observou estrutura de variação espacial com alcance de 10 metros, patamar crescente com o secamento de solo e efeito pepita em torno de $20 \%$ da variação total.

Gonçalves (1997), estudando um solo podzólico vermelho escuro, verificou que a umidade do solo nas oito tensões avaliadas, apresentou dependência espacial. Quanto maior foi a tensão, maior também foi a dependência espacial dos valores de umidade do solo. Na faixa monitorada pelo tensiometro, a dependência espacial pode ser descrita com um único semivariograma com alcance de 24 metros e efeito pepita de $35 \%$ de variação total.

Já para Fietz (1998) os dados de umidade de solo em todas as tensões apresentaram distribuição normal, baixo grau de variabilidade e estrutura de dependência espacial, com valores de efeito pepita de 14 e $56 \%$ de variação total e alcance de 22 metros.

A determinação da umidade em que os solos adquirem características friáveis é muito importante para se definir as faixas de umidade em que poderão ser feitos preparos sem afetar a estrutura do solo, pois se estiver muito seco, apresenta alta coesão, exigindo maior potência e maior número de operações das máquinas agrícolas. Por outro lado, se o solo estiver muito úmido ocorrerão danos a estrutura, pois filmes de água estarão dispostos ao redor das partículas, funcionando como lubrificante, favorecendo a desagregação pela pressão exercida pelas máquinas e implementos agrícolas, compactando-o (Klein, 1998). 


\subsubsection{Porosidade total, macroporosidade e microporosidade}

A porosidade do solo, segundo Tognon (1991), é a propriedade do solo que interfere na aeração, condução e retenção de água, capacidade de penetração e ramificação das raízes no solo e, consequentemente, no aproveitamento de água e nutrientes disponiveis.

Dependendo das condições, existe considerável diferença no total de espaço poroso dos diversos solos. Os solos arenosos de superfície situam-se numa faixa de 35 a $50 \%$, enquanto que os solos argilosos variam de 40 a $60 \%$, ou talvez ainda mais, nos casos de elevado teor de matéria orgânica. A porosidade varia também com a profundidade, atingindo 25 a $30 \%$ em alguns solos compactos, isto responde em parte, pela aeração inadequada de tais horizontes (Buckman \& Brady, 1966 e Kiehl, 1979).

Para o manejo do solo, além do conhecimento da porosidade, torna-se necessário o conhecimento da distribuição dos poros por tamanho, separando-os em macroporos (responsáveis pela drenagem, garantindo o arejamento) e microporos (responsáveis pela retenção da umidade no solo).

Berner et al (1995), utilizaram o semivariograma para análise da variabilidade espacial das propriedades estudadas, o qual permite expressar a estrutura da variância da propriedade em função da distância entre os pontos de amostragem. Se a variância dos dados aumenta com o incremento da distância, então a variância e a distância são grandezas que covariam. Quanto ao sistema de manejo, este tendeu a afetar as características relacionadas a porosidade do solo, principalmente até $20 \mathrm{~cm}$ de profundidade.

Já Gonçalves (1997), obteve a porosidade total à partir dos valores da densidade do solo e de partículas. Os resultados obtidos revelaram a importância de se amostrar com espaçamento variável, uma vez que o menor espaçamento permitiu a descrição da estrutura da dependência espacial, usada para interpolar entre os pontos de larga escala. A densidade de partículas e porosidade total não mostraram dependência espacial, porém, a densidade do solo e a umidade na saturação mostraram dependência espacial na curta escala com "efeito pepita" acima de $50 \%$ do patamar. 
Segundo Klein (1998), trabalhando em uma área de latossolo roxo irrigada com plantio direto, sem preparo do solo e tráfego intenso de maquinarias, ocorreram as maiores alterações na porosidade do solo até a profundidade de $40 \mathrm{~cm}$, sendo que na camada de 15 até $35 \mathrm{~cm}$, observou-se uma alteração menor na porosidade total, permanecendo no entanto a tendência na distribuição do tamanho dos poros, com diminuição de macro e aumento de microporos. Na camada superficial ( 0 a $15 \mathrm{~cm})$, em virtude do não revolvimento do solo, ocorreu a maior redução na porosidade, diminuindo em $20 \%$ o volume de poros em relação a mata (Klein, 1998).

\subsubsection{Densidade do solo e de partículas}

A preocupação com a determinação da densidade do solo, tem crescido muito nos últimos anos, devido ao aumento das áreas irrigadas, do plantio direto, e da preocupação com a compactação do solo, provocada pelo manejo cultural em algumas culturas como as da cana de açúcar e do citros.

A relação existente entre a massa de uma amostra de solo seca a $105^{\circ} \mathrm{C}$ e a soma dos volumes ocupados pelas partículas e pelos poros, podem ser definidas como sendo a densidade do solo (Demolom ,1952; Blake ,1965 e Kiehl ,1979).

A densidade do solo depende da natureza, das dimensões e da forma como se acham dispostas as partículas do solo. A fase liquida também afeta o volume aparente, fazendo variar a densidade do solo conforme o estado de umidade. Ela geralmente aumenta com a profundidade do perfil, pois as camadas superiores sobre as subjacentes, provocam o fenômeno da compactação, reduzindo a porosidade do solo.

Os métodos empregados para esta determinação, fundamentam-se na obtenção de dois dados principais: a massa e o volume de uma amostra de solo.

Para Gomes et al. (1978) a estrutura do solo pode ser quantificada indiretamente através da medida de determinadas características físicas do solo, as quais estão intimamente relacionadas, entre elas, a densidade do solo, que além de possibilitar o cálculo da porosidade, quando a densidade de partículas é conhecida, é utilizada juntamente com ela para a avaliação da compactação do solo. 
A definição desta propriedade física do solo, como a sua variabilidade espacial, não diferem para nenhum dos autores dos trabalhos consultados, mas os métodos de coletar as amostras de solo, para sua determinação, variam de autor para autor.

Para Klein (1998), trabalhando na região de Guaíra - SP, a densidade do solo da mata, apresentou diferença significativa no perfil, apenas na camada superficial $(0,03$ $\mathrm{cm}$ ), certamente pela influência da liteira, indicando a homogeneidade do solo na sua condição natural, sem camadas de impedimento ou acumulo de argila. Já a área de sequeiro e irrigado tiveram a sua estrutura modificada, com alterações significativas até a profundidade de $0,4 \mathrm{~m}$, sendo que, para o sistema de plantio direto irrigado os valores da densidade do solo foram significativamente superiores até essa profundidade. Constatou ainda, que a umidade ótima de compactação está situada na faixa de umidade na qual o solo está friável, o que é preocupante do ponto de vista de manejo agrícola, uma vez que a recomendação de preparos são feitas nesta condição de umidade.

A compactação do solo é um processo que ocorre quando uma força atua sobre ele, causando diminuição no volume de macroporos, aumento na densidade natural do solo, aeração mais pobre, infiltração e movimento interno de água mais lentos, podendo modificar a quantidade de nutrientes disponível, na medida em que altera a mineralização dos compostos orgânicos, interferindo sobremaneira, no desenvolvimento radicular das plantas (Seixas, 1988; Souto et al.,1995).

Pesquisadores têm demonstrado claramente o efeito da compactação nas propriedades físicas do solo. A compactação aumenta a densidade do solo e a sua resistência mecânica, e diminui a porosidade total, o tamanho e a continuidade dos poros, com reduções significativas, principalmente no volume dos macroporos, enquanto os microporos permanecem praticamente inalterados (Dias Junior \& Pierce, 1996).

O manejo incorreto de um solo cultivado provoca a sua compactação, alterando a estrutura e, consequentemente, a densidade do solo. De maneira geral podese afirmar que, quanto mais elevada for a densidade do solo, menor será a sua porosidade total. portanto, maiores serão as restrições para o desenvolvimento das plantas, principalmente em solos argilosos (Leite et al.,1995). 


\subsection{Coleta de amostras}

Segundo Reichardt et al. (1986), a análise de dados que "medem" um ou mais aspectos da variabilidade espacial de um solo depende essencialmente do método de amostragem empregado, que por sua vez está ligado ao delineamento experimental escolhido e aos objetivos do experimento. A forma de amostragem regionalizada e a aplicação de técnicas geoestatística procuram dar uma solução para a situação onde a variabilidade do parâmetro medido pela estatística clássica é muito grande.

Dentro de todo processo de análise do solo, a amostragem é a etapa mais crítica, devendo ser feita com todo o cuidado. Para realizá-la corretamente, deve-se retirar um número de amostras que seja suficiente em termos de representatividade, devendo ser considerado como pontos fundamentais o tamanho e uniformidade da área quanto a cor, posição na encosta, cobertura vegetal ou cultura, textura, drenagem, além do histórico da área, de forma a minimizar a variabilidade (Raij, 1987).

Muitos autores realizaram trabalhos sobre a variabilidade espacial do solo, mas não citam o método utilizado, o tamanho dos cilindros, o número de amostras coletadas, nem mesmo a umidade e a posição em que foram coletadas no solo (vertical ou trincheira). Esses fatores, também poderiam, com certeza, alterar ou mascarar os valores obtidos, aumentando ou diminuindo o efeito da variabilidade das propriedades do solo.

\subsubsection{Número de amostras necessárias}

O número de amostras necessárias para se determinar as propriedades do solo, também tem sido motivo de diversos estudos, todos buscando um número ideal, que possa representar melhor possível a área de interesse, e que esteja dentro do orçamento previsto pelo agricultor e/ou o pesquisador.

Estudando a variabilidade de algumas características fisicas e químicas, Saraiva et al (1992) em função do maior coeficiente de variação dentre as quadrículas de amostragem, por profundidade e por sistemas de cultivo, calculou o número de amostras necessárias para apresentar uma percentagem de variação (f) com $95 \%$ de probabilidade 
em torno do valor analítico médio verdadeiro, concluindo que, para densidade do solo e de partículas, são necessárias três amostras simples.

Já Moraes \& Libardi (1993), concluem que deveria ser motivo de maior atenção pelos pesquisadores, a substituição de um número maior de amostras por amostras de maior volume, a fim de se tentar diminuir a variabilidade, talvez com certa economia no trabalho de coleta de amostras, entre outros.

\subsubsection{Métodos para análise física dos solos}

Os métodos para análise física do solo, em laboratório, conhecidos são: método do torrão (geralmente utilizado em solos pedregosos), método de amostras deformadas (a terra coletada com trados, é passada em peneiras de $2 \mathrm{~mm}$ ), e o método de amostras indeformadas (usam cilindros como reservatórios de volume conhecido, retirados diretamente do perfil ou da superfície do solo).

Alguns autores, trabalharam comparando esses métodos de determinação das propriedades físicas do solo, e através dos resultados encontrados, concluíram que, o método do cilindro é o mais prático e rápido.

Medina \& Oliveira Jr (1987), estudando a relação entre a capacidade de campo determinada in situ e em laboratório, utilizaram dois métodos para a coleta de amostras usadas no laboratório, o método do torrão e o método da amostra deformada. Concluíram que, apesar de não se ter detectado nenhuma vantagem das amostras representadas por torrões de solo em relação às deformadas que são mais fáceis de coletar, a recomendação acerca do uso destas últimas em latossolo amarelo muito argiloso, estará sujeita aos resultados de novos estudos, semelhantes a este, que incluam amostras obtidas utilizando o método do anel volumétrico.

Sinidras et al (1984), estudando as características físicas de um latossolo roxo distrófico sob plantio direto e convencional, concluíram que as curvas de retenção de água, determinadas através de amostras com estrutura alterada, superestimaram a água disponível, e as de estrutura não alteradas, devem ser preferidas por simularem melhor as condições de campo. 
Remortel \& Shields (1993), concluíram que para o método do torrão e o método do cilindro volumétrico, são empregados o mesmo tempo para serem coletados, média de 8 minutos por amostra após a abertura do perfil. Entretanto, o método do cilindro teve claras vantagens sobre o do torrão, pois o equipamento e as amostras, são menos volumosos, e podem evitar distúrbios durante o transporte, o qual é, uma consideração muito importante quando da coleta de amostras em locais de difícil acesso. Este método também é menos trabalhoso para manipulação durante as análises no laboratório.

Estas amostras em cilindros, por conservarem as caracteristicas do solo nas mesmas condições que se encontravam no campo, são consideradas o melhor método, porém, não são retiradas de uma mesma maneira ou com o mesmo tamanho pelos técnicos, alguns a retiram do solo enterrando o anel diretamente com um martelo (utilizando um "castelo" como batedor) ou macaco hidráulico, outros se utilizam de ferramentas que levam estes anéis embutidos dentro do corpo da peça.

Este método não é recomendado para solos rochosos ou com pedregulhos, pois enfrenta dificuldades de penetração no solo, e pode trazer resíduos de rochas ou pedras no interior do cilindro, afetando o resultado das determinações das propriedades avaliadas. Em solos nesta condição, recomenda-se o método do torrão.

\subsubsection{Equipamentos utilizados na coleta de amostras}

Para o método do cilindro volumétrico, encontramos diversas maneiras e ferramentas para executar a amostragem. Este método vem sendo utilizado desde 1914, quando Kopecky o idealizou, sendo muito prático para coleta de amostras nos diferentes horizontes do perfil exposto do solo. Ele utiliza um anel que tem um volume de $50 \mathrm{~cm}^{3} \mathrm{e}$ é colocado no solo por pancadas ou por pressão, removendo-o a seguir com excesso de terra, a qual será desbastada com auxílio de uma faca cortante até igualar com as bordas.

Lutz (1947), criou um dispositivo para pressionar um cilindro volumétrico de $6 \mathrm{~cm}$ de diâmetro e $4 \mathrm{~cm}$ de altura no solo. Jamison et al. (1950) acharam que o amostrador de Lutz só trabalhava satisfatoriamente em solos friáveis e soltos, mas não 
podiam ser utilizados em solos secos ou duros sem fraturar ou estragar o corpo da mostra. Então eles modificaram o amostrador, aumentando o tamanho do cilindro para $9,5 \mathrm{~cm}$ de diâmetro por $6,5 \mathrm{~cm}$ de altura, e adicionaram um martelo de correr.

O amostrador de San Dimas é um coletor de cilindros, contendo corte rotativo ao redor de um tubo coletor estacionário e de operação manual. Os cilindros mediam $6,9 \mathrm{~cm}$ de diâmetro por $5 \mathrm{~cm}$ de altura.(Andrews \& Broadfoot, 1958).

Wells (1959) desenvolveu um tubo de amostragem que é introduzido no solo com um martelo pesado. Ele tira amostras de $5 \mathrm{~cm}$ e pode amostrar até $120 \mathrm{~cm}$, em partes de 15 a 30cm, mas surgiram alguns problemas com compressão das amostras.

Fox \& Page-Hanify (1959) desenharam um coletor para amostras indeformadas, para coletar solos sem rochas até $60 \mathrm{~cm}$ de profundidade com cilindros de $2,5 \mathrm{~cm}$ a $7,6 \mathrm{~cm}$ de diâmetro. $O$ tempo de amostragem era em torno de 5 minutos.

O método de Revut \& Rode (1969), possuíam anéis cilíndricos que eram pressionados dentro do solo. Os anéis eram chanfrados no lado de fora, com duas medidas de anéis, $4 \mathrm{~cm}$ de altura por $5,6 \mathrm{~cm}$ de diâmetro, e $8 \mathrm{~cm}$ de altura por $8,7 \mathrm{~cm}$ de diâmetro

Um amostrador que pode tirar cilindros de amostras indeformadas de $10,2 \mathrm{~cm}$ de diâmetro encaixando-o num tubo plástico, foi descrito por Mielke (1973). Devido a amostra ser colocada dentro do tubo plástico, o dano do cilindro é reduzido.

Utilizando esta metodologia , Fernandes et al. (1983), usaram tubos de PVC para coletar amostras indeformadas até $50 \mathrm{~cm}$ de profundidade. Para melhorar esse processo, Mielke \& Wilhelm (1983), desenvolveram um sistema de ancoragem fixando o equipamento para evitar que o mesmo, seja levantado do solo no processo de introdução do cilindro.

Para coletar cilindros de solo de $4,3 \mathrm{~cm}$ de diâmetro até a profundidade de $120 \mathrm{~cm}$, Turner (1974), desenhou um amostrador leve, facilmente manejável. As amostras eram contidas em um tubo plástico para minimizar os distúrbios e contaminações. Ele detectou uma compressão do cilindro de solo menor que $10 \%$. 
A densidade do solo foi determinada por Freire \& Scardua (1975), segundo o método de Blake (1965), usando anéis volumétricos que foram introduzidos em cada horizonte do solo com o auxílio do cilindro de Uhland (1949).

Ginn et al. (1978), montaram um amostrador hidráulico para coleta de cilindros num trator. Estes cilindros tinham $10 \mathrm{~cm}$ de diâmetro e eram retirados até $100 \mathrm{~cm}$ de profundidade e a $100 \mathrm{~cm}$ do centro da maquina. A vantagem deste sistema era de se obter as amostras nas linhas e entre linhas sem mover o trator.

Beltrame et al. (1981), utilizaram anéis plásticos (PVC) com 14,6cm de diâmetro e $10 \mathrm{~cm}$ de altura. Um anel de aço biselado colocado embaixo do anel de plástico e outro não biselado colocado acima para proteção, foram enterrados no solo, fazendo pressão com um macaco hidráulico contra uma barra de ferro fixada no solo por duas hastes helicoidais. Os anéis eram retirados do solo e os anéis de proteção e corte removidos, e a amostra era modulada com espátula.

Foale \& Upchurch (1982), criaram um aparelho manual para coletar amostras de 2 a $5 \mathrm{~cm}$ de diâmetro para profundidades de até 2 metros, usando um martelo com guia para introduzir o aparelho no solo, e um dispositivo para remover o anel.

Para observação da massa radícular, Srivastava et al. (1982), desenharam um amostrador para extrair grandes amostras indeformadas. Este amostrador utilizou um equipamento comercial para introduzir o anel no solo. Um cilindro hidráulico e um suporte, foram utilizados para retirar o cilindro do solo.

Tutle et al. (1984), desenharam um equipamento portátil para coletar amostras de locais distantes e de difícil acesso. $\mathrm{O}$ amostrador era enterrado no solo com um martelo de impacto, e era eficiente em solos com raízes e rochas. Duas pessoas eram necessárias para remover a amostra.

Sharma \& DeDatta (1985), criaram um amostrador de solo para coletar cilindros de amostra indeformada de volume conhecido de 0 a $10 \mathrm{~cm}$ de profundidade em solos macios e encharcados.

A busca por facilitar a operação de coleta e aumentar a confiabilidade na qualidade das amostras, através da automação das ferramentas utilizando tratores, eleva consideravelmente os custos da operação de coleta dessas amostras, além de provocar o 
aumento da compactação do solo devido ao peso dessas máquinas e a necessidade de umidade no momento da coleta. Por outro lado, a utilização de macacos hidráulicos como sugere Pedrotti (1994), exige um sistema de ancoragem, que torna muito trabalhoso e demorado a operação de coleta.

\subsubsection{Comparação de diferentes tamanhos de cilindros.}

Extensionistas, projetistas e agricultores não tem encontrado facilidades para a realização de análises físico-hídricas de solo, devido principalmente ao reduzido número de laboratórios que as realizam em nosso meio. Por outro lado, essas determinações em laboratórios, muitas vezes, apresentam limitações quanto a sua representatividade nas aplicações práticas, por envolverem erros de amostragem ou serem realizadas com amostras que não representem a estrutura natural do solo durante o ciclo da cultura (Arruda et al. 1987).

A operação de coleta deve ser executada com cuidado, evitando a possibilidade de se compactar a amostra no momento em que a terra esta entrando no cilindro, através do contato com a parede do mesmo, ou quando o volume de terra excede o tamanho do cilindro podendo ser comprimido na parte superior do equipamento. Esses efeitos, podem ser provocados pela ferramenta, tamanho do cilindro e peso utilizado para coletar essas amostras, assim como outros fatores referentes a umidade e tipo de solo.

Alguns trabalhos foram realizados, visando comparar as diferenças que poderiam ser encontradas, em função da utilização de diferentes tamanhos de cilindros, na coleta das amostras indeformadas

As densidades do solo, foram medidas com diferentes tamanhos de cilindros, coletados de dois solos de florestas, franco e franco siltoso. Os valores das densidades do solo foram computadas com e sem correções para volumes de madeira e raízes. Correções para volumes de madeira e raízes foram consideradas desnecessárias sob as condições de solo e vegetação amostrados (raízes + madeiras apenas 2 a 3\% para volumes). A densidade do solo encontrada, não variou pela utilização de tamanhos diferentes de cilindros (Terry et al. 1981). 
Para, Nesmith et al (1986) a sonda de raios gama não parece adequada para medidas da densidade do solo nos $10 \mathrm{~cm}$ de profundidade do perfil do solo. Nesse estudo foram comparados dois tamanhos de cilindros, o cilindro maior com diâmetro de $14,6 \mathrm{~cm}$ e altura de $10,1 \mathrm{~cm}$, e o menor com diâmetro de $5,4 \mathrm{~cm}$ e $5,9 \mathrm{~cm}$ de altura. $\mathrm{O}$ cilindro maior obteve maior precisão nos resultados para avaliação da densidade do solo, mas devido a sua destrutividade e inconveniência na utilização, esse tamanho não é desejado. O cilindro menor, foi concluído como o melhor método sob essas condições prescritas, devido alta correlação com o cilindro maior, e por ser mais fácil de manusear. Esses resultados foram encontrados para coleta de amostras de solos de superfície úmida à $10 \mathrm{~cm}$ de profundidade do perfil.

Constantini, (1995), estudando densidade do solo, afirma que, a comparação das variâncias estimadas para quatro tamanhos diferentes de amostradores de cilindros, indicaram não haver nenhuma diferença significativa entre: tamanho de cilindro ou local amostrado, e também, nenhuma diferença significativa da interação entre local e tamanho de cilindros. Os diâmetros internos dos cilindros eram: 3,48, 4,83, 5,98 e $9,12 \mathrm{~cm}$ e a altura de todos aproximadamente $10 \mathrm{~cm}$.

\subsection{Métodos estatísticos para estudo da variabilidade}

Laslett \& McBratney (1990), trabalhando com abordagem probabilística, concluíram que, um estudo de solo envolve três passos essenciais: a configuração da amostragem no campo, o delineamento das análises e ensaios de laboratório, e a seleção de um método apropriado para predizer valores em locais não amostrados.

A estatística é sem dúvida uma ferramenta que permite o estudo de uma população a partir de amostras que estimem essa população, uma vez que seria praticamente impossível fazer uma avaliação total. Se a amostra é representativa, todas as estimativas dela obtidas, tais como a média e a variância são validas, quando essa condição não é satisfeita, o tratamento estatístico dos dados, podem levar a falsos resultados (Silva, 1988).

Ainda para o mesmo autor, independente da estatística, em certas situações, a análise da variabilidade dos dados pode ser feita de uma maneira bem simples, 
localizando as amostras geograficamente no espaço e, a simples observação dos dados puros, pode levar o pesquisador experiente a soluções para contornar o problema.

Machado (1994), concluiu que, as duas ferramentas estatísticas utilizadas, a clássica e a geoestatística, não são concorrentes e se complementam, no sentido de se obter, no primeiro caso, a magnitude da variação e no segundo, a estrutura da variabilidade.

\subsubsection{Dependência espacial}

O alcance da dependência espacial representa a distância em que os pontos amostrais estão correlacionados entre si, ou seja, os pontos localizados numa área de raio igual ao alcance são mais homogêneos entre si do que com aqueles localizados fora dessa área (Souza et al,1997).

Webster \& Burgess (1984), estudando vários tipos de malhas para estimativas das propriedades dos solos, concluíram que, se a variação for isotrópica (mesma variação em todas as direções) a malha quadrada se mostrou mais eficiente, enquanto se for anisotrópica (maior variação em uma direção) a malha retangular é mais eficiente.

A geoestatística é definida como sendo a aplicação da teoria de funções aleatórias para o reconhecimento, exploração e estimação de fenômenos naturais. Ela reconhece que observações tomadas próximas umas das outras são mais semelhantes que aquelas separadas por uma distância maior, ou seja, as observações são regionalizadas. (Machado, 1994).

Li \& Lake (1994) afirmam que todos os estimadores produzem resultados confiáveis apenas para pequenas distâncias, pois, para distâncias maiores, os resultados são erráticos pelo fato do número de pares de pontos decrescerem a medida que a distância aumenta.

A capacidade de detectar a variabilidade é determinada em grande parte pelo plano amostral, que precisa ser definido tendo em mente as estruturas que se deseja detectar. Malhas regulares, embora muito úteis, podem ser modificadas a fim de captar as estruturas à pequenas distâncias, como no caso da densidade do solo, onde não se tem 
informações do que acontece a distâncias inferiores a $5 \mathrm{~m}$. Portanto, o plano amostral pode variar para cada propriedade em estudo (Ribeiro Junior, 1995).

\subsubsection{Delineamento em quadrados latinos}

Os delineamentos em quadrado latino, como os blocos casualizados, consideram os princípios de repetição, casualização e controle local. Neste delineamento o controle é efetuado em duas direções: blocos horizontais (linhas) e blocos verticais (colunas), e é muito usado em pesquisas onde 2 fontes principais de variação estão presentes e que precisam ser controladas. A sua aplicação é mais comum na experimentação animal, mas também é utilizado para eliminar a heterogeneidade do solo em duas direções perpendiculares (Pimentel Gomes, 1990).

A sua configuração é constituída de linhas e colunas onde cada uma delas tem a estrutura de um bloco, isto é, se são I tratamentos, o número total de parcelas será $\mathrm{I}^{2}$. Nele, cada tratamento será representado uma única vez em cada linha e em cada coluna, onde podemos observar duas fontes de variabilidade nas unidades experimentais. Como o número de repetições deve ser igual ao número de tratamentos, em geral não se usam quadrados latinos no caso de termos mais de 8 tratamentos, pois então o número de repetições seria, não raro, um tanto exagerado. 


\section{MATERIAIS E MÉTODOS}

$\mathrm{O}$ trabalho foi conduzido em dois solos, com diferentes texturas, em áreas localizadas na Fazenda Areão e Fazenda Sertãozinho, no Campus da Escola Superior de Agricultura "Luiz de Queiroz", ESALQ/USP em Piracicaba - SP. As coordenadas geográficas do município são $22^{\circ} 42^{\prime}$ de latitude sul, longitude oeste de $47^{\circ} 38^{\prime}$ ' e altitude média de 546m acima do nível do mar.

O clima da Região é do tipo Mesotérmico Cwa, de acordo com a classificação de Köeppen, com média de precipitações anuais de $1253 \mathrm{~mm}$, temperatura média anual de $21,2^{\circ} \mathrm{C}$, umidade relativa média de $74 \%$, sendo o período mais sêco do ano entre os meses de junho, julho e agosto, e as chuvas concentradas no período de novembro a fevereiro, sendo comumente de alta intensidade e de curta duração (Villa Nova, 1989).

\subsection{Parâmetros avaliados}

Foram analizados, tipo de solo, equipamentos (tamanho de aneis volumétricos), tempo e energia consumida para coletar as amostras indeformadas.

\subsubsection{Tipos de solo.}

- Podzólico Vermelho Escuro (PVE), com horizonte A de textura argilosa (média de $45 \%$ de argila) e profundidade média de $30 \mathrm{~cm}$, cultivado com capim Tanzânia irrigado por pivo central, localizado no campo experimental de irrigação do Departamento de Engenharia Rural, situado na Fazenda Areão (Figura 1-a).

- Latossolo Vermelho-Amarelo, com textura arenosa (média de $78 \%$ de areia), no pomar de laranjas do campo experimental do Departamento de Produção Vegetal, situado na Fazenda Sertãozinho. (Figura 1-b). 


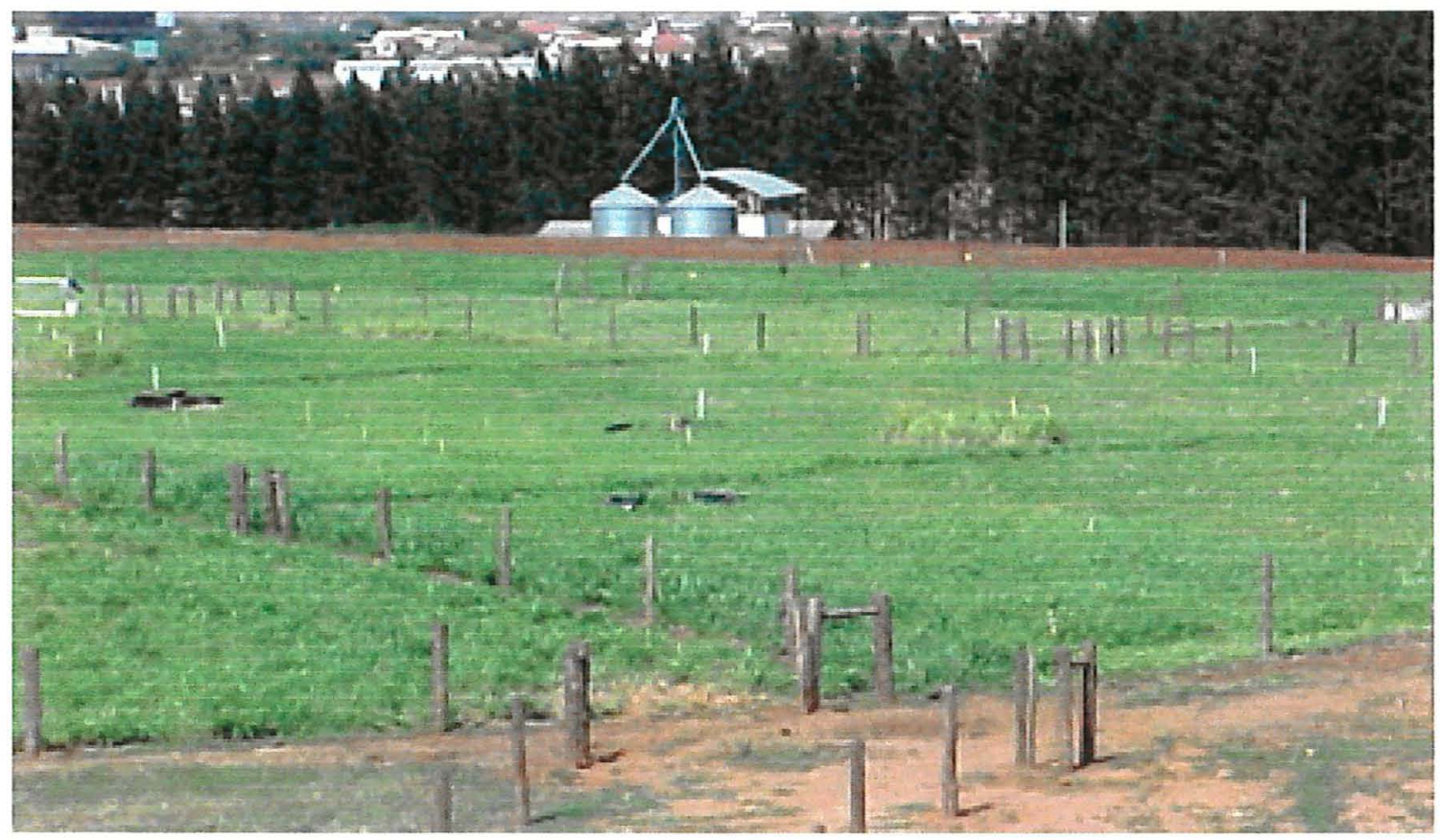

a) Solo argiloso na fazenda Areão.

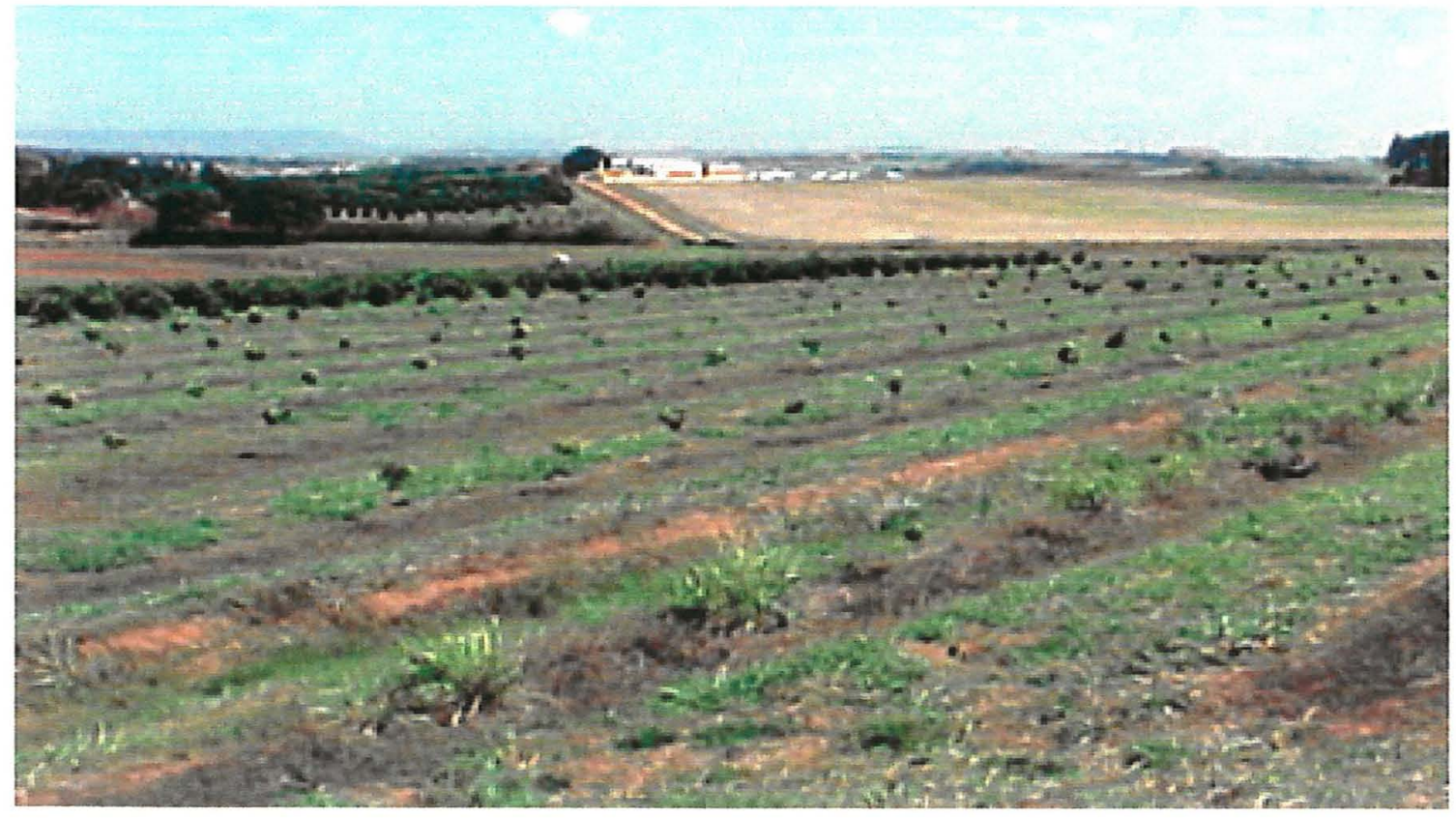

b) Solo arenoso na fazenda Sertãozinho.

Figura 1- a) Área irrigada por pivô central no solo argiloso da fazenda Areão; b) plantação de laranjas no solo arenoso da fazenda Sertãozinho. 


\subsubsection{Equipamentos e tamanho de anéis volumétricos.}

Os equipamentos avaliados, foram os amostradores de solo mais utilizados para coleta de amostras indeformadas, cujas especificações técnicas são:

A) Trado de Uhland (TU): são aneis de aço inoxidável, com diâmetro de $7,0 \mathrm{~cm}$, altura de $7,0 \mathrm{~cm}$ e volume de $270 \mathrm{~cm}^{3}$, introduzidos no solo no interior de uma ferramenta, que é encaixada em uma base de ferro, com uma haste que contém uma massa de $4,5 \mathrm{~kg}$, que ao cair de uma altura de $50 \mathrm{~cm}$, provoca um impacto suficiente para provocar a penetração do anel no solo (Figura 2a).

B) Anel de Kopecky (AK): são aneis de aço inoxidável, com diâmetro de 4,8cm, altura de $3,0 \mathrm{~cm}$ e volume de $55 \mathrm{~cm}^{3}$, introduzidos diretamente no solo por um castelo de madeira e martelo de ferro revestido com borracha, com uma massa de aproximadamente $1,2 \mathrm{~kg}$ (Figura $2 \mathrm{~b}$ ).

C) Trado modelo Soil Moisture (TSM): são aneis de aço inoxidável, com diâmetro de $5,2 \mathrm{~cm}$, altura de $6,0 \mathrm{~cm}$ e volume de $127,5 \mathrm{~cm}^{3}$, introduzidos no solo no interior de uma ferramenta, que é rosqueada em uma base de ferro, com uma haste que contém uma massa de $2,5 \mathrm{~kg}$, que ao cair de uma altura de $30 \mathrm{~cm}$, provoca um impacto suficiente para provocar a penetração do anel no solo (Figura 2c).

D) Trado Bravifer AI-50 (TB50): são aneis de aço inoxidável com diâmetro de $4,9 \mathrm{~cm}$, altura de $2,65 \mathrm{~cm}$ e volume de $50 \mathrm{~cm}^{3}$, introduzidos no solo no interior de uma caçamba com uma haste de $15 \mathrm{~cm}$, onde se rosqueam dois cabos de $40 \mathrm{~cm}$, permitindo coletar amostras até $1 \mathrm{~m}$ de profundidade. Para penetar no solo, utilizamos uma massa de $1,6 \mathrm{~kg}$ caindo de uma altura de $40 \mathrm{~cm}$, no lugar da marreta de borracha, que acompanha o equipamento, para eliminar o efeito do operador (Figura $2 \mathrm{~d}$ ).

E) Trado Bravifer AI-100 (TB100): é a mesma ferramenta, descrita no item D, utilizando aneis maiores, em aço inoxidável com diâmetro de $4,9 \mathrm{~cm}$, altura de $5,3 \mathrm{~cm}$ e volume de $100 \mathrm{~cm}^{3}$ (Figura $2 \mathrm{~d}$ ). 


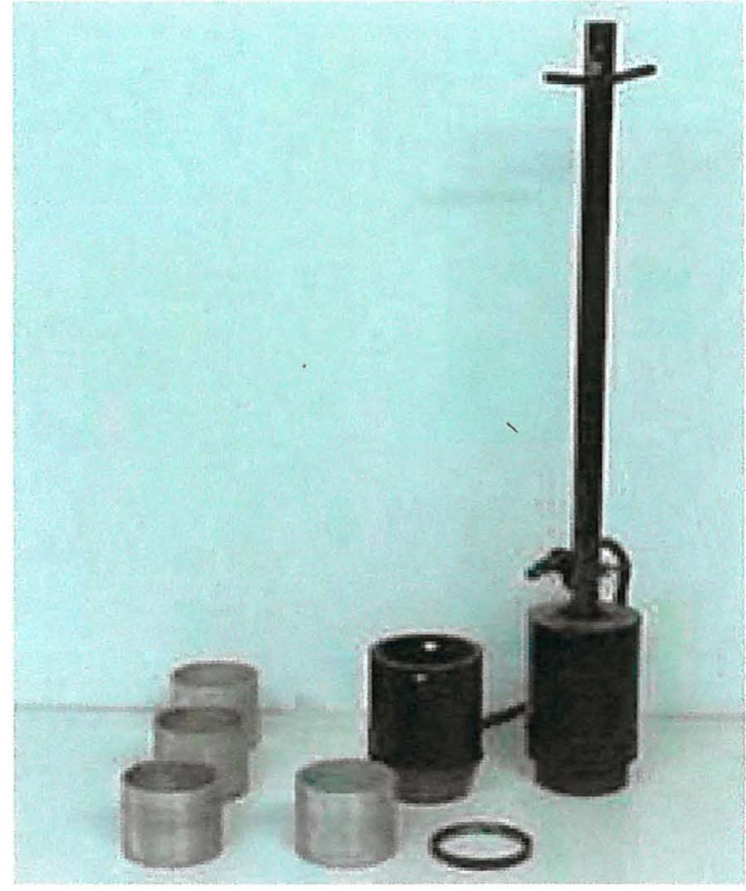

a) Trado Uhland (TU)

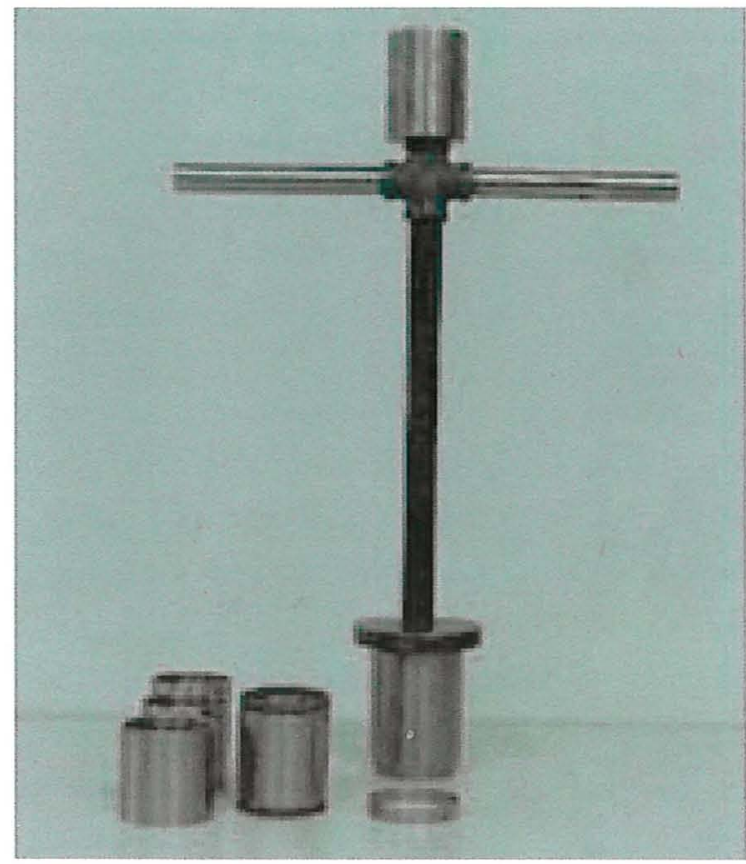

c) Trado modelo Soil Moisțure (TSM)

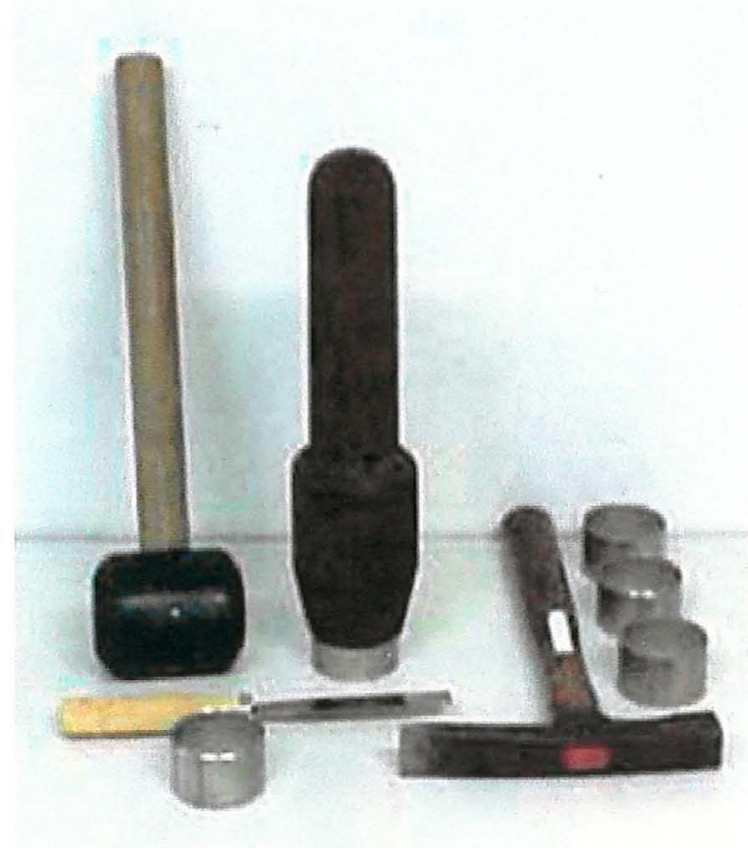

b) Anel de Kopecky (AK)

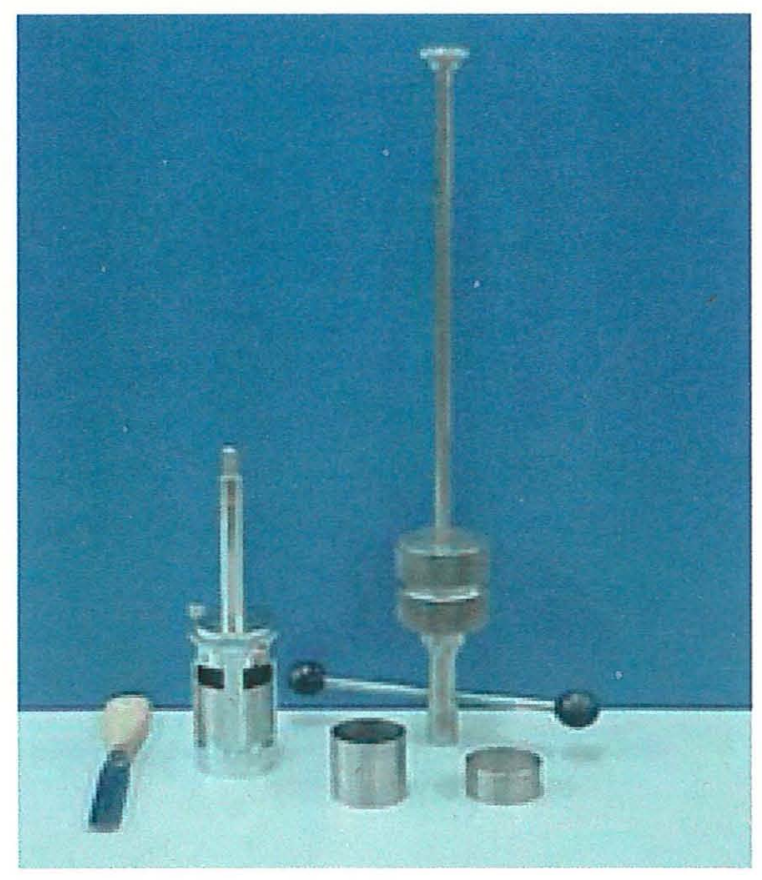

d) e e) Trado Bravifer AI-50 e AI-100

Figura 2- Equipamentos: a) trado de Uhland (TU); b) Anel de Kopecky (AK); c) trado Soil Moisture (TSM); d) trado Bravifer AI-50 (TB50) e e) trado Bravifer AI100 (TB100). 


\subsection{Umidade do solo}

As coletas de amostra foram realizadas, com os teores de água próximos de $100 \%, 70 \%$ e $40 \%$ da Capacidade de Campo. O solo foi saturado nos pontos de coleta, coberto com lona plástica e a sua umidade foi monitorada utilizando-se tensiômetros, até os teores de água desejados (Figura 3). Nos dias da amostragem nos dois solos, argilosos e arenosos, foram também coletadas amostras do solo com trado tipo sonda, para determinação da umidade gravimétrica, no laboratório.

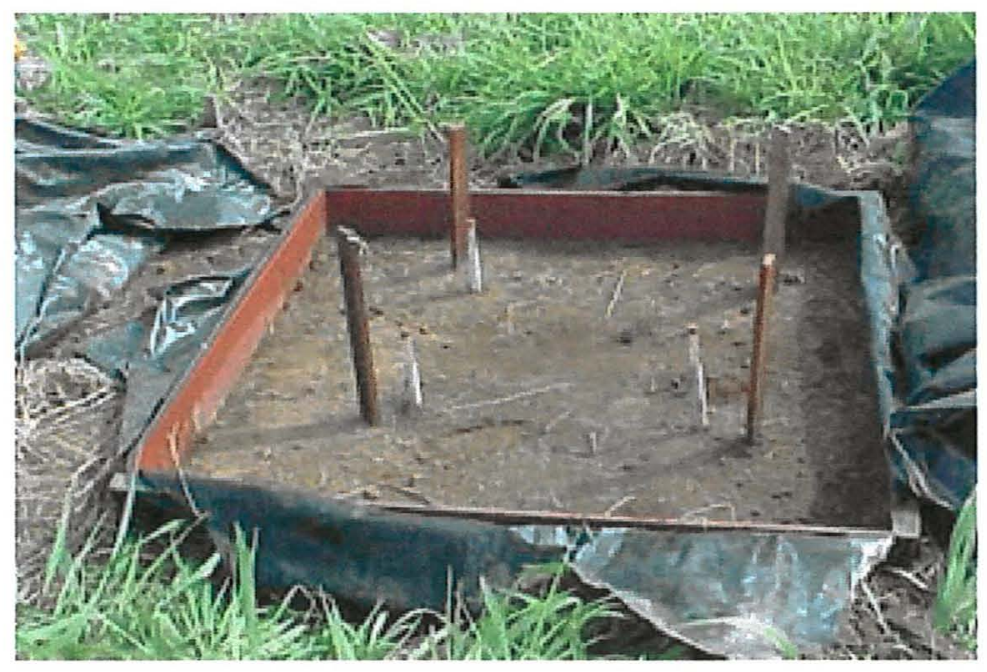

Figura 3- Quadro de saturação do solo com os tensiômetros instalados.

\subsection{Amostragem de solo}

A amostragem foi realizada de forma sistematizada em grade, com 6 pontos coletados com espaçamento regular, cuja distância foi determinada, utilizando-se o semivariograma experimental da área de solo argiloso da fazenda Areão, obtido por Gonçalves (1997), para que os pontos amostrados estejam fora do limite do alcance, garantindo assim, a hipótese de independência dos pontos amostrados (Figura 4).

Para o solo arenoso da fazenda Sertãozinho, foi adotado o mesmo espaçamento (20 metros) do solo argiloso da fazenda Areão, pois a estrutura espacial do solo, não foi avaliada. 


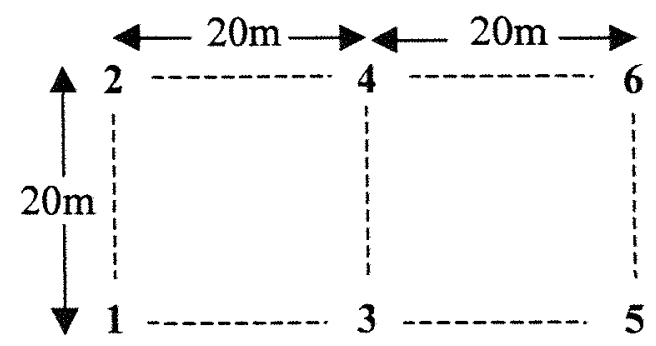

Figura 4- Grade da área de amostragem com alcance de $20 \mathrm{~m}$.

Em cada ponto de amostragem, foram coletadas cinco amostras com cada uma das ferramentas, num total de 25 amostras coletadas numa área de $1 \mathrm{~m}^{2}$, utilizando-se como esquema experimental o Quadrado Latino, procurando-se, assim, controlar a variabilidade espacial do solo nas duas direções, além de, não permitir que os pontos onde foram utilizados os anéis de maior volume sejam vizinhos, evitando que os possiveis disturbios provocados no solo pelo impácto na sua introdução, interfiram nas determinações de suas propriedades físicas. A grande proximidade entre os pontos amostrados, foi utilizada para garantir a hipótese da existência de alta dependência entre esses pontos. (Figura 5).

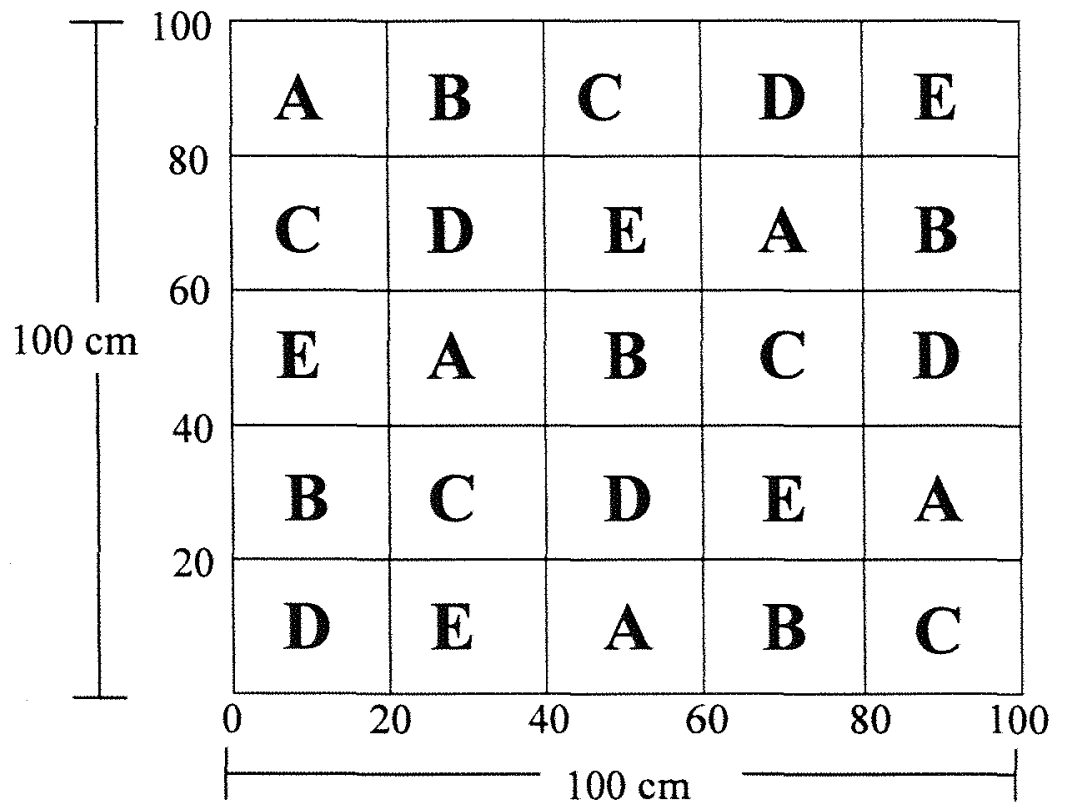

Figura 5- Grade de coleta de amostras, com as posições das ferramentas. 
As amostras foram retiradas à profundidade média de $20 \mathrm{~cm}$, tendo como referência a metade da altura do anel, isto é, para o anel utilizado no método (a), a profundidade inicial foi de aproximadamente $16,5 \mathrm{~cm}$; para o (b) foi de $18,5 \mathrm{~cm}$; para $o$ (c) de $17 \mathrm{~cm}$; para o (d) $17,5 \mathrm{~cm}$ e para o (e) de $18,5 \mathrm{~cm}$.

Para se atingir as profundidades iniciais, utilizou-se um trado de caneca com diâmetro de 4 polegadas, e uma ferramenta para nivelar o fundo do orifício, conhecida como limpa fundo, para deixar a base lisa e sem terra fofa esboroada das suas laterais, evitando assim o mascaramento no momento da determinação da densidade do solo (Figura 6).

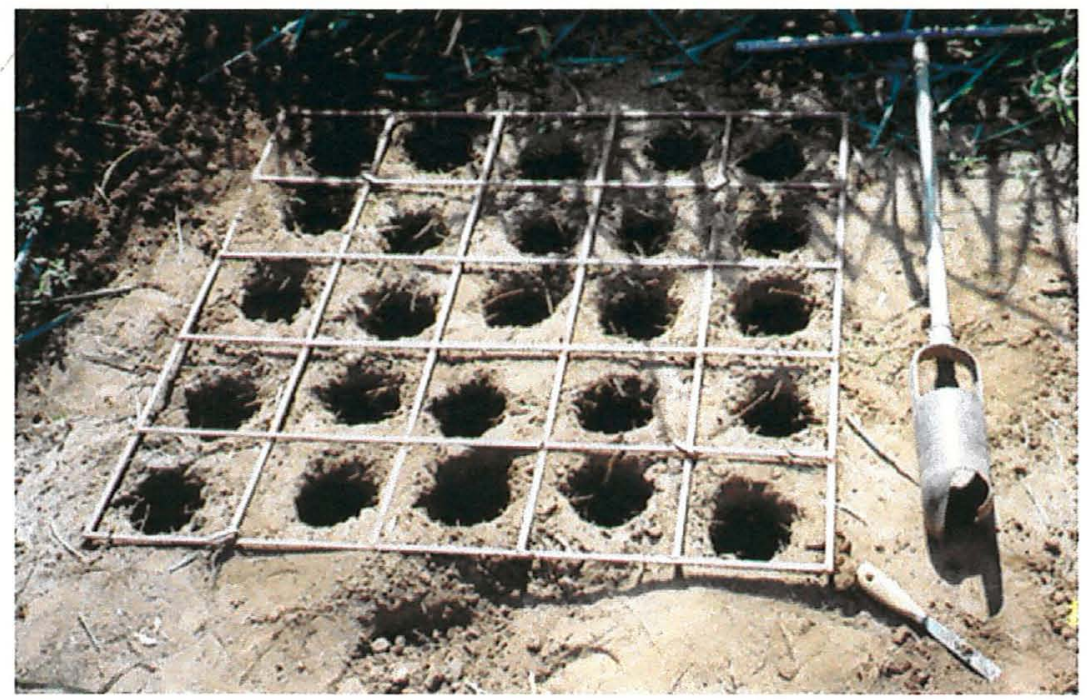

Figura 6- Quadro de coleta com os orifícios para retirada das amostras.

A amostragem foi realizada na seguinte ordem, primeiro foram coletadas as cinco repetições com as ferramentas que não necessitam de abertura de trincheiras para serem removidas do solo, que são as ferramentas D-(TB50), E-(TB100) e C-(TSM). A seguir foram introduzidos no solo, os cinco cilindros da ferramenta B-(AK), que só foram retirados do solo, após a coleta das cinco amostras com a ferramenta A-(TU), que também exigem abertura de trincheiras para sua retirada. 
Imediatamente após serem retiradas do solo, as amostras foram embrulhadas em papel alumínio e guardadas em caixas térmicas, conservando assim sua umidade natural para posterior maquiagem no laboratório.

\subsection{Tempo (s) e energia consumida (J)}

Foram cronometrados os tempos gastos na operação para a retirada de cada anel e o número de impáctos utilizados para introduzí-los no solo. O tempo de operação registrado foi o da introdução da ferramenta no solo, sua retirada, até o cilindro ser embrulhado em papel alumínio, com a colocação de outro na ferramenta. O tempo para abertura do orifício até o ponto inicial da coleta, que foi considerado igual para todos os métodos, não foi cronometrado.

A energia consumida, foi determinada através do número de impáctos utilizados para introduzir o equipamento no solo, multiplicado pela energia potencial gravitácional, que foi calculada utilizando a eq. (1).

$$
E=n \cdot E p_{g}=n \cdot(m \cdot g \cdot h)
$$

Considerando:

$$
\begin{aligned}
E & =\text { energia consumida }(J) \\
\mathrm{Ep}_{\mathrm{g}} & =\text { energia potencial gravitacional }(\mathrm{J}) \\
\mathrm{n} & =\mathrm{n}^{\mathrm{o}} \text { de impáctos } \\
\mathrm{m} & =\text { massa em Kg} \\
\mathrm{g} & =\text { aceleração da gravidade }=9,8 \mathrm{~m} \cdot \mathrm{s}^{-2} \\
\mathrm{~h} & =\text { altura da haste onde cai o peso ou martelo. }
\end{aligned}
$$

\subsection{Porosidade total, macroporosidade e microporosidade.}

Depois desta preparação no laboratório, em cada cilindro foi colocado um disco de tecido de malhas ralas, preso por elástico em uma das faces e pesados com a umidade natural (PU). A seguir, os cilindros foram colocados em uma bandeja com água até $2 / 3$ de sua altura e coberto com plástico durante dois dias, para ficarem saturadas. 
Logo após atingirem a saturação, as amostras foram pesadas (P1) e colocadas na mesa de tensão à altura de $60 \mathrm{~cm}$ de coluna de água, até serem totalmente drenadas, quando foram pesadas (P2), e colocadas na estufa com temperatura de $105^{\circ} \mathrm{C}$ durante 48 horas e pesadas novamente (P3), de acordo com a tecnologia recomendada pela EMBRAPA (1979).

A determinação das propriedades, porosidade total, macroporosidade (Ma), e microporosidade (Mi) pelo método direto, foram realizadas utilizando as eq. (2), eq. (3) e eq. (4)

$$
\begin{aligned}
\mathrm{PT} \% & =\frac{P_{1}-P 3}{\text { Volume }} \\
\mathrm{Ma} \% & =\frac{P_{1}-P 2}{\text { Volume }} \\
\mathrm{Mi} \% & =\frac{P 2-P 3}{\text { Volume }}
\end{aligned}
$$

A porosidade total também foi calculada pelo método indireto, que segundo Kiehl (1979), é largamente utilizado, pois parte de dois dados geralmente indispensáveis numa ficha de análise de solos: as densidades do solo e de partículas, utilizando-se a eq.(5):

$$
\mathrm{PT} \%=1-\frac{D_{S}}{D_{P}}
$$

As determinações utilizando a mesa de tensão, são recomendadas para trabalhos em série, uma vez que comportam muitas amostras. Há quem faça restrição ao método pelo fato de algumas amostras drenarem mais água do que deviam, depois de retiradas da bandeja de embebição, para serem pesadas. Essa perda de água alteraria o volume de liquido correspondente à porosidade do solo (Kiehl, 1979). 


\subsection{Textura, umidade gravimétrica, densidade do solo e de partículas.}

A umidade gravimétrica foi determinada para cada amostra, calculando-se U\% através da eq. (6).

$$
\mathrm{U} \%=\frac{\text { Peso úmido }- \text { peso seco }}{\text { Peso seco }- \text { tara do anel }} \times 100
$$

As amostras depois de pesadas sêcas, foram destorroadas, moídas e passadas na peneira de $2 \mathrm{~mm}$, para a determinação da textura através do método de Bouyoucos e da densidade de partículas pelo método do picnômetro com água (Kiehl, 1979).

Para as análises granulométricas, foram utilizadas cinco amostras em cada grade de amostragem, uma amostra de cada ferramenta, coletadas no centro da grade, isto é, as coordenadas $(\mathrm{x}, \mathrm{y})$ em centimetros, de cada amostra foram, respectivamente, ferramentas: $\mathrm{A}(30,50), \mathrm{B}(50,50), \mathrm{C}(70,50), \mathrm{D}(30,50)$ e $\mathrm{E}(50,70)$.

A densidade do solo foi determinada, dividindo-se a massa de solo sêco, pelo volume do cilindro conforme metodologia da EMBRAPA (1979).

\subsection{Análises estatísticas}

As análises estatísticas foram realizadas utilizando-se como esquema experimental o Quadrado Latino e a estatística clássica, da seguinte forma:

1) Para as propriedades determinadas com cada ferramenta (tamanho de cilindro), foram calculadas a média, desvio padrão e o coeficiente de variação, para cada grade, e entre as grades analisadas para os mesmos tipos de solo.

2) Foram feitas as análises de variância e o teste de Tukey a $5 \%$ e a $1 \%$, entre os valores médios encontrados para cada propriedade com os amostradores, para cada grade.

Segundo Pimentel Gomes (1990), delineamento em quadrado latino segue o modelo estatístico da eq. (7)

$$
Y_{i j(k)}=m+l_{i}+c_{i}+t_{k}+e_{i j(k)}
$$


em que:

$$
\begin{aligned}
\mathrm{Y}_{\mathrm{ij}(\mathrm{k})}= & \text { valor observado para a variável em estudo referente ao k-ésimo } \\
& \text { tratamento, na } \mathrm{i} \text {-ésima linha e na } \mathrm{j} \text {-ésima coluna; } \\
\mathrm{m}= & \text { média de todas as unidades experimentais para a variável em estudo; } \\
\mathrm{l}_{\mathrm{i}}= & \text { efeito da linha } \mathrm{i} \\
\mathrm{c}_{\mathrm{i}}= & \text { efeito da coluna } \mathrm{j} \\
\mathrm{t}_{\mathrm{k}}= & \text { efeito do tratamento } \mathrm{k} ; \\
\mathbf{e}_{\mathrm{ij}(\mathrm{k})}= & \text { erro experimental. }
\end{aligned}
$$

Admitindo-se, $\mathrm{K}$ - tratamentos, $\mathrm{I}$ - linhas e $\mathrm{J}$ - colunas $(\mathrm{I}=\mathrm{J}=\mathrm{K})$, o esquema da análise de variância fica:

\begin{tabular}{ccccc}
\hline FV & GL & SQ & QM & F \\
\hline Linhas & $\mathrm{K}-1$ & & \\
Colunas & $\mathrm{K}-1$ & & \\
Tratamentos & $\mathrm{K}-1$ & & \\
Resíduo & $(\mathrm{K}-1)(\mathrm{K}-2)$ & & \\
\hline Total & $\mathrm{K}^{2}-1$ & & \\
\hline
\end{tabular}

Considerando,

$$
\begin{aligned}
& \mathrm{L}_{\mathrm{i}}=\text { total da linha } \mathrm{i} ; \\
& \mathrm{C}_{\mathrm{j}}=\text { total da coluna } \mathrm{j} ; \\
& \mathrm{T}_{\mathrm{k}}=\text { total do tratamento } \mathrm{k} ; \mathrm{e} \\
& \mathrm{G}=\text { total geral. }
\end{aligned}
$$

As somas de quadrados são dadas pelas equações (8), (9), (10), (11) e (12).

$$
\begin{aligned}
& \text { SQTotal }=\sum_{i, j} Y_{i j}^{2}-\mathrm{C}, \text { onde } \mathrm{C}=\frac{G^{2}}{I J}=\frac{G^{2}}{I^{2}} \\
& \text { SQLinhas }=\frac{1}{I} \sum_{i=1}^{I} L_{i}^{2}-\mathrm{C} \\
& \text { SQColunas }=\frac{1}{I} \sum_{j=1}^{j} C_{i}^{2}-\mathrm{C}
\end{aligned}
$$


SQTratamentos $=\frac{1}{I} \sum_{k=1}^{K} T_{i}^{2}-\mathrm{C}$

SQResiduo $=$ SQTotal $-\mathrm{SQL}-\mathrm{SQC}-\mathrm{SQT}$ 


\section{RESULTADOS E DiscuSSÃo}

As amostragens previstas nos seis pontos, tanto no solo argiloso da fazenda Areão, como no solo arenoso da fazenda Sertãozinho, não foram realizadas coleta de amostras nas grades de amostragens com teores de água próximos à saturação, nem nos pontos com teores de água a $40 \%$ da capacidade de campo.

A umidade do solo próxima a $40 \%$ da capacidade de campo, correspondeu a tensões muito acima de $80 \mathrm{kPa}$, limite de leitura deste equipamento, tanto nos solos mais argilosos da fazenda Areão, como nos solos arenosos da fazenda Sertãozinho. A umidade gravimétrica, foi determinada através de amostras colhidas com o trado tipo sonda, na profundidade 15 a $25 \mathrm{~cm}$.

Quando o solo estava com umidade de $40 \%$ da capacidade de campo, não foi realizada coleta de amostras de solo, na grade de amostragem número 5 nos dois solos, pois a resistência a penetração dificultava a retirada das amostras, ou exigia um número grande de impactos, provocando fissuras no solo dentro dos cilindros, fazendo com que as amostras destorroassem, e caíssem de dentro dos anéis ao serem retirados do solo. Somente com a ferramenta B- anel de Kopecky, foi possível a coleta das amostras, porém, com a uniformidade bastante comprometida e com presença de fissuras.

Nas grades de amostragem número 6 dos dois solos, a umidade foi determinada com auxilio de tensiômetros, que apresentavam leituras na faixa de $2 \mathrm{kPa} e$ $4 \mathrm{kPa}$. O solo nesta condição estava saturado, não permitindo a coleta de amostras. $\mathrm{O}$ excesso de umidade e a retirada das ferramentas do solo, promove a formação de vácuo nos orificios, puxando o solo de dentro dos cilindros, diminuindo a sua quantidade ou mesmo removendo o solo totalmente. 
Nas demais grades de amostragem, números 1, 2, 3 e 4, tanto no solo argiloso, como no solo arenoso quando não se encontravam secos, nem saturados, as amostras foram coletadas normalmente, e os resultados para cada propriedade fisica foi analisada. A caracterização do solo serão apresentadas a seguir, conforme a ordem em que foram coletadas.

\subsection{Granulometria}

As análises granulométricas das amostras coletadas, apresentaram baixos coeficientes de variação para todas as frações nas grades amostradas no solo argiloso, e para o solo arenoso, os coeficientes de variação foram baixos para o teor de areia e argila, e médio para silte. Os coeficientes de variação para o solo argiloso, foram: 6,0\% para areia, $10,1 \%$ para silte e 9,1\% para argila, e para o solo arenoso: $2,0 \%$ para areia, $15,9 \%$ para silte, e $9,5 \%$ para argila.

\subsubsection{Amostras coletadas no solo argiloso da Fazenda Areão}

Os resultados obtidos para textura do solo, nas quatro grades de amostragem, apresentaram teores médios de argila, areia e silte, que no diagrama triangular para classificação de solo, ficaram no limite entre solo Franco Argiloso e Argila.

Os valores de granulometria e as respectivas classificações do solo, para cada ferramenta nas grades de amostragem e suas médias, podem ser visualizadas na Tabela 1.

\subsubsection{Amostras coletadas no solo a renoso da Fazenda Sertãozinho}

Com base nos resultados médios obtidos, de percentagem de areia, silte e argila, o solo foi classificado como franco arenoso, nas quatro grades amostradas neste local.

Os valores de granulometria e as respectivas classificações do solo, para cada ferramenta nas grades de amostragem e suas médias, podem ser visualizadas na Tabela 2. 
Tabela 1- Análise granulométrica com percentagens de areia, silte e argila na fazenda Areão, e as respectivas classificações do solo, para as grades de amostragem número 1 (a), grade 2 (b), grade 3 (c), grade 4 (d) e para média geral (e).

(a)

\begin{tabular}{lcccc}
\hline \multicolumn{1}{c}{ Amostradores } & Areia (\%) & Silte (\%) & Argila (\%) & Classificação \\
\hline A - Uhland Grande & 38 & 22 & 40 & Argila \\
B - Anel Kopeck & 38 & 21 & 41 & Argila \\
C - Trado mod.Soil Moisture & 39 & 24 & 37 & Franco argiloso \\
D - Bravifer $50 \mathrm{~cm} 3$ & 39 & 24 & 37 & Franco argiloso \\
E- Bravifer $100 \mathrm{~cm} 3$ & 37 & 23 & 40 & Argila \\
\hline \multicolumn{1}{c}{ Média } & 38 & 23 & 39 & Franco argiloso \\
\hline
\end{tabular}

(b)

\begin{tabular}{lcccc}
\hline \multicolumn{1}{c}{ Amostradores } & Areia (\%) & Silte (\%) & Argila (\%) & Classificação \\
\hline A - Uhland Grande & 41 & 26 & 33 & Franco argiloso \\
B - Anel Kopeck & 41 & 25 & 34 & Franco argiloso \\
C - Trado mod.Soil Moisture & 41 & 28 & 31 & Franco argiloso \\
D - Bravifer $50 \mathrm{~cm} 3$ & 42 & 24 & 34 & Franco argiloso \\
E - Bravifer $100 \mathrm{~cm} 3$ & 40 & 24 & 36 & Franco argiloso \\
\hline \multicolumn{1}{c}{ Média } & 41 & 26 & 34 & Franco argiloso \\
\hline
\end{tabular}

(c)

\begin{tabular}{lcccc}
\hline \multicolumn{1}{c}{ Amostradores } & Areia (\%) & Silte (\%) & Argila (\%) & Classificação \\
\hline A - Uhland Grande & 42 & 24 & 34 & Franco argiloso \\
B - Anel Kopeck & 39 & 24 & 37 & Franco argiloso \\
C - Trado mod.Soil Moisture & 41 & 27 & 32 & Franco argiloso \\
D - Bravifer $50 \mathrm{~cm} 3$ & 38 & 25 & 37 & Franco argiloso \\
E - Bravifer $100 \mathrm{~cm} 3$ & 33 & 31 & 36 & Franco argiloso \\
\hline \multicolumn{1}{c}{ Média } & 39 & 26 & 35 & Franco argiloso \\
\hline
\end{tabular}

(d)

\begin{tabular}{lcccc}
\hline \multicolumn{1}{c}{ Amostradores } & Areia (\%) & Silte (\%) & Argila (\%) & Classificação \\
\hline A - Uhland Grande & 35 & 23 & 42 & Argila \\
B - Anel Kopeck & 36 & 23 & 41 & Argila \\
C - Trado mod.Soil Moisture & 37 & 21 & 42 & Argila \\
D - Bravifer $50 \mathrm{~cm} 3$ & 39 & 23 & 38 & Franco argiloso \\
E - Bravifer $100 \mathrm{~cm} 3$ & 39 & 22 & 39 & Argila \\
\hline \multicolumn{1}{c}{ Média } & 37 & 22 & 40 & Argila \\
\hline
\end{tabular}

(e)

\begin{tabular}{lcccc}
\hline \multicolumn{1}{c}{ Amostradores } & Areia (\%) & Silte (\%) & Argila (\%) & Classificação \\
\hline A - Uhland Grande & 39 & 24 & 37 & Franco argiloso \\
B - Anel Kopeck & 39 & 23 & 38 & Franco argiloso \\
C - Trado mod.Soil Moisture & 40 & 25 & 35 & Franco argiloso \\
D - Bravifer $50 \mathrm{~cm} 3$ & 39 & 24 & 37 & Franco argiloso \\
E - Bravifer $100 \mathrm{~cm} 3$ & 37 & 25 & 38 & Franco argiloso \\
\hline \multicolumn{1}{c}{ Média } & 39 & 24 & 37 & Franco argiloso \\
\hline
\end{tabular}


Tabela 2- Análise granulométrica com percentagens de areia, silte e argila na fazenda Sertãozinho, e as respectivas classificações do solo, para as grades de amostragem número $1(\mathrm{a})$, grade $2(\mathrm{~b})$, grade $3(\mathrm{c})$, grade 4 (d) e para média geral (e).

(a)

\begin{tabular}{lcccc}
\hline \multicolumn{1}{c}{ Amostradores } & Areia (\%) & Silte (\%) & Argila (\%) & Classificação \\
\hline A - Uhland Grande & 78 & 7 & 15 & Franco arenoso \\
B - Anel Kopeck & 78 & 6 & 16 & Franco arenoso \\
C - Trado mod.Soil Moisture & 79 & 7 & 14 & Franco arenoso \\
D - Bravifer $50 \mathrm{~cm} 3$ & 80 & 6 & 14 & Franco arenoso \\
E - Bravifer $100 \mathrm{~cm} 3$ & 79 & 6 & 15 & Franco arenoso \\
\hline \multicolumn{1}{c}{ Média } & 79 & 6 & 15 & Franco arenoso \\
\hline
\end{tabular}

(b)

\begin{tabular}{lcccc}
\hline \multicolumn{1}{c}{ Amostradores } & Areia (\%) & Silte (\%) & Argila (\%) & Classificação \\
\hline A - Uhland Grande & 77 & 7 & 16 & Franco arenoso \\
B - Anel Kopeck & 78 & 5 & 17 & Franco arenoso \\
C - Trado mod.Soil Moisture & 78 & 5 & 17 & Franco arenoso \\
D - Bravifer $50 \mathrm{~cm} 3$ & 77 & 7 & 16 & Franco arenoso \\
E - Bravifer $100 \mathrm{~cm} 3$ & 78 & 6 & 16 & Franco arenoso \\
\hline \multicolumn{1}{c}{ Média } & 78 & 6 & 16 & Franco arenoso \\
\hline
\end{tabular}

(c)

\begin{tabular}{lcccc}
\hline \multicolumn{1}{c}{ Amostradores } & Areia (\%) & Silte (\%) & Argila (\%) & Classificação \\
\hline A - Uhland Grande & 81 & 6 & 13 & Franco arenoso \\
B - Anel Kopeck & 79 & 8 & 13 & Franco arenoso \\
C - Trado mod.Soil Moisture & 78 & 7 & 15 & Franco arenoso \\
D - Bravifer $50 \mathrm{~cm} 3$ & 79 & 8 & 13 & Franco arenoso \\
E - Bravifer $100 \mathrm{~cm} 3$ & 77 & 7 & 16 & Franco arenoso \\
\hline \multicolumn{1}{c}{ Média } & 79 & 7 & 14 & Franco arenoso \\
\hline
\end{tabular}

(d)

\begin{tabular}{lcccc}
\hline \multicolumn{1}{c}{ Amostradores } & Areia (\%) & Silte (\%) & Argila (\%) & Classificação \\
\hline A - Uhland Grande & 78 & 6 & 16 & Franco arenoso \\
B - Anel Kopeck & 82 & 5 & 13 & Franco arenoso \\
C - Trado mod.Soil Moisture & 77 & 6 & 17 & Franco arenoso \\
D - Bravifer $50 \mathrm{~cm} 3$ & 82 & 5 & 13 & Franco arenoso \\
E - Bravifer $100 \mathrm{~cm} 3$ & 78 & 7 & 15 & Franco arenoso \\
\hline \multicolumn{1}{c}{ Média } & 79 & 6 & 15 & Franco arenoso \\
\hline
\end{tabular}

(e)

\begin{tabular}{lcccc}
\hline \multicolumn{1}{c}{ Amostradores } & Areia (\%) & Silte (\%) & Argila (\%) & Classificação \\
\hline A - Uhland Grande & 79 & 6 & 15 & Franco arenoso \\
B - Anel Kopeck & 79 & 6 & 15 & Franco arenoso \\
C - Trado mod.Soil Moisture & 78 & 6 & 16 & Franco arenoso \\
D - Bravifer $50 \mathrm{~cm} 3$ & 80 & 6 & 14 & Franco arenoso \\
E - Bravifer 100 cm3 & 78 & 6 & 16 & Franco arenoso \\
\hline \multicolumn{1}{c}{ Média } & 79 & 6 & 15 & Franco arenoso \\
\hline
\end{tabular}




\subsection{Densidade de partículas}

Para a determinação deste parâmetro, observamos que os coeficientes de variação foram baixos, menores que $1,5 \%$, para os dois tipos de solo, em todas as grades de amostragens.

\subsubsection{Solos argilosos amostrados na fazenda Areão}

Os valores médios das densidades de partículas (Dp) do solo, com os respectivos coeficientes de variação, obtidos para cada ferramenta nas grades de amostragem, junto com os testes de significância $\mathrm{F}$, diferença mínima significativa de Tukey a $5 \%$ e $1 \%$, e o coeficiente de variação entre as ferramentas de coleta, são apresentados na tabela 3.

A análise estatística, entre as médias obtidas de densidade de partículas, não apresentou diferenças significativas em nenhuma das grades amostradas no solo argiloso da fazenda Areão.

Tabela 3- Densidades de partículas do solo, obtidas com as ferramentas de coleta no solo argiloso, à profundidade média de $20 \mathrm{~cm}$. Valores médios de 5 repetições.

\begin{tabular}{lcccccccc} 
& \multicolumn{2}{c}{ Grade 1 } & \multicolumn{2}{c}{ Grade 2 } & \multicolumn{2}{c}{ Grade 3 } & \multicolumn{2}{c}{ Grade 4 } \\
\hline \multicolumn{1}{c}{ Ferramenta } & Dp & CV & Dp & CV & Dp & CV & Dp & CV \\
\hline A-Trado Uhland & $2,66 \mathrm{a}$ & 0,6 & $2,65 \mathrm{a}$ & 0,5 & $2,61 \mathrm{a}$ & 0,8 & $2,62 \mathrm{a}$ & 0,9 \\
B-Anel Kopecky & $2,66 \mathrm{a}$ & 0,5 & $2,62 \mathrm{a}$ & 1,1 & $2,62 \mathrm{a}$ & 1,3 & $2,64 \mathrm{a}$ & 0,8 \\
C-Trado Soil Moisture & $2,66 \mathrm{a}$ & 0,3 & $2,64 \mathrm{a}$ & 0,5 & $2,65 \mathrm{a}$ & 1,2 & $2,64 \mathrm{a}$ & 0,8 \\
D-Trado Bravifer AI-50 & $2,65 \mathrm{a}$ & 0,7 & $2,64 \mathrm{a}$ & 0,9 & $2,63 \mathrm{a}$ & 0,6 & $2,65 \mathrm{a}$ & 1,0 \\
E-Trado Bravifer AI-100 & $2,67 \mathrm{a}$ & 0,5 & $2,65 \mathrm{a}$ & 0,6 & $2,62 \mathrm{a}$ & 1,4 & $2,62 \mathrm{a}$ & 0,5 \\
\hline \multicolumn{1}{c}{ F } & 1,291 n.s. & 1,263 n.s. & 2,059 n.s. & 1,570 n.s. \\
Dms (5\%) & 0,03 & 0,04 & 0,05 & 0,04 \\
Dms (1\%) & 0,04 & 0,06 & 0,06 & 0,06 \\
CV(\%) & 0,3 & 0,4 & 0,8 & 0,5 \\
\hline
\end{tabular}

Médias seguidas de mesma letra e na mesma coluna, não diferem entre si (Tukey a 5\%).

\subsubsection{Solos arenosos amostrados na fazenda Sertãozinho}

Os valores médios das densidades de partículas (Dp) do solo, com os respectivos coeficientes de variação, obtidos para cada ferramenta nas grades de 
amostragem, junto com os testes de significância $\mathrm{F}$, diferença mínima significativa de Tukey a $5 \%$ e $1 \%$, e o coeficiente de variação entre as ferramentas de coleta, são apresentados na tabela 4 .

A análise estatística, entre as médias obtidas de densidade de partículas, apresentou diferenças significativas a (1\%) apenas para a grade de amostragem numero 1, as grades .2, 3 e 4 amostradas, não apresentaram diferenças no solo arenoso da fazenda Sertãozinho.

A diferença encontrada na grade 1 , deve ser atribuída ao método de determinação ou ao solo, pois as amostras são retiradas dos cilindros, deformadas e peneiradas antes de serem analisadas, não sofrendo portanto, nenhuma influência da ferramenta de coleta.

Tabela 4- Densidades de partículas do solo, obtidas com as ferramentas de coleta no solo arenoso, à profundidade média de $20 \mathrm{~cm}$. Valores médios de 5 repetições.

\begin{tabular}{lcccccccc} 
& \multicolumn{3}{c}{ Grade 1 } & \multicolumn{2}{c}{ Grade 2 } & \multicolumn{2}{c}{ Grade 3 } & \multicolumn{2}{c}{ Grade 4 } \\
\hline \multicolumn{1}{c}{ Ferramentas } & Dp & CV & Dp & CV & Dp & CV & Dp & CV \\
\hline A-Trado Uhland & $2,63 \mathrm{a}$ & 0,6 & $2,64 \mathrm{a}$ & 0,3 & $2,63 \mathrm{a}$ & 0,5 & $2,63 \mathrm{a}$ & 0,9 \\
B-Anel Kopecky & $2,60 \mathrm{ab}$ & 0,6 & $2,62 \mathrm{a}$ & 0,8 & $2,62 \mathrm{a}$ & 0,5 & $2,61 \mathrm{a}$ & 0,9 \\
C-Trado Soil Moisture & $2,62 \mathrm{a}$ & 0,5 & $2,64 \mathrm{a}$ & 0,4 & $2,63 \mathrm{a}$ & 0,2 & $2,62 \mathrm{a}$ & 0,4 \\
D-Trado Bravifer AI-50 & $2,58 \mathrm{~b}$ & 1,4 & $2,63 \mathrm{a}$ & 0,5 & $2,61 \mathrm{a}$ & 0,2 & $2,61 \mathrm{a}$ & 0,4 \\
E-Trado Bravifer AI-100 & $2,62 \mathrm{a}$ & 0,6 & $2,64 \mathrm{a}$ & 0,4 & $2,62 \mathrm{a}$ & 0,2 & $2,62 \mathrm{a}$ & 0,4 \\
\hline \multicolumn{1}{c}{ F } & $7,458^{* *}$ & 1,402 n.s. & 3,092 n.s. & 0,982 n.s. \\
Dms (5\%) & 0,03 & 0,03 & 0,02 & 0,04 \\
Dms (1\%) & 0,04 & 0,04 & 0,03 & 0,05 \\
CV(\%) & 0,76 & \multicolumn{2}{c}{0,29} & \multicolumn{2}{c}{0,29} & 0,29 \\
\hline Médias seguidas de me
\end{tabular}

Os coeficientes de variação foram baixos para todas as amostras coletadas com as ferramentas nos dois locais. Resultados semelhantes foram encontrados por Tavares Filho (1987), que obteve coeficientes de confiança de 90, 95 e 99\% e uma variação percentual de $10 \%$, quando concluiu que, para representar a densidade de partículas da área de $10 \mathrm{ha}$, seria necessária a coleta de apenas uma amostra. 


\subsection{Umidade gravimétrica do solo}

Entre as propriedades físicas do solo estudadas, a umidade do solo é uma das mais importantes, uma vez que existe uma umidade ideal para amostragem que deve ser identificada.

\subsubsection{Solos argilosos a mostrados na fazenda Areão}

A umidade do solo no dia da amostragem, obtida com o auxilio de tensiômetros no solo argiloso, apresentaram faixas de tensões para as grades de coleta número 1 e número 2, que representavam teores de água próximos a $70 \%$ da capacidade de campo. Para as grades número 3 e número 4, os teores de água se encontravam próximos a $100 \%$ da capacidade de campo deste solo.

Os valores médios de umidade gravimétrica $U \%\left(\mathrm{~g} \cdot \mathrm{g}^{-1}\right)$ e o respectivo coeficiente de variação, obtidos para cada ferramenta nas grades de amostragem, junto com os testes de significância $F$, diferença mínima significativa (dms) de Tukey a $5 \%$ e $1 \%$, e o coeficiente de variação entre as ferramentas, são apresentados na Tabela 5.

Tabela 5- Umidades gravimétricas do solo (U\%) obtidas com as ferramentas de coleta no solo argiloso da fazenda Areão, à profundidade média de $20 \mathrm{~cm}$. Valores médios de 5 repetições.

\begin{tabular}{lcccccccc} 
& \multicolumn{3}{c}{ Grade 1} & \multicolumn{2}{c}{ Grade 2} & \multicolumn{2}{c}{ Grade 3 } & \multicolumn{2}{c}{ Grade 4 } \\
\hline \multicolumn{1}{c}{ Ferramentas } & U\% & CV & U\% & CV & U\% & CV & U\% & CV \\
\hline A-Trado Uhland & 18,9 a & 3,2 & 17,7 ab & 5,4 & 19,2 a & 5,3 & 20,1 a & 14,2 \\
B-Anel Kopecky & 17,9 a & 4,2 & 17,2 b & 4,4 & 19,5 a & 4,2 & 20,9 a & 15,4 \\
C-Trado Soil Moisture & 18,2 a & 5,2 & 18,9 a & 4,0 & 20,3 a & 10,6 & 18,2 a & 10,6 \\
D-Trado Bravifer AI-50 & 18,1 a & 5,2 & 17,6 ab & 6,6 & 19,9 a & 12,5 & 20,2 a & 13,6 \\
E-Trado Bravifer AI-100 & 17,9 a & 5,5 & 17,7 ab & 4,4 & 19,1 a & 5,1 & 18,5 a & 15,4 \\
\hline \multicolumn{1}{c}{ F } & 1,573 n.s. & $10,394 * *$ & 1,303 n.s. & 1,514 n.s. \\
Dms (5\%) & 1,45 & 1,37 & 2,99 & 4,32 \\
Dms (1\%) & 1,88 & 1,75 & 3,87 & 5,60 \\
CV(\%) & 4,76 & 5,68 & & 8,04 & 13,96 \\
\hline
\end{tabular}

Médias seguidas de mesma letra, e na mesma coluna, não diferem entre si (Tukey a 5\%).

A análise estatística apresentou, entre as médias obtidas de umidade, diferenças significativas a (1\%), apenas para a grade de amostragem numero 2 . As 
grades 1, 3 e 4, não apresentaram diferenças significativas no solo argiloso da fazenda Areão.

A média geral da umidade do solo, obtida entre as 20 amostras coletadas nas quatro grades de amostragem, com cada ferramenta, no solo argiloso da fazenda Areão, foram: A $(19,0 \%)$, B $(18,9 \%)$, C $(18,9 \%)$, D $(18,9 \%)$, E $(18,3 \%)$ e a geral $(18,8 \%)$, e estão representados na Figura 7.

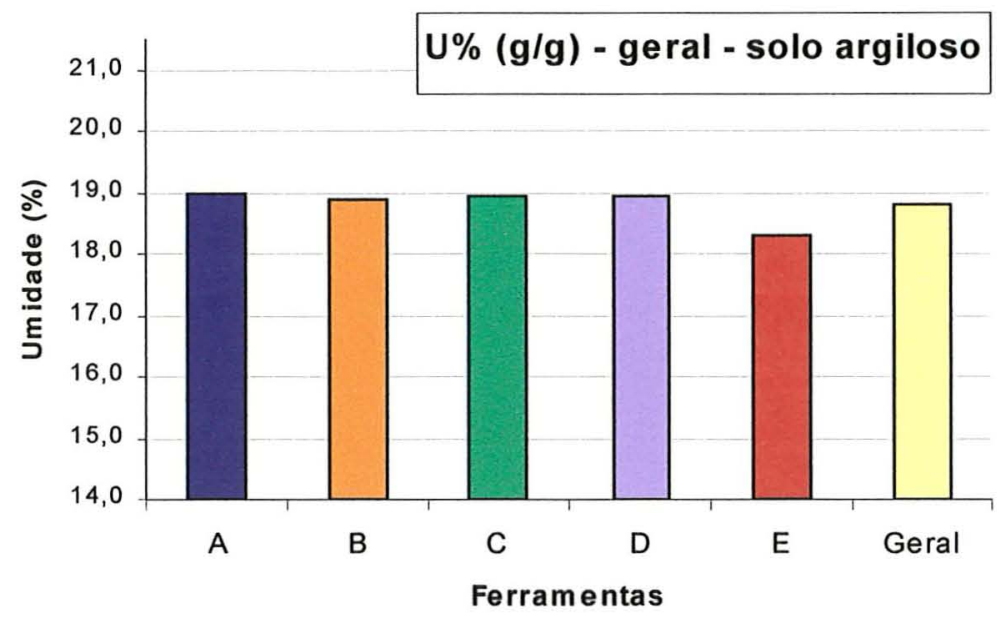

Figura 7- Médias da umidade gravimétrica do solo (U\%), determinadas com as ferramentas de coleta A, B, C, D, E, e a geral, nas quatro grades coletadas no solo argiloso da fazenda Areão.

Os valores mínimos e máximos de umidade obtidos com as diferentes ferramentas, foram respectivamente, grade 1: A(18,3 e 19,9\%), B(16,8 e 18,6\%), C(16,9 e $19,4 \%), D(16,8$ e $18,8 \%)$ e $E(16,8$ e $18,9 \%)$. Na grade 2 : $A(16,1$ e $18,5 \%), B(16,2$ e $18,3 \%), C(18,3$ e $20,1 \%), D(16,5$ e $19,6 \%)$ e $E(16,9$ e $18,7 \%)$. Na grade $3: \mathrm{A}(17,9$ e $20,5 \%), \mathrm{B}(18,4$ e $20,5 \%), \mathrm{C}(18,5$ e $24,0 \%), \mathrm{D}(18,0$ e $23,8 \%)$ e $\mathrm{E}(18,3$ e $20,6 \%)$ e, na grade 4: $\mathrm{A}(17,0$ e $24,6 \%), \mathrm{B}(16,3$ e $24,8 \%), \mathrm{C}(16,3$ e $20,8 \%), \mathrm{D}(17,8$ e $24,7 \%)$ e $\mathrm{E}(16,4$ e $23,2 \%)$.

As umidades do solo obtidas pelas 25 amostras coletadas, com as ferramentas A, B, C, D e E, foram plotadas nas suas respectivas grades, onde podemos visualizar e avaliar a sua distribuição dentro de cada grade (Figura 8).

$\mathrm{Na}$ Figura 8a, observamos que as diferentes umidades gravimétricas determinadas nas amostragens, crescem numa mesma direção, indo da coordenada $(0 ; 0)$ 
para a $(100 ; 100)$, e na Figura 8c, a umidade cresce na direção, da coordenada $(100 ; 100)$ para a $(0 ; 0)$, indicando não haver influência de ferramenta, mas sim, o comportamento desta propriedade no solo. Na Figura 8d, os valores altos de umidade, encontrados com as diferentes ferramentas nas coordenadas $\mathrm{B}(50 ; 50), \mathrm{A}(70 ; 70), \mathrm{D}(70 ; 90)$ e $\mathrm{E}(90 ; 90)$, confirmam ser uma característica do solo, e não influência das ferramentas.

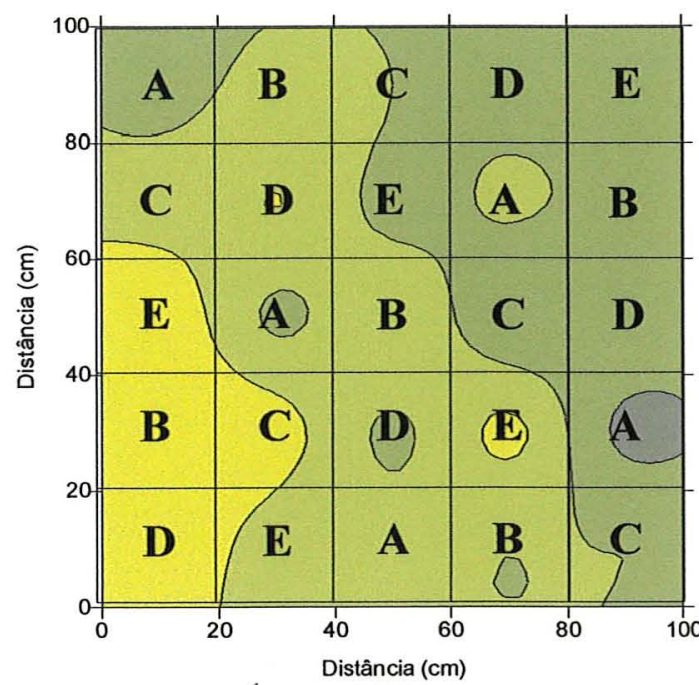

a) U\% $\left(g \cdot g^{-1}\right)$ - grade amostragem 1

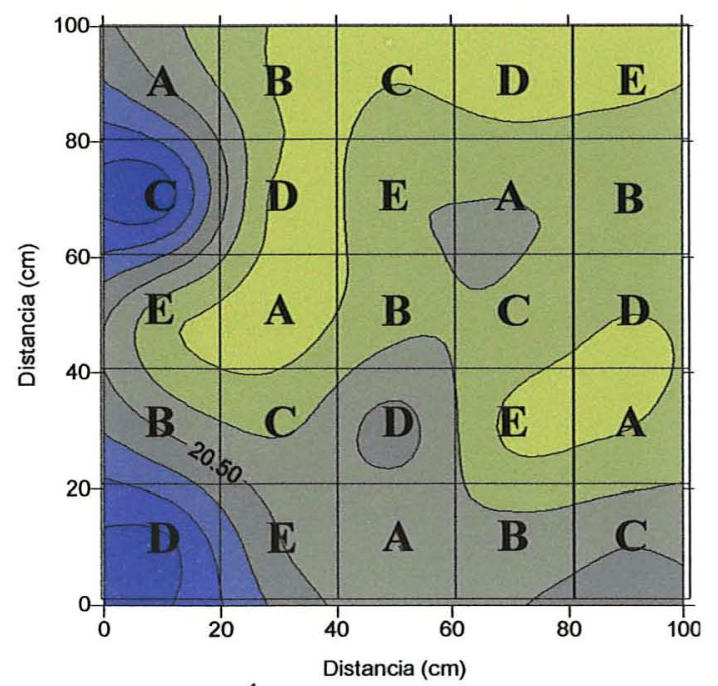

c) $U \%\left(\right.$ g.g $\left.g^{-1}\right)$ - grade amostragem 3

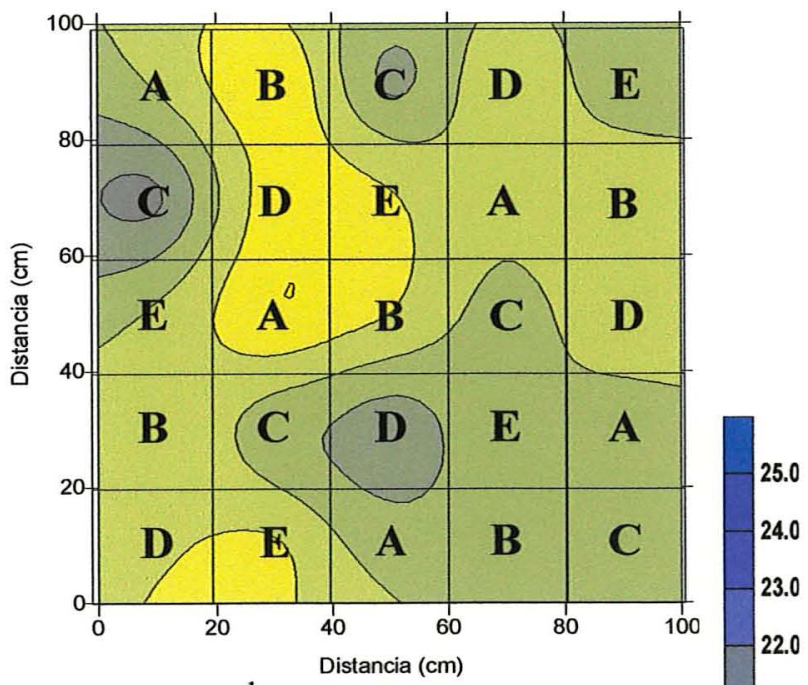

b) U\% $\left(g \cdot g^{-1}\right)$ - grade amostragem 2

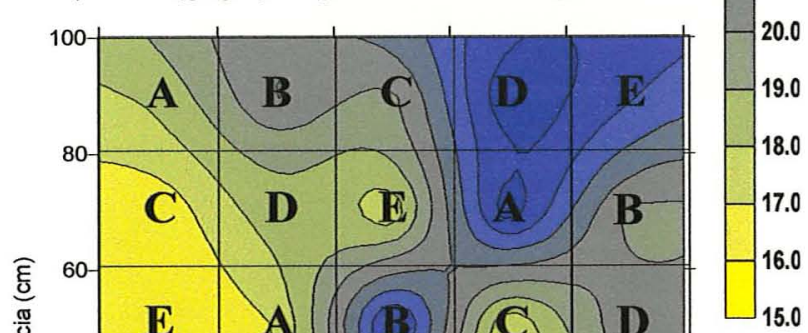

Figura 8- Mapas de contorno, com a distribuição espacial da umidade do solo U\%, nas quatro grades de amostragem, do solo argiloso da fazenda Areão: a) grade 1, b) grade 2 , c) grade 3 e d) grade 4 .

Apesar dos valores obtidos para a umidade gravimétrica nas grades, com todas as ferramentas serem próximos, apresentaram elevadas variações, tendo em vista que as 
grades eram de $1 \mathrm{~m}^{2}$. Outro fator que deve ser levado em conta, é o aumento dos coeficientes de variação de todas as ferramentas, nas grades que apresentaram maiores médias de umidade gravimétrica no solo argiloso, fato que confirma a preocupação que devemos ter com a umidade do solo no momento da amostragem.

\subsubsection{Amostras coletadas no solo arenoso da Fazenda Sertãozinho}

No momento da coleta das amostras, a tensão de água no solo obtida com auxilio de tensiômetros, apresentaram para as grades de amostragem, as seguintes faixas de tensões: grade número 1 (entre 4,5 e 9,4kPa), grade número 2(entre 5 e $10 \mathrm{kPa}$ ), grade número 3 (entre 15 e $37 \mathrm{kPa}$ ) e grade número $4($ entre 24 e $49 \mathrm{kPa}$ ), o que representam teores de água entre $60 \%$ e $100 \%$ da capacidade de campo para este solo.

Os valores médios de umidade $U \%\left(g . g^{-1}\right)$ e os respectivos coeficientes de variação, obtidos para cada ferramenta nas grades de amostragem, junto com os testes de significância $F$, diferença mínima significativa (dms) de Tukey a $5 \%$ e $1 \%$, e o coeficiente de variação entre as ferramentas, são apresentados na Tabela 6 .

Tabela 6- Umidade gravimétrica do solo (U\%), obtidas com as ferramentas de coleta no solo arenoso da fazenda Sertãozinho, à profundidade média de $20 \mathrm{~cm}$. Valores médios de 5 repetições.

\begin{tabular}{lcccccccc} 
& \multicolumn{2}{c}{ Grade 1 } & \multicolumn{2}{c}{ Grade 2 } & \multicolumn{2}{c}{ Grade 3 } & \multicolumn{2}{c}{ Grade 4 } \\
\hline \multicolumn{1}{c}{ Ferramenta } & U\% & CV & U\% & CV & U\% & CV & U\% & CV \\
\hline A-Trado Uhland & $10,2 \mathrm{c}$ & 2,3 & $10,4 \mathrm{a}$ & 3,8 & $11,3 \mathrm{a}$ & 9,0 & $10,1 \mathrm{~b}$ & 2,5 \\
B-Anel Kopecky & $11,4 \mathrm{a}$ & 6,6 & $10,4 \mathrm{a}$ & 6,3 & $11,8 \mathrm{a}$ & 9,2 & $11,4 \mathrm{a}$ & 6,7 \\
C-Trado Soil Moisture & $10,4 \mathrm{bc}$ & 3,6 & $10,0 \mathrm{a}$ & 5,0 & $11,4 \mathrm{a}$ & 5,9 & $10,4 \mathrm{ab}$ & 7,0 \\
D-Trado Bravifer AI-50 & $10,9 \mathrm{ab}$ & 3,7 & $10,5 \mathrm{a}$ & 5,9 & $11,7 \mathrm{a}$ & 8,6 & $10,9 \mathrm{ab}$ & 8,8 \\
E-Trado Bravifer AI-100 & $10,7 \mathrm{~b}$ & 2,7 & $10,4 \mathrm{a}$ & 5,0 & $11,6 \mathrm{a}$ & 5,3 & $10,4 \mathrm{ab}$ & 6,3 \\
\hline \multicolumn{1}{c}{ F } & $10,225^{* *}$ & 0,515 n.s. & 0,589 n.s. & $3,932 *$ \\
Dms (5\%) & 0,66 & 1,15 & & 1,29 & 1,11 \\
Dms (1\%) & 0,86 & & 1,49 & 1,68 & 1,44 \\
CV(\%) & 4,40 & 1,77 & & 1,90 & 4,61 \\
\hline
\end{tabular}

Médias seguidas de mesma letra e na mesma coluna, não diferem entre si (Tukey a 5\%).

A análise estatística, apresentou. entre as médias obtidas, diferenças significativas a (1\%) para a grade 1 , diferenças significativas a (5\%) para a grade 4 do 
solo arenoso na fazenda Sertãozinho, e baixos coeficientes de variação para as ferramentas, mínimo de 2,3\% e máximo de $9,2 \%$, em todas as grades de amostragem.

As médias gerais da umidade do solo, obtidas entre as 20 amostras coletadas com cada ferramenta, nas quatro grades de amostragens no solo arenoso da fazenda Sertãozinho, foram: $\mathrm{A}(10,5 \%), \mathrm{B}(11,2 \%), \mathrm{C}(10,5 \%), \mathrm{D}(11,0 \%), \mathrm{E}(10,8 \%)$ e a geral $(10,8 \%)$, e estão representados na Figura 9. O coeficiente de variação $(\mathrm{Cv})$, entre as médias foi $2,9 \%$.

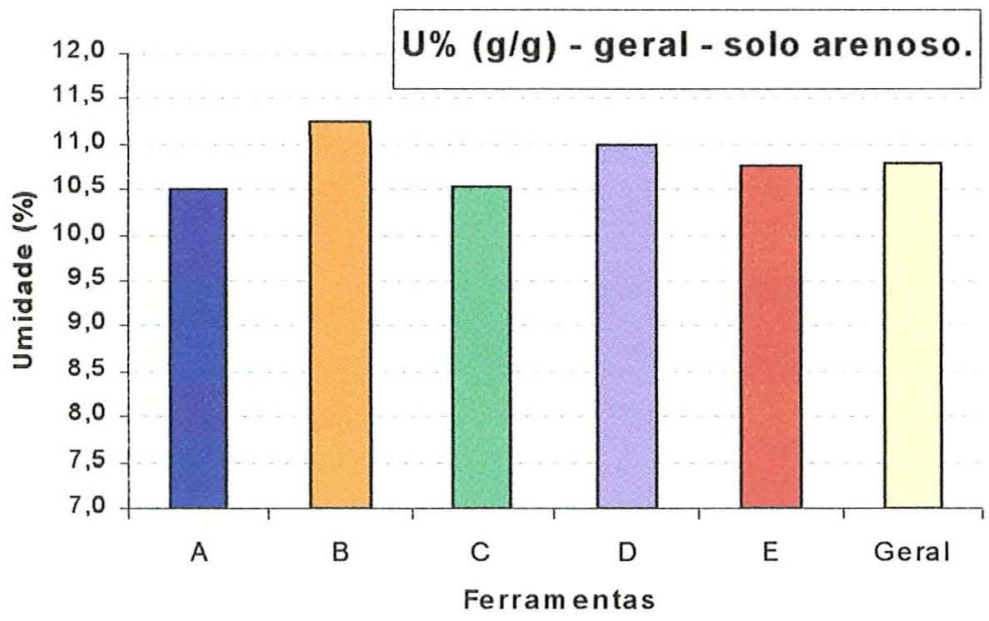

Figura 9- Médias da umidade gravimétrica do solo (U\%), determinadas com as ferramentas de coleta A, B, C, D, E, e a geral, nas quatro grades coletadas no solo arenosos da fazenda Sertãozinho.

Os valores, mínimos e máximos, de umidade do solo determinadas em cada grade pelas diferentes ferramentas, foram respectivamente, grade 1: $\mathrm{A}(10,0$ e 10,5\%), $\mathrm{B}(10,5$ e $12,6 \%), \mathrm{C}(9,8$ e 10,7\%), $\mathrm{D}(10,3$ e $11,3 \%)$ e $\mathrm{E}(10,2$ e $10,9 \%)$. Na grade $2: \mathrm{A}(9,9$ e $10,8 \%), B(9,6$ e $11,4 \%), C(9,2$ e $10,4 \%), D(9,7$ e $11,3 \%)$ e $E(10,2$ e $11,4 \%)$. Na grade 3: $\mathrm{A}(10,1$ e $12,4 \%), \mathrm{B}(10,4$ e $12,8 \%), \mathrm{C}(10,5$ e $12,1 \%), \mathrm{D}(10,7$ e $12,8 \%)$ e $\mathrm{E}(10,6$ e $12,1 \%)$ e, na grade $4: \mathrm{A}(9,9$ e $10,5 \%), \mathrm{B}(10,3$ e $12,2 \%), \mathrm{C}(9,3$ e $11,2 \%), \mathrm{D}(9,5$ e $11,8 \%)$ e $\mathrm{E}(9,6$ e $11,3 \%)$.

Nas Figuras 10a e 10d, os pontos onde foram utilizadas a ferramenta B, apresentam valores mais altos de umidade, demonstrando ser influência da ferramenta e não do solo, nestas grades. Na Figura 10b, as umidades determinadas pelas ferramentas, 
decrescem numa mesma direção, do centro para as laterais da grade 2, e na Figura 10c, as umidades decrescem na diagonal, no sentido das coordenadas $(100 ; 0)$ para $(0 ; 100)$, parecendo não haver influência de ferramentas, e sim, ser uma característica do solo.

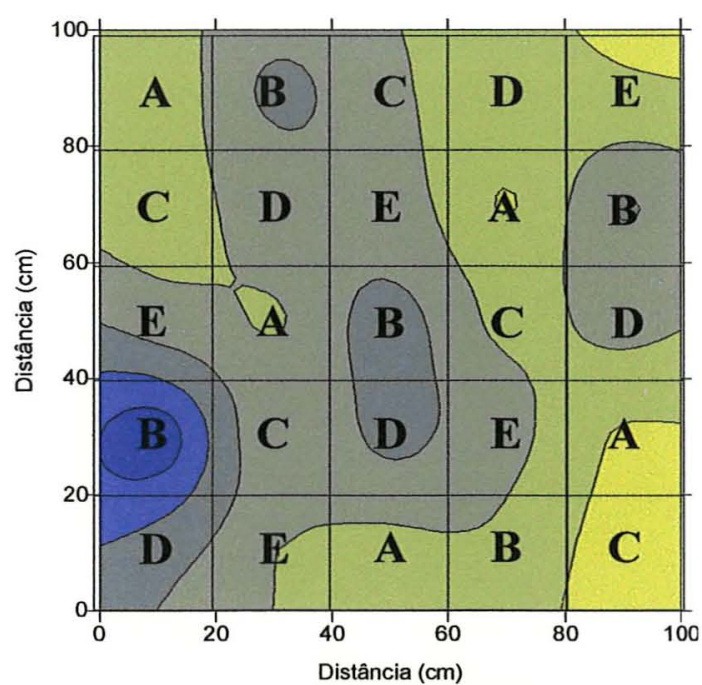

a) $\mathrm{U} \%(\mathrm{~g} / \mathrm{g})$ - grade amostragem 1

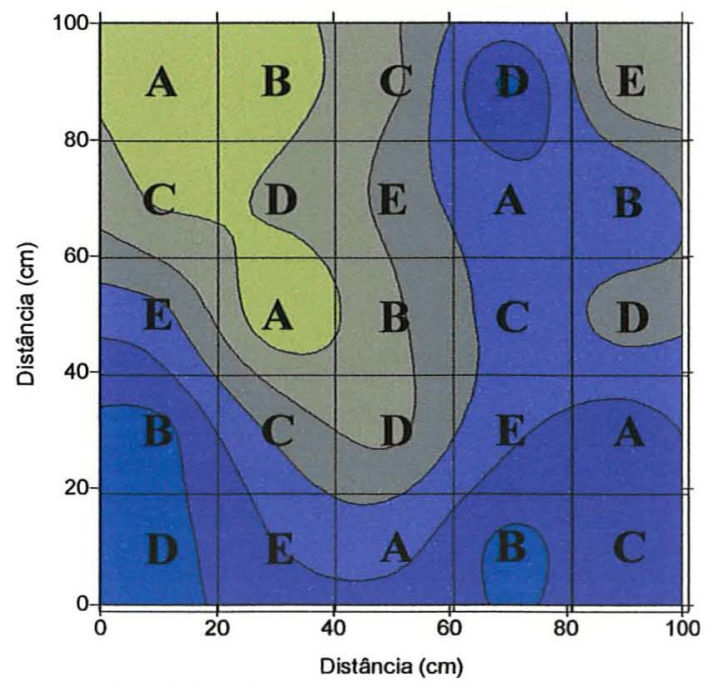

c) $\mathrm{U} \%(\mathrm{~g} / \mathrm{g})$ - grade amostragem 3

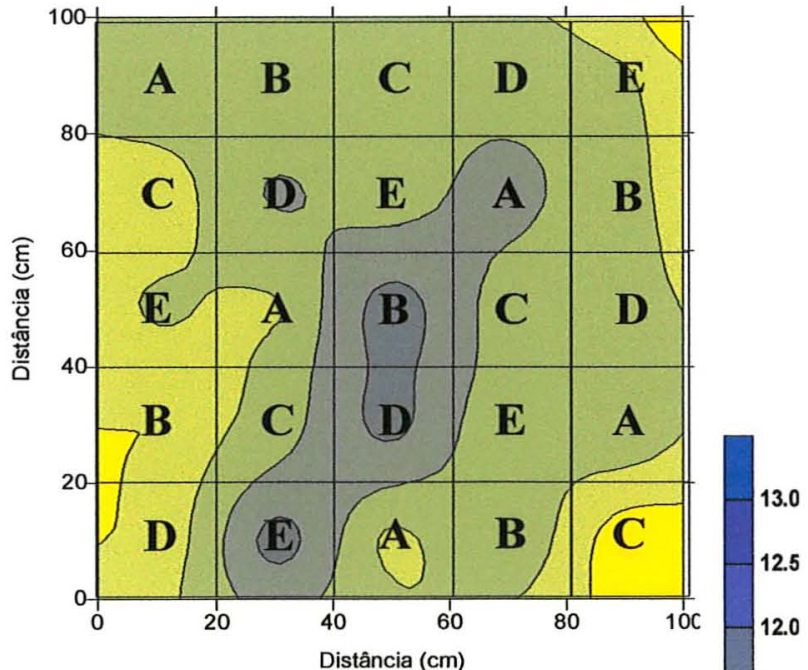

b) $\mathrm{U} \%(\mathrm{~g} / \mathrm{g})$ - grade amostragem 2

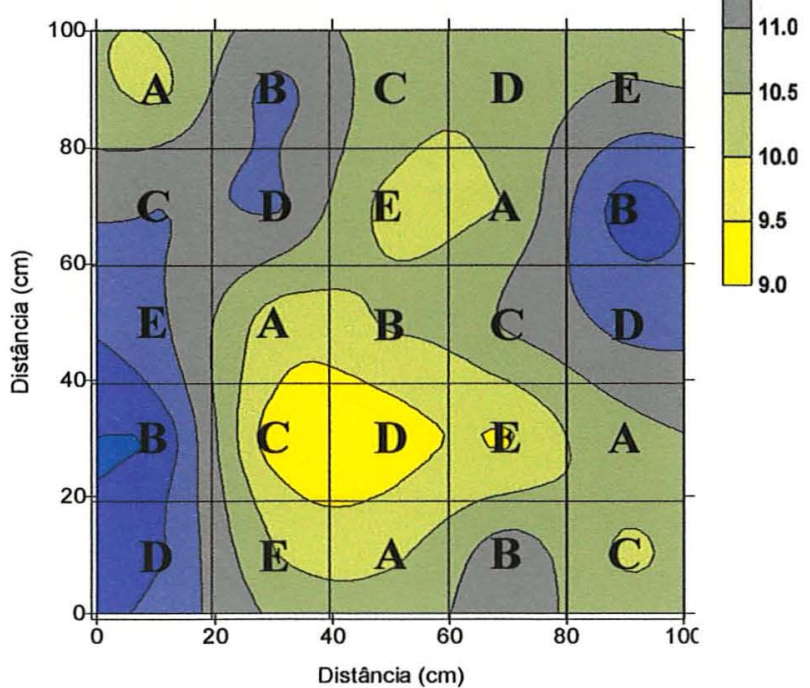

d) $U \%(g / g)$ - grade amostragem 4

Figura 10- Mapas de contorno, com a distribuição espacial da umidade do solo U\%(g/g), nas quatro grades de amostragem do solo arenoso da fazenda Sertãozinho: a) grade $1, b$ ) grade 2, c) grade 3 e d) grade 4 .

Em todas as grades de amostragem e na média geral, as ferramentas que utilizam cilindros de menor volume, obtiveram as maiores médias de umidades 
gravimétricas, $\mathrm{B}(11,2 \%), \mathrm{D}(11,0 \%), \mathrm{E}(10,8 \%), \mathrm{C}(10,5 \%)$ e $\mathrm{A}(10,5 \%)$, demonstrando que, para os solos arenosos o tamanho do cilindro influiu nos resultados desta propriedade.

\subsection{Densidade do solo}

A determinação da densidade do solo, além de constituir um dado importante de caráter físico do solo, possibilita, quando a densidade de partículas é conhecida, a determinação da porosidade total do solo, que são utilizadas para avaliação da compactação do solo. É utilizada também, no cálculo de outras propriedades relacionadas a água do solo, como a condutividade hidráulica, umidade volumétrica e água disponível.

\subsubsection{Solos argilosos amostrados na fazenda Areão}

Os valores médios da densidade do solo, $\mathrm{Ds}\left(\mathrm{g}_{\mathrm{cm}} \mathrm{cm}^{-3}\right)$ e os respectivos coeficientes de variação, obtidos para cada ferramenta nas grades de amostragem, junto com os testes de significância $\mathrm{F}$, diferença mínima significativa de Tukey a $5 \%$ e $1 \%$, e o coeficiente de variação entre as ferramentas, são apresentados na Tabela 7.

Tabela 7- Densidades do solo $\left(\mathrm{g} . \mathrm{cm}^{-3}\right)$, obtidas com as ferramentas de coleta no solo argiloso da fazenda Areão, à profundidade média de $20 \mathrm{~cm}$. Valores médios de 5 repetições.

\begin{tabular}{lcccccccc} 
& \multicolumn{3}{c}{ Grade 1 } & \multicolumn{2}{c}{ Grade 2 } & \multicolumn{2}{c}{ Grade 3 } & \multicolumn{2}{c}{ Grade 4 } \\
\hline \multicolumn{1}{c}{ Ferramentas } & Ds & CV & Ds & CV & Ds & CV & Ds & CV \\
\hline A-Trado Uhland & $1,44 \mathrm{~b}$ & 3,6 & $1,57 \mathrm{c}$ & 5,0 & $1,54 \mathrm{~b}$ & 5,3 & $1,52 \mathrm{~b}$ & 5,7 \\
B-Anel Kopecky & $1,64 \mathrm{a}$ & 1,6 & $1,72 \mathrm{a}$ & 1,6 & $1,64 \mathrm{a}$ & 2,4 & $1,65 \mathrm{a}$ & 4,2 \\
C-Trado Soil Moisture & $1,44 \mathrm{~b}$ & 1,4 & $1,59 \mathrm{bc}$ & 2,2 & $1,54 \mathrm{~b}$ & 5,0 & $1,57 \mathrm{ab}$ & 3,4 \\
D-Trado Bravifer AI-50 & $1,46 \mathrm{~b}$ & 1,5 & $1,73 \mathrm{a}$ & 1,5 & $1,56 \mathrm{ab}$ & 3,7 & $1,55 \mathrm{ab}$ & 7,1 \\
E-Trado Bravifer AI-100 & $1,46 \mathrm{~b}$ & 1,5 & $1,69 \mathrm{ab}$ & 3,3 & $1,60 \mathrm{ab}$ & 3,5 & $1,60 \mathrm{ab}$ & 3,1 \\
\hline \multicolumn{1}{c}{ F } & $15,938^{* *}$ & $10,394 * *$ & & $3,899 *$ & $3,189 *$ \\
\multicolumn{1}{c}{ Dms (5\%) } & 0,096 & 0,106 & 0,097 & 0,126 \\
Dms (1\%) & 0,124 & 0,137 & & 0,125 & 0,163 \\
CV(\%) & 6,10 & & 5,02 & 4,46 & 5,32 \\
\hline
\end{tabular}

Médias seguidas de mesma letra e na mesma coluna, não diferem entre si (Tukey a 5\%). 
A análise estatística apresentou, entre as médias obtidas, diferenças significativas a (1\%), para as grades 1 e 2 , e a (5\%) para as grades 3 e 4 , amostradas no solo argiloso da fazenda Areão.

As médias da densidade do solo $\left(\mathrm{g} . \mathrm{cm}^{-3}\right)$, obtidas entre as 20 amostras coletadas com cada ferramenta, nas quatro grades de amostragem, e a geral no solo argiloso da fazenda Areão, foram: $A\left(1,52 \mathrm{~g} \cdot \mathrm{cm}^{-3}\right), \mathrm{B}\left(1,66 \mathrm{~g} \cdot \mathrm{cm}^{-3}\right), \mathrm{C}\left(1,54 \mathrm{~g} \cdot \mathrm{cm}^{-3}\right)$, $\mathrm{D}\left(1,57 \mathrm{~g} \cdot \mathrm{cm}^{-3}\right), \mathrm{E}\left(1,59 \mathrm{~g} \cdot \mathrm{cm}^{-3}\right)$ e geral $\left(1,58 \mathrm{~g} \cdot \mathrm{cm}^{-3}\right)$, e estão representadas na Figura 11.

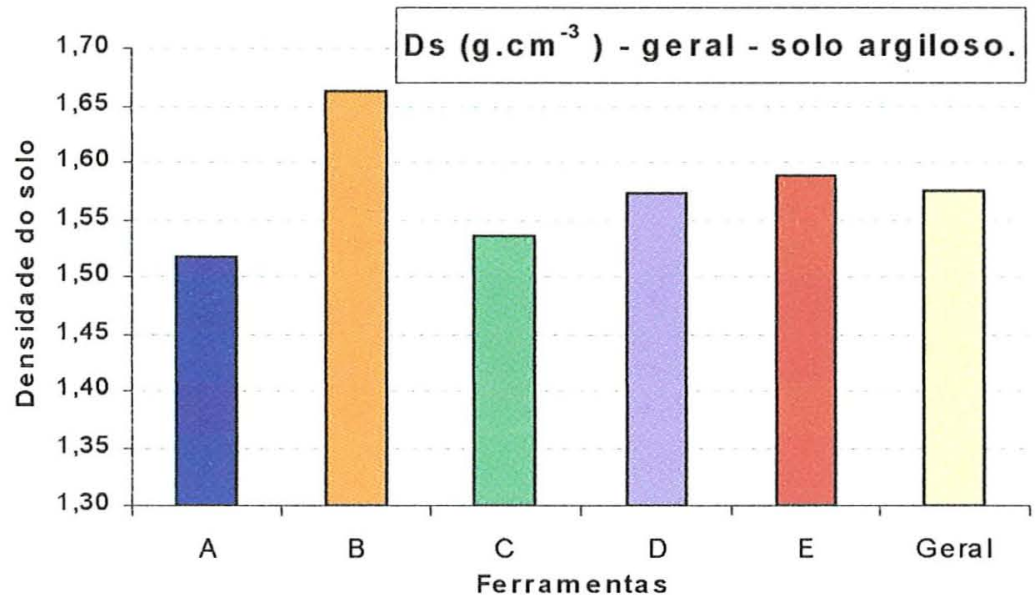

Figura 11- Médias da densidade do solo $\left(\mathrm{g} . \mathrm{cm}^{-3}\right)$, determinadas com as ferramentas de coleta A, B, C, D, E, e a geral, nas quatro grades de amostragem no solo argiloso da fazenda Areão.

As densidades do solo obtidas pelas 25 amostras coletadas, com as ferramentas A, B, C, D e E, foram plotadas nas suas respectivas grades, onde podemos visualizar e avaliar a sua distribuição dentro de cada grade (Figura 12).

Na Figura 12a, os valores mínimos e máximos da densidade do solo, foram, respectivamente para as ferramentas na grade 1: $\mathrm{A}\left(1,37\right.$ e $\left.1,50 \mathrm{~g} \cdot \mathrm{cm}^{-3}\right) ; \mathrm{B}(1,62 \mathrm{e}$ $\left.1,66 \mathrm{~g} \cdot \mathrm{cm}^{-3}\right) ; C\left(1,39\right.$ e $\left.1,51 \mathrm{~g} \cdot \mathrm{cm}^{-3}\right) ; \mathrm{D}\left(1,39\right.$ e $\left.1,52 \mathrm{~g} \cdot \mathrm{cm}^{-3}\right)$, e $\mathrm{E}\left(1,37\right.$ e $\left.1,53 \mathrm{~g} \cdot \mathrm{cm}^{-3}\right)$. A determinação da densidade do solo pela ferramenta $B$, apresentou a média $0,19 \mathrm{~g} . \mathrm{cm}^{-3}$ $(13 \%)$ maior, que a média das outras ferramentas.

Na Figura 12b, os valores mínimos e máximos da densidade do solo, foram, respectivamente para as ferramentas na grade 2 : $\mathrm{A}\left(1,44\right.$ e $\left.1,63 \mathrm{~g} \cdot \mathrm{cm}^{-3}\right) ; \mathrm{B}(1,69$ e 
$\left.1,75 \mathrm{~g} \cdot \mathrm{cm}^{-3}\right) ; C\left(1,53\right.$ e $\left.1,61 \mathrm{~g} \cdot \mathrm{cm}^{-3}\right) ; \mathrm{D}\left(1,68\right.$ e $\left.1,75 \mathrm{~g} \cdot \mathrm{cm}^{-3}\right)$, e $\mathrm{E}\left(1,60\right.$ e $\left.1,76 \mathrm{~g} \cdot \mathrm{cm}^{-3}\right)$. A ferramenta $\mathrm{A}$, apresentou em uma das amostras, coordenada $(30 ; 50)$, os pesos úmido e seco $10 \%$ mais baixo que as outras, provavelmente por fissuras na amostra, causando uma diminuição de $0,16 \mathrm{~g} \cdot \mathrm{cm}^{-3}$ em relação à média dos outros 4 valores. As amostras retiradas com esse tamanho de anel, nesta grade, ficaram soltas, exigindo bastante atenção tanto na retirada do anel do interior da ferramenta, como no transporte e no preparo da mesma no laboratório. Este problema pode ter ocorrido, devido ao numero excessivo de impactos, média de 40 batidas com a massa de $4,5 \mathrm{~kg}$, necessários para penetrar no solo, ou talvez, por raízes ou outros materiais presentes na amostra, que diminuíram o seu volume dentro da estufa.

$\mathrm{Na}$ Figura 12c, os valores mínimos e máximos para densidade do solo, obtidos na grade 3, com as ferramentas A, B. C, D e E, foram, respectivamente: $(1,41$ e $\left.1,61 \mathrm{~g} \cdot \mathrm{cm}^{-3}\right),\left(1,60\right.$ e $\left.1,69 \mathrm{~g} \cdot \mathrm{cm}^{-3}\right),\left(1,42\right.$ e $\left.1,62 \mathrm{~g} \cdot \mathrm{cm}^{-3}\right),\left(1,46\right.$ e $\left.1,62 \mathrm{~g} \cdot \mathrm{cm}^{-3}\right)$ e $(1,51 \mathrm{e}$ $\left.1,66 \mathrm{~g} . \mathrm{cm}^{-3}\right)$. Os valores mínimos encontrados com as ferramentas: $\mathrm{A}$, coordenadas (10; 90); C, coordenadas $(10 ; 70)$ e D, coordenadas $(10 ; 10)$, estão associados aos pontos cujas umidades estavam mais elevadas. Pode ser observado, que o efeito apresentou-se em três ferramentas diferentes, aumentando seus coeficientes de variação, e diminuindo as suas médias na grade.

Na Figura 12d, os valores mínimos e máximos para densidade do solo, obtidos na grade 4, com as ferramentas A, B. C, D e E, foram, respectivamente: $(1,38$ e $\left.1,60 \mathrm{~g} \cdot \mathrm{cm}^{-3}\right),\left(1,57\right.$ e $\left.1,75 \mathrm{~g} \cdot \mathrm{cm}^{-3}\right),\left(1,50\right.$ e $\left.1,63 \mathrm{~g} \cdot \mathrm{cm}^{-3}\right),\left(1,36\right.$ e $\left.1,65 \mathrm{~g} \cdot \mathrm{cm}^{-3}\right)$ e $(1,52$ e $\left.1,62 \mathrm{~g} \cdot \mathrm{cm}^{-3}\right)$. Os valores mínimos encontrados com as ferramentas: A, coordenadas (70; $70)$ e D, coordenadas ( $70 ; 90)$, estão associados aos pontos cujas umidades estavam mais elevadas. O valor máximo que foi encontrado com a ferramenta $B$, coordenadas $(10 ; 30)$, se encontra num ponto onde a umidade estava mais baixa na grade 4. É importante notar que nesta grade, os valores de densidade do solo obtidos com a ferramenta $\mathrm{B}$, associados aos pontos onde as umidades estavam elevadas, não seguiram o comportamento das demais ferramentas. 


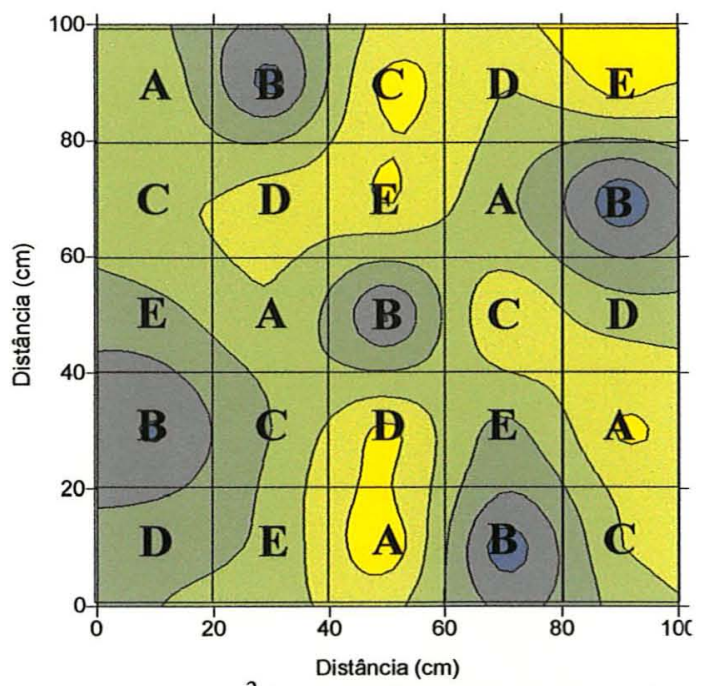

a) Ds $\left(\mathrm{g} . \mathrm{cm}^{-3}\right)$ - grade amostragem 1

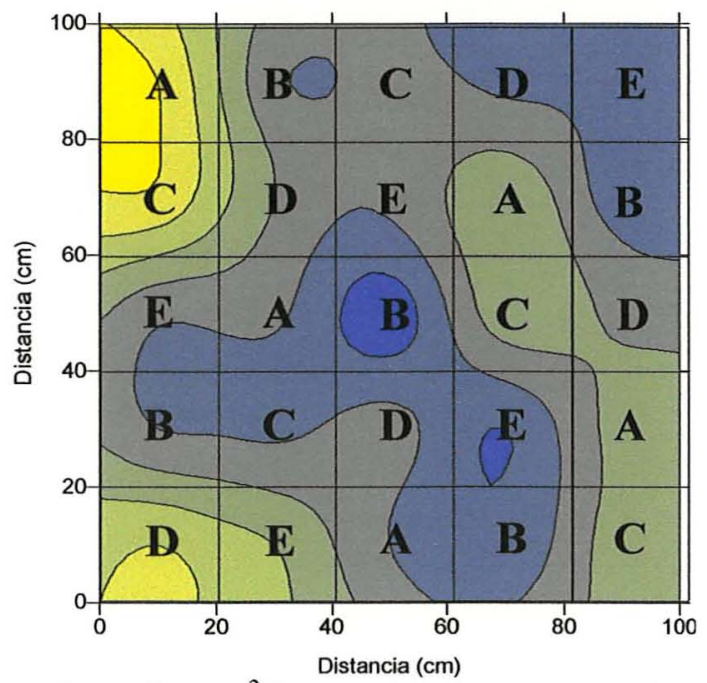

c) Ds $\left(\right.$ g.cm $\left.{ }^{-3}\right)$ - grade amostragem 3

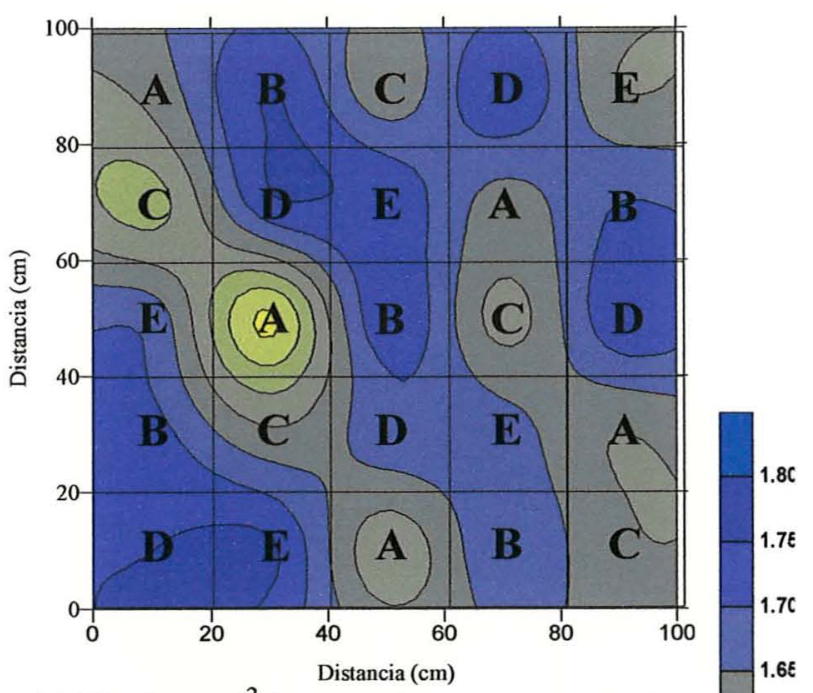

b) Ds $\left(\right.$ g. $\left.\mathrm{cm}^{-3}\right)$ - grade amostragem 2

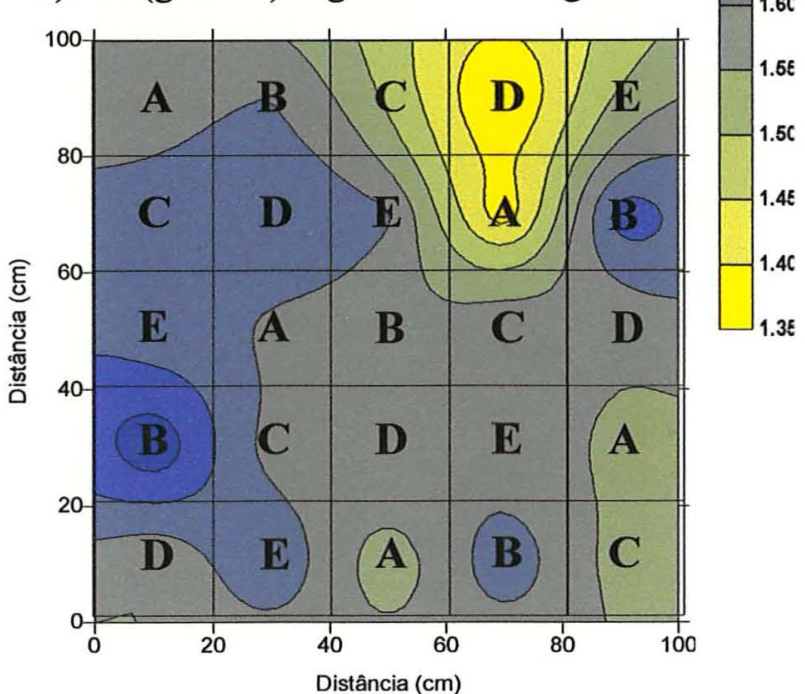

d) Ds $\left(\mathrm{g} . \mathrm{cm}^{-3}\right)$ - grade amostragem 4

Figura 12- Mapas de contorno, com a distribuição espacial das densidades do solo $\left(\right.$ g. $\left.\mathrm{cm}^{-3}\right)$ nas quatro grades de amostragem do solo argiloso da fazenda Areão: a) grade 1, b) grade 2, c) grade 3 e d) grade 4.

No solo argiloso, verificamos que a umidade do solo no momento da coleta, pode afetar significativamente a estrutura do solo no interior do anel. $\mathrm{O}$ efeito combinado da umidade inadequada e equipamentos, pode provocar modificações expressivas nos resultados da densidade do solo, afetando a qualidade $\mathrm{e}$ representatividade das amostras. 


\subsubsection{Amostras coletadas no solo arenoso da Fazenda Sertãozinho}

Os valores médios da densidade do solo, $\operatorname{Ds}\left(\mathrm{g} . \mathrm{cm}^{-3}\right)$ e os respectivos coeficientes de variação, obtidos para cada ferramenta nas grades de amostragem, junto com os testes de significância $\mathrm{F}$, diferença mínima significativa de Tukey a $5 \%$ e $1 \%$, e o coeficiente de variação entre as ferramentas, são apresentados na Tabela 8.

Tabela 8- Densidade do solo $\left(\right.$ g.cm $\left.\mathrm{cm}^{-3}\right)$, obtidas com as ferramentas de coleta no solo arenoso da fazenda Sertãozinho, à profundidade média de $20 \mathrm{~cm}$. Valores médios de 5 repetições.

\begin{tabular}{lcccccccc} 
& \multicolumn{2}{c}{ Grade 1} & \multicolumn{2}{c}{ Grade 2 } & \multicolumn{2}{c}{ Grade 3 } & \multicolumn{2}{c}{ Grade 4 } \\
\hline \multicolumn{1}{c}{ Ferramentas } & Ds & CV & Ds & CV & Ds & CV & Ds & CV \\
\hline A-Trado Uhland & 1,71 ab & 0,9 & $1,72 \mathrm{a}$ & 1,5 & $1,78 \mathrm{ab}$ & 2,0 & $1,67 \mathrm{a}$ & 3,5 \\
B-Anel Kopecky & $1,77 \mathrm{a}$ & 2,9 & $1,77 \mathrm{a}$ & 1,7 & $1,77 \mathrm{ab}$ & 1,2 & $1,73 \mathrm{a}$ & 2,0 \\
C-Trado Soil Moisture & $1,67 \mathrm{~b}$ & 2,6 & $1,72 \mathrm{a}$ & 1,3 & $1,76 \mathrm{~b}$ & 1,4 & $1,68 \mathrm{a}$ & 2,7 \\
D-Trado Bravifer Al-50 & $1,73 \mathrm{ab}$ & 2,4 & $1,74 \mathrm{a}$ & 3,1 & $1,77 \mathrm{ab}$ & 1,0 & $1,70 \mathrm{a}$ & 1,6 \\
E-Trado Bravifer AI-100 & $1,71 \mathrm{ab}$ & 2,2 & $1,74 \mathrm{a}$ & 1,8 & $1,80 \mathrm{a}$ & 2,1 & $1,69 \mathrm{a}$ & 1,6 \\
\hline \multicolumn{1}{c}{ F } & $7,574 * *$ & 2,822 n.s. & $4,434^{*}$ & 1,242 n.s. \\
Dms (5\%) & 0,056 & 0,057 & 0,032 & 0,088 \\
Dms (1\%) & 0,072 & 0,074 & 0,042 & 0,114 \\
CV(\%) & 1,97 & & 1,22 & 0,85 & 1,28 \\
\hline
\end{tabular}

Médias seguidas de mesma letra e na mesma coluna, não diferem entre si (Tukey a 5\%).

A análise estatística, entre as médias obtidas de densidade do solo, apresentou diferenças significativas a (1\%), para a grade 1 , e de $(5 \%)$ para a grade 3 , no solo arenoso da fazenda Sertãozinho. Apesar dos baixos coeficientes de variação para as ferramentas em todas as grades amostradas (menores de 3,5\%), as diferenças nos valores absolutos encontrados entre o menor e o maior valor, dentro das grades são significativas para esta propriedade.

As médias da densidade do solo $\left(\mathrm{g} . \mathrm{cm}^{-3}\right)$, obtidas entre as 20 amostras coletadas nas quatro grades de amostragem, com cada ferramenta, e a geral, para o solo arenoso da fazenda Sertãozinho, foram: $\mathrm{A}\left(1,72 \mathrm{~g} \cdot \mathrm{cm}^{-3}\right), \mathrm{B}\left(1,76 \mathrm{~g} \cdot \mathrm{cm}^{-3}\right), \mathrm{C}\left(1,71 \mathrm{~g} \cdot \mathrm{cm}^{-3}\right)$, $\mathrm{D}\left(1,74 \mathrm{~g} \cdot \mathrm{cm}^{-3}\right), E\left(1,73 \mathrm{~g} \cdot \mathrm{cm}^{-3}\right)$ e geral $\left(1,73 \mathrm{~g} \cdot \mathrm{cm}^{-3}\right)$, e estão representadas na Figura 13. 


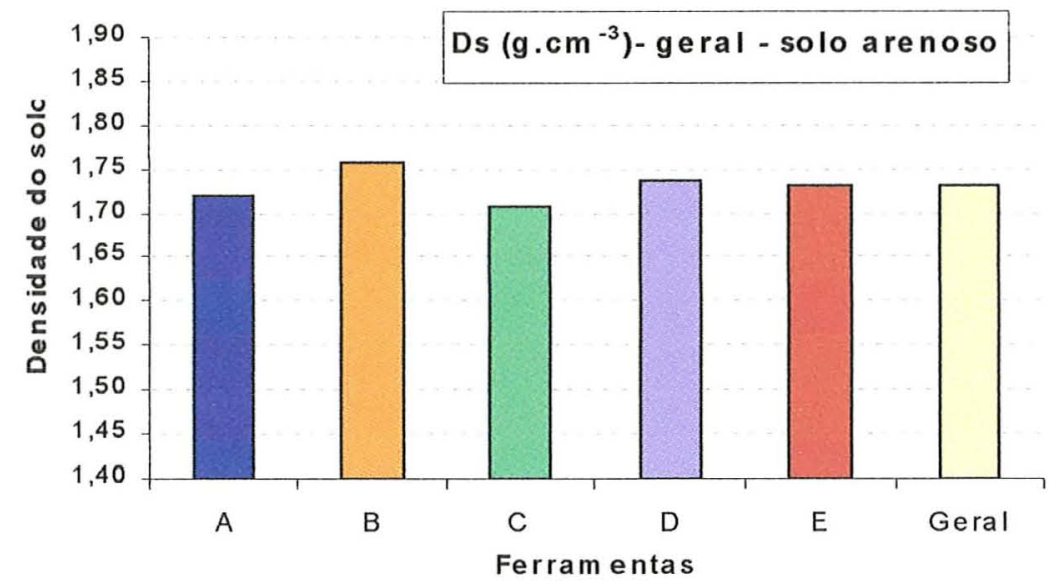

Figura 13- Médias da densidade do solo $\left(\mathrm{g} . \mathrm{cm}^{-3}\right)$, determinadas com as ferramentas de coleta A, B, C, D, E, e a geral, nas quatro grades de amostragem no solo arenoso da fazenda Sertãozinho.

Na Figura 14a, os valores mínimos e máximos da densidade do solo, foram, respectivamente para as ferramentas na grade 1 : $\mathrm{A}\left(1,70\right.$ e $\left.1,74 \mathrm{~g} \cdot \mathrm{cm}^{-3}\right), \mathrm{B}(1,70 \mathrm{e}$ $\left.1,84 \mathrm{~g} \cdot \mathrm{cm}^{-3}\right), C\left(1,61\right.$ e $\left.1,72 \mathrm{~g} \cdot \mathrm{cm}^{-3}\right), \mathrm{D}\left(1,70\right.$ e $\left.1,79 \mathrm{~g} \cdot \mathrm{cm}^{-3}\right)$ e $\mathrm{E}\left(1,67\right.$ e $\left.1,77 \mathrm{~g} \cdot \mathrm{cm}^{-3}\right) . A$ diferença entre o menor valor de densidade do solo nesta grade, obtido com a ferramenta C, na coordenada $(50 ; 90)$, e o maior valor obtido com a ferramenta B, coordenada (90; $70)$, foi de $14,3 \%\left(0,13 \mathrm{~g} \cdot \mathrm{cm}^{-3}\right)$.

Na Figura 14b, os valores mínimos e máximos da densidade do solo, foram, respectivamente para as ferramentas na grade 2 : $\mathrm{A}\left(1,67\right.$ e $\left.1,73 \mathrm{~g} \cdot \mathrm{cm}^{-3}\right), \mathrm{B}(1,73 \mathrm{e}$ $\left.1,80 \mathrm{~g} \cdot \mathrm{cm}^{-3}\right), C\left(1,68\right.$ e $\left.1,73 \mathrm{~g} \cdot \mathrm{cm}^{-3}\right), \mathrm{D}\left(1,69\right.$ e $\left.1,83 \mathrm{~g} \cdot \mathrm{cm}^{-3}\right)$ e $\mathrm{E}\left(1,70\right.$ e $\left.1,77 \mathrm{~g} \cdot \mathrm{cm}^{-3}\right)$. A

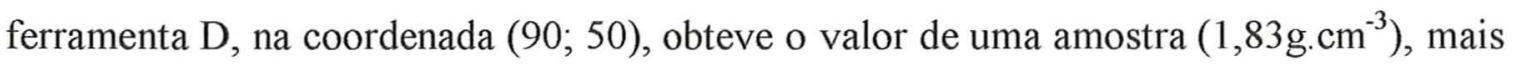
alta que a média das outras quatro $\left(1,72 \mathrm{~g} \cdot \mathrm{cm}^{-3}\right)$. A diferença entre o menor valor obtido com a ferramenta $\mathrm{A}$, coordenada $(50 ; 10)$, e o maior valor obtido com a ferramenta $\mathrm{D}$, foi de $0,16 \mathrm{~g} \cdot \mathrm{cm}^{-3}(9,6 \%)$.

Na Figura 14c, os valores mínimos e máximos da densidade do solo, foram, respectivamente para as ferramentas na grade 3 : $\mathrm{A}\left(1,72\right.$ e $\left.1,81 \mathrm{~g} . \mathrm{cm}^{-3}\right), \mathrm{B}(1,74 \mathrm{e}$ $\left.1,79 \mathrm{~g} . \mathrm{cm}^{-3}\right), \mathrm{C}\left(1,73\right.$ e $\left.1,78 \mathrm{~g} \cdot \mathrm{cm}^{-3}\right), \mathrm{D}\left(1,74 \mathrm{e} 1,79 \mathrm{~g} . \mathrm{cm}^{-3}\right)$ e $\mathrm{E}\left(1,76 \mathrm{e} 1,85 \mathrm{~g} \cdot \mathrm{cm}^{-3}\right)$.

Na Figura 14d, os valores mínimos e máximos da densidade do solo, foram, respectivamente para as ferramentas na grade 4 : $\mathrm{A}\left(1,57\right.$ e $\left.1,72 \mathrm{~g} \cdot \mathrm{cm}^{-3}\right), \mathrm{B}(1,69 \mathrm{e}$ 
1,77g.cm $\left.{ }^{-3}\right), C\left(1,62\right.$ e $\left.1,74 \mathrm{~g} \cdot \mathrm{cm}^{-3}\right), D\left(1,67\right.$ e $\left.1,73 \mathrm{~g} \cdot \mathrm{cm}^{-3}\right)$ e $\mathrm{E}\left(1,66\right.$ e $\left.1,72 \mathrm{~g} \cdot \mathrm{cm}^{-3}\right)$. Nesta grade, uma das amostras coletadas pela ferramenta A, coordenada $(10 ; 90)$, após a secagem na estufa à $110^{\circ}$, apresentou uma diminuição em seu volume $(0,5 \mathrm{~cm}$ na altura da amostra), provocando a redução no valor da densidade do solo naquele ponto $\left(1,57 \mathrm{~g} \cdot \mathrm{cm}^{-3}\right)$, menor que a média das outras 4 amostras $\left(1,70 \mathrm{~g} \cdot \mathrm{cm}^{-3}\right)$. A diferença entre o menor valor, obtido com a ferramenta $\mathrm{A}$, e o maior com a ferramenta $\mathrm{B}$, coordenada (10; $70)$, foi de $0,20 \mathrm{~g} \cdot \mathrm{cm}^{-3}(12,7 \%)$.

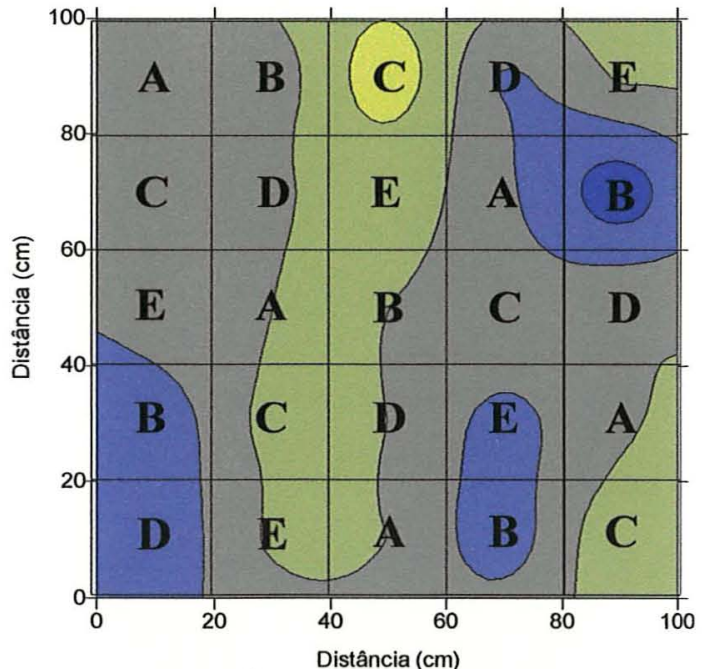

a) Ds $\left(\mathrm{g} . \mathrm{cm}^{-3}\right)$ - grade amostragem 1

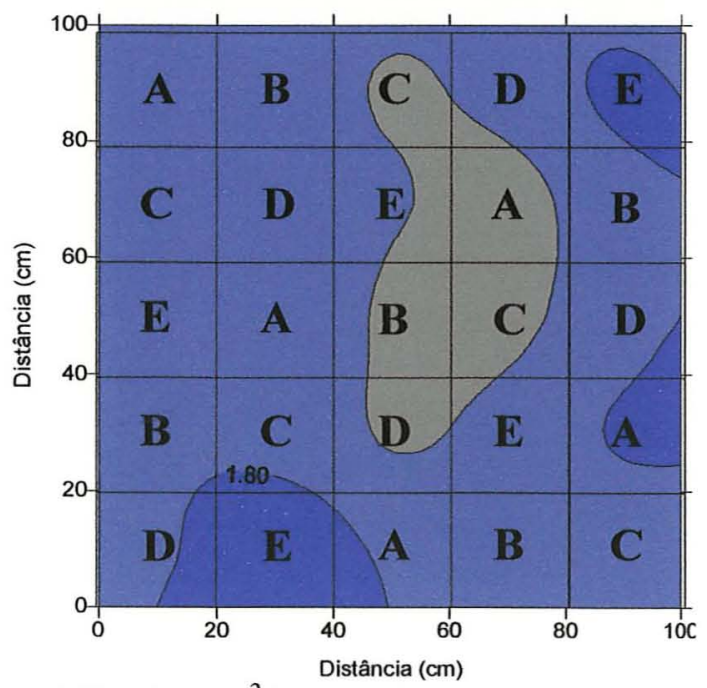

c) Ds $\left(\mathrm{g} . \mathrm{cm}^{-3}\right)$ - grade amostragem 3

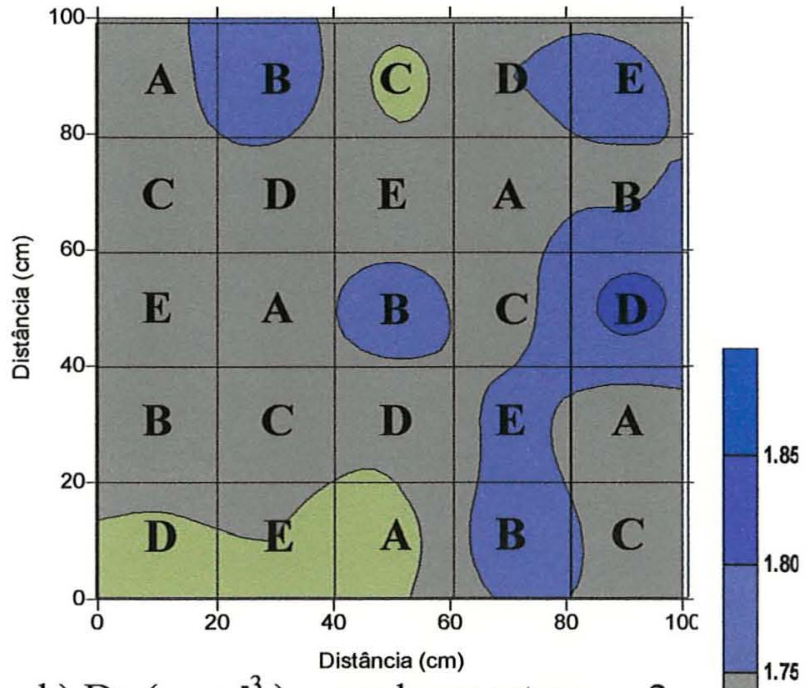

b) Ds $\left(\mathrm{g} . \mathrm{cm}^{-3}\right)$ - grade amostragem 2

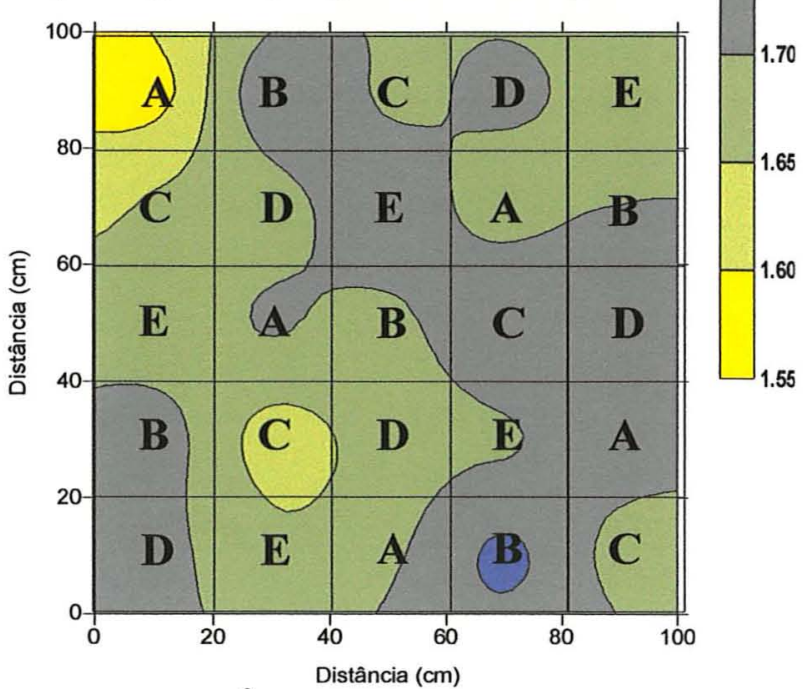

d) Ds $\left(\mathrm{g} \cdot \mathrm{cm}^{-3}\right)$ - grade amostragem 4

Figura 14- Mapas de contorno, da distribuição espacial das densidades do solo (g. $\mathrm{cm}^{-3}$ ) nas quatro grades de amostragem do solo arenoso da fazenda Sertãozinho: a) grade 1, b) grade 2, c) grade 3 e d) grade 4 . 


\subsection{Correlação entre umidade e densidade do solo}

Com a finalidade de verificar, a influência da umidade do solo na coleta das amostras de densidade do solo, foram feitas avaliações de regressões entre os valores médios das duas propriedades, obtidos com as diferentes ferramentas nas quatro grades de amostragem, para os dois tipos de solo, argiloso e arenoso.

\subsubsection{Solos argilosos amostrados na fazenda Areão}

Para este estudo, U\% $(\mathrm{g} / \mathrm{g}) \times$ Ds $\left(\mathrm{g} . \mathrm{cm}^{-3}\right)$, foram utilizados os valores médios de umidade do solo $\mathrm{e}$ as respectivas densidades do solo, obtidas pelas diferentes ferramentas, num total de 100 amostras. As médias foram separadas em classes da seguinte forma: $\mathrm{U}(\mathrm{g} / \mathrm{g})<17 \% ; 17,1$ a $18,5 \% ; 18,6$ a $20 \% ; 20,1$ a $21 \%$ e $\mathrm{U}>21 \%$.

$\mathrm{Na}$ Figura 15, está representada a equação de regressão entre as umidades médias do solo e as densidades do solo, onde o coeficiente de determinação $\left(\mathrm{R}^{2}=0,97\right)$ apresentou um valor alto e negativo, demonstrando que para este solo argiloso, os valores dessas duas propriedades, seguem em sentidos opostos, significando que se 0 solo estiver com a umidade alta no momento da amostragem, poderemos obter valores baixos para a densidade do solo, ou o oposto, umidade baixa, deveremos obter valores altos de densidade do solo.

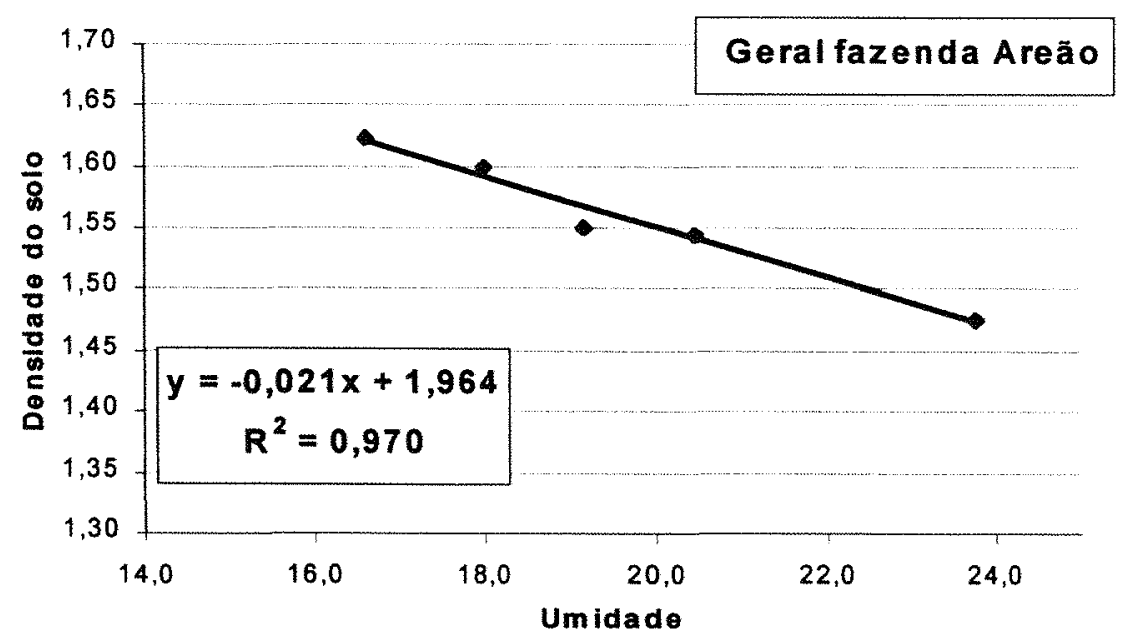

Figura 15- Correlação entre as médias de $\mathrm{U} \%(\mathrm{~g} / \mathrm{g})$ e $\mathrm{Ds}\left(\mathrm{g} \cdot \mathrm{cm}^{-3}\right)$, obtidas com as diferentes ferramentas no solo argiloso da fazenda Areão, num total de 100 amostras, separadas em classes: $\mathrm{U}(\%)<17 \% ; 17,1$ a $18,5 \%$; 18,6 a $20 \%$; 20,1 a $21 \%$ e $U(\%)>21 \%$. 
Esta tendência também pode ser confirmada, comparando os mapas de contorno da umidade $\mathrm{U} \%(\mathrm{~g} / \mathrm{g})$ na Figura 8 e da densidade do solo na Figura 12, onde podemos ver claramente os sentidos opostos de crescimento dos valores dessas propriedades.

\subsubsection{Amostras coletadas no solo arenoso da Fazenda Sertãozinho}

Para o estudo do solo arenoso da fazenda Sertãozinho, os valores médios de umidades do solo e os respectivos valores de densidades do solo, obtidos com as diferentes ferramentas, num total de 100 resultados, foram separados em classes da seguinte forma: $\mathrm{U}(\%)<9,5 \%$; 9,6 a $10,5 \% ; 10,6$ a $11,5 \% ; 11,6$ a $12,5 \%$ e $U(\%)>12,6 \%$.

$\mathrm{Na}$ Figura 16, está representada a equação de regressão entre as umidades médias do solo e as densidades do solo, onde o coeficiente de determinação $\left(\mathrm{R}^{2}=0,945\right)$ também apresentou um valor alto, porém positivo, demonstrando que para este solo arenoso, os valores dessas duas propriedades, seguem no mesmo sentido, aumentando ou diminuindo seus valores, na mesma direção, fato que pode ser observado, comparando os gráficos das médias de umidade gravimétrica na Figura 9, e o gráfico das médias de densidade do solo na Figura 13.

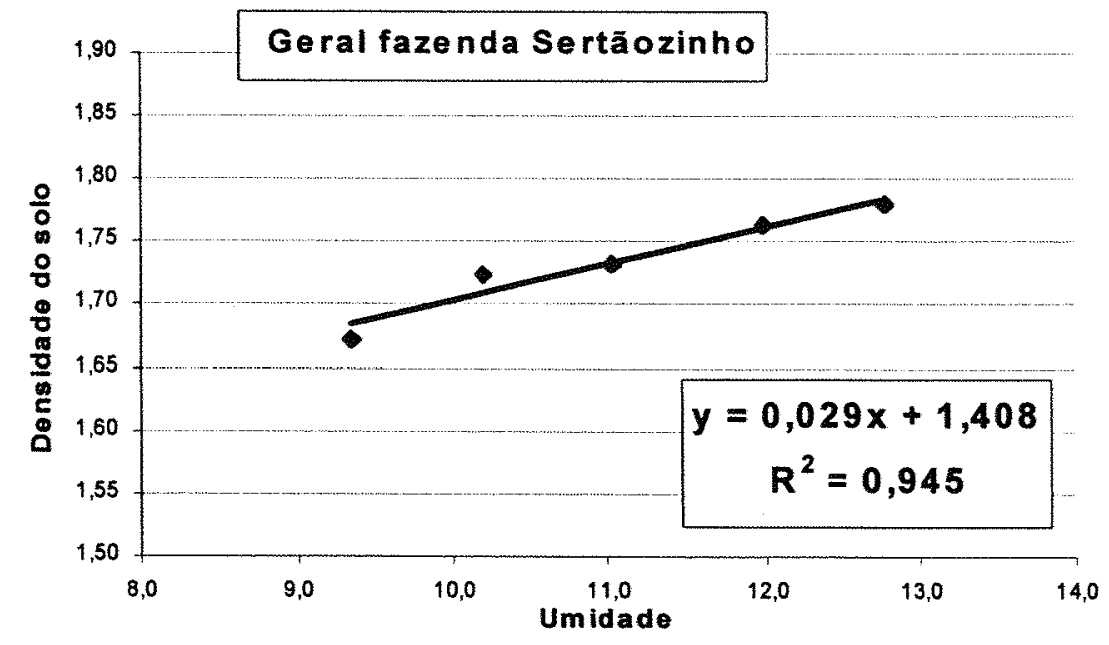

Figura 16- Correlação entre as médias de $U \%(\mathrm{~g} / \mathrm{g})$ e $\mathrm{Ds}\left(\mathrm{g} \cdot \mathrm{cm}^{-3}\right)$, obtidas com as diferentes ferramentas no solo arenoso da fazenda Sertãozinho, num total de 100 amostras, separadas em classes: $\mathrm{U}(\%)<9,5 \% ; 9,6$ a $10,5 \% ; 10,6$ a $11,5 \% ; 11,6$ a $12,5 \%$ e $U(\%)>12,6 \%$. 


\subsection{Umidade volumétrica do solo}

Com os valores determinados para umidade gravimétrica $U \%(\mathrm{~g} / \mathrm{g})$ e para densidade do solo Ds $\left(\mathrm{g} . \mathrm{cm}^{-3}\right)$, calculamos os valores de umidade volumétrica do solo $\left(\theta_{s} \%\right)$ encontrados para os dois tipos de solo.

\subsubsection{Solos argilosos amostrados na fazenda Areão}

Os valores médios de umidade com base em volume $\left(\theta_{\mathrm{s}} \%\right)$ e os respectivos coeficientes de variação, obtidos para cada ferramenta nas grades de amostragem, junto com os testes de significância $F$, diferença mínima significativa de Tukey a 5\% e 1\%, e o coeficiente de variação entre as ferramentas, são apresentados na Tabela 9.

A análise estatística, entre as médias obtidas de umidade volumétrica, apresentou diferenças significativas a (1\%) para a grade 1 , e a $(5 \%)$ para as grades $3 \mathrm{e}$ 4. A grade 2, amostrada no solo arenoso da fazenda Areão não apresentou diferenças significativas.

Tabela 9- Umidades volumétricas do solo $\left(\theta_{\mathrm{s}} \%\right)$, obtidas com as ferramentas de coleta no solo argiloso da fazenda Areão, à profundidade média de $20 \mathrm{~cm}$. Valores médios de 5 repetições.

\begin{tabular}{|c|c|c|c|c|c|c|c|c|}
\hline \multirow[b]{2}{*}{ rramentas } & \multicolumn{2}{|c|}{ Grade 1} & \multicolumn{2}{|c|}{ Grade 2} & \multicolumn{2}{|c|}{ Grade 3} & \multicolumn{2}{|c|}{ Grade 4} \\
\hline & $\theta_{\mathrm{s}} \%$ & $\mathrm{CV}$ & $\theta_{\mathrm{s}} \%$ & $\mathrm{CV}$ & $\theta_{\mathrm{s}} \%$ & $\mathrm{CV}$ & $\theta_{\mathrm{s}} \%$ & $\mathrm{CV}$ \\
\hline A-Trado Uhland & $27,2 \mathrm{~b}$ & 3,7 & $27,9 \mathrm{a}$ & 9,5 & $29,4 \mathrm{~b}$ & 4,1 & $28,9 \mathrm{~b}$ & 8,3 \\
\hline B-Anel Kopecky & 29,4 a & 5,1 & $29,5 \mathrm{a}$ & 3,0 & $31,9 a$ & 4,7 & $34,4 \mathrm{a}$ & 11,7 \\
\hline C-Trado Soil Moisture & $26,3 \mathrm{~b}$ & 3,0 & $30,0 \mathrm{a}$ & 2,7 & $31,3 \mathrm{ab}$ & 6,0 & $28,5 \mathrm{~b}$ & 7,8 \\
\hline D-Trado Bravifer AI-50 & $26,4 \mathrm{~b}$ & 4,8 & $30,4 \mathrm{a}$ & 4,9 & $31,0 a b$ & 9,6 & $31,0 \mathrm{ab}$ & 6,6 \\
\hline E-Trado Bravifer AI-100 & $26,2 \mathrm{~b}$ & 2,1 & $29,8 \mathrm{a}$ & 1,0 & $30,4 \mathrm{ab}$ & 1,9 & $29,6 \mathrm{ab}$ & 11,9 \\
\hline $\mathrm{F}$ & 9,40 & & 2,76 & & 3,59 & & 4,38 & \\
\hline Dms $(5$ & $2,($ & & 2 , & & 2,2 & & 4,7 & \\
\hline Dms (1\%) & 2, & & 3 , & & 2,8 & & 6,1 & \\
\hline & 5, & & 1 & & 1,5 & & 7,2 & \\
\hline
\end{tabular}


As umidades volumétricas do solo obtidas pelas 25 amostras coletadas, no solo argiloso, com as ferramentas A, B, C, D e E, foram plotadas nas suas respectivas grades, onde podemos visualizar e avaliar a sua distribuição dentro de cada grade (Figura 17).

Na Figura 17a, os valores mínimos e máximos da umidade volumétrica do solo $\left(\theta_{\mathrm{s}} \%\right)$, foram, respectivamente para as ferramentas na grade $1: \mathrm{A}(25,5$ e $27,9 \%)$; $\mathrm{B}(27,2$ e $30,9 \%) ; \mathrm{C}(25,4$ e $27,2 \%) ; \mathrm{D}(24,9$ e $27,9 \%)$, e $\mathrm{E}(23,4$ e $26,3 \%)$. Nesta grade, a ferramenta B, apresentou nas coordenadas $(30 ; 90),(50 ; 50),(70,10)$ e $(90,70)$, os valores mais altos de umidade, obtendo a média $10,8 \%$ maior, que a média das outras quatro ferramentas.

Na Figura 17b, os valores mínimos e máximos da umidade volumétrica $\left(\theta_{\mathrm{s}} \%\right)$, foram, respectivamente para as ferramentas na grade 2: $\mathrm{A}(23,2$ e $29,4 \%) ; \mathrm{B}(28,4$ e $30,8 \%) ; C(29,0$ e $31,0 \%) ; D(28,8$ e $32,8 \%)$, e $E(29,3$ e $30,2 \%)$. Nesta grade, a ferramenta A, apresentou uma das amostras, coordenada ( $30 ; 50)$, a mesma que apresentou baixos valores de umidade gravimétrica e densidade do solo, com valor de umidade $23,2 \%$, mais baixo que a média dos outros 4 valores $(29,1 \%)$, fato que reduziu também a sua média geral para $27,9 \%$.

Na Figura $17 \mathrm{c}$, os valores mínimos e máximos de umidade volumétrica $\left(\theta_{\mathrm{s}} \%\right)$, foram, respectivamente para as ferramentas na grade 3: $\mathrm{A}(28,5$ e $31,4 \%) ; \mathrm{B}(29,3$ e $33,0 \%) ; C(29,6$ e $34,2 \%) \mathrm{D}(28,4$ e $34,9 \%)$ e $\mathrm{E}(29,6$ e $31,1 \%)$.

$\mathrm{Na}$ Figura 17d, os valores mínimos e máximos obtidos, de umidade volumétrica $\left(\theta_{\mathrm{s}} \%\right)$, foram respectivamente para as ferramentas na grade 4: $\mathrm{A}(27,2 \mathrm{e}$ $33,8 \%) ; B(28,5$ e $39,0 \%) ; C(26,6$ e $31,1 \%)$; $D(28,4$ e $33,6 \%)$ e $E(26,6$ e $35,2 \%)$. Esta grade apresentou a maior diferença entre os valores mínimo (26,6\%), obtidos com as ferramentas $\mathrm{C}$, coordenada $(10 ; 50)$ e $\mathrm{E}$, coordenada $(10 ; 70)$, e o máximo $(39,0 \%)$, obtido com a ferramenta $\mathrm{B}$, coordenada $(50 ; 50)$, no solo argiloso da fazenda Areão. 

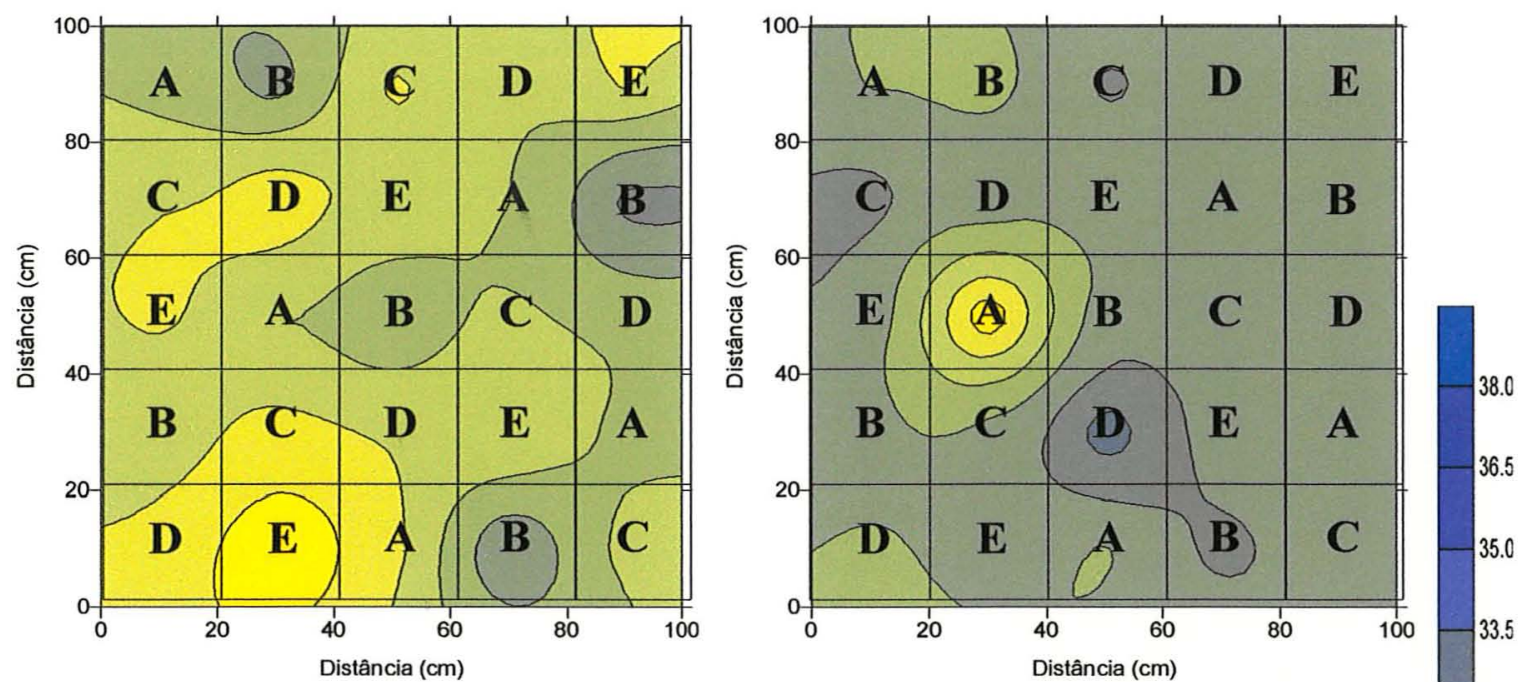

a) $\theta_{\mathrm{s}} \%\left(\mathrm{~cm}^{-3} \cdot \mathrm{cm}^{-3}\right)$ - grade amostragem 1

b) $\theta_{\mathrm{s}} \%\left(\mathrm{~cm}^{-3} \cdot \mathrm{cm}^{-3}\right)$ - grade amostragem 2
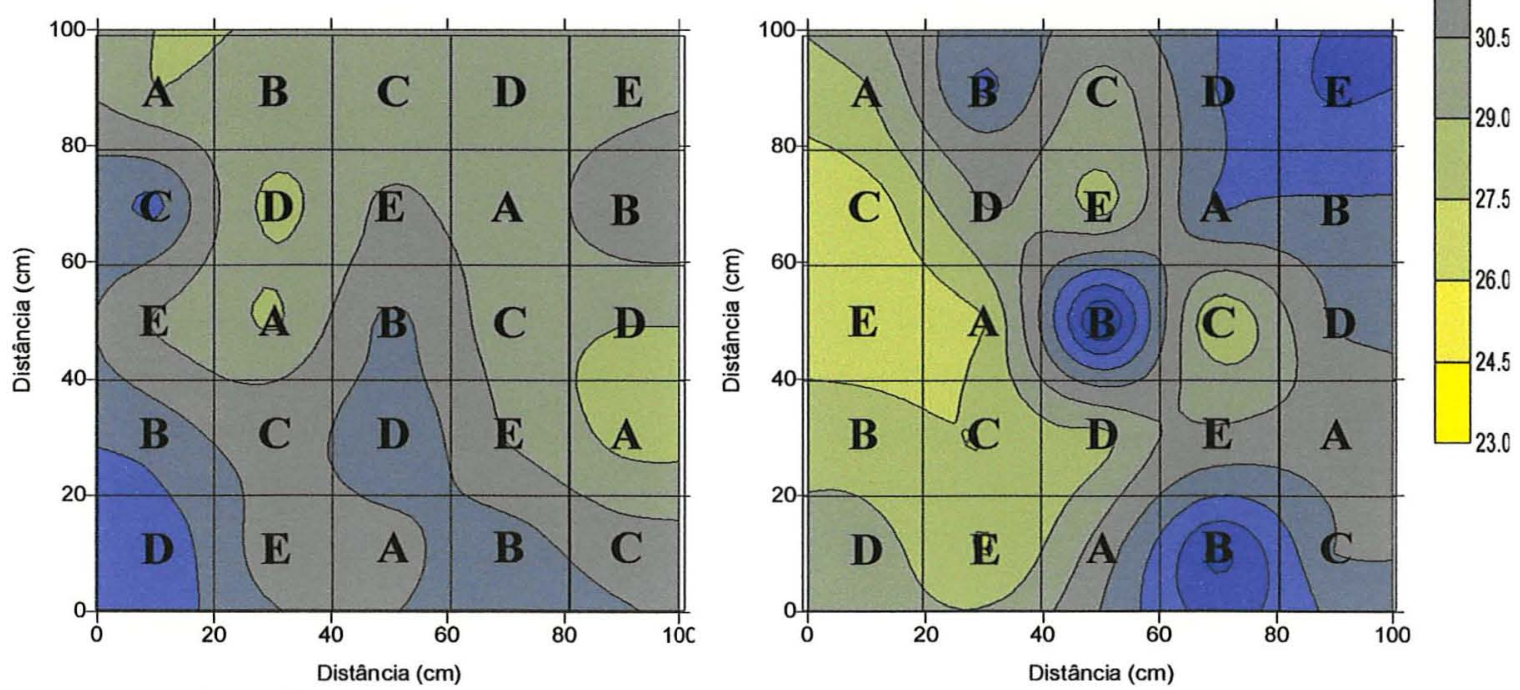

c) $\theta_{\mathrm{s}} \%\left(\mathrm{~cm}^{-3} \cdot \mathrm{cm}^{-3}\right)$ - grade amostragem 3

d) $\theta_{\mathrm{s}} \%\left(\mathrm{~cm}^{-3} \cdot \mathrm{cm}^{-3}\right)$ - grade amostragem 4

Figura 17- Mapas de contorno, com a distribuição espacial das umidades volumétricas $\theta_{\mathrm{s}} \%\left(\mathrm{~cm}^{-3} \cdot \mathrm{cm}^{-3}\right)$ nas quatro grades de amostragem do solo argiloso da fazenda Areão: a) grade 1, b) grade 2, c) grade 3 e d) grade 4.

As médias da umidade volumétrica $\theta_{\mathrm{s}} \%\left(\mathrm{~cm}^{3} \cdot \mathrm{cm}^{-3}\right)$, obtidas entre as 20 amostras coletadas nas quatro grades de amostragem, com cada ferramenta, e a geral, para o solo arenoso da fazenda Areão, foram: $\mathrm{A}(28,8 \%), \mathrm{B}(31,3 \%), \mathrm{C}(29,0 \%)$, $\mathrm{D}(29,7 \%), \mathrm{E}(28,8 \%)$ e geral (29,5\%), e estão representadas na Figura 18. 


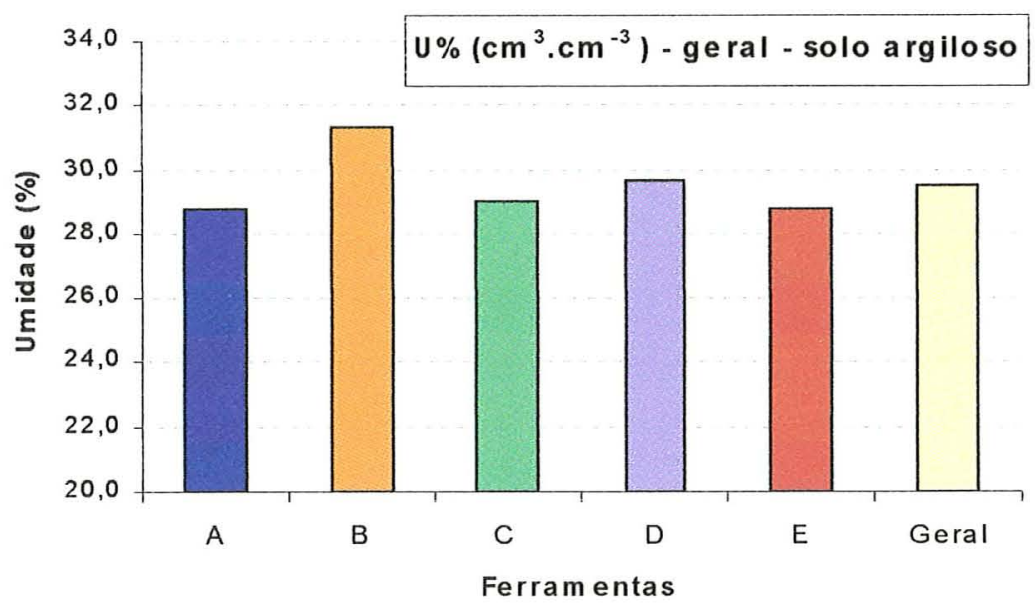

Figura 18- Médias da umidade volumétrica do solo $\theta_{\mathrm{S}} \%\left(\mathrm{~cm}^{3} \cdot \mathrm{cm}^{-3}\right)$, determinadas com as ferramentas A, B, C, D, E, e a geral, nas quatro grades amostradas no solo argiloso da fazenda Areão.

Como a umidade volumétrica é calculada utilizando-se a densidade do solo e a umidade gravimétrica, seus valores encontrados com a ferramenta B no solo argiloso, também apresentaram, como no caso da densidade do solo, valores maiores que a média das outras 4 ferramentas, em 3 grades de amostragem: na grade 1, os valores obtidos foram $11 \%$ maiores, na grade 3 , foram $4,7 \%$, e na grade 4 , foram $15,1 \%$ maiores. A influência da densidade do solo nesses valores, pode ser confirmado, comparando os gráficos das médias da umidade gravimétrica (Figura 7), da densidade do solo (Figura 11) e o da umidade volumétrica (Figura 18).

\subsubsection{Amostras coletadas no solo arenoso da Fazenda Sertãozinho}

Os valores médios de umidade com base em volume $\left(\theta_{\mathrm{s}} \%\right)$ e os respectivos coeficientes de variação, obtidos para cada ferramenta nas grades de amostragem, junto com os testes de significância $\mathrm{F}$, diferença mínima significativa de Tukey a $5 \%$ e $1 \%$, e o coeficiente de variação entre as ferramentas, são apresentados na Tabela 10.

A análise estatística, entre as médias obtidas de umidade volumétrica $\left(\theta_{\mathrm{s}} \%\right)$, apresentou diferenças significativas a $(1 \%)$ para a grade 1 , e a $(5 \%)$ para a grade 4 . As grades 2 e 3, amostradas no solo arenoso da fazenda Sertãozinho, não apresentaram diferenças significativas. 
Tabela 10- Umidades volumétricas do solo $\left(\theta_{\mathrm{s}} \%\right)$, obtidas com as ferramentas de coleta no solo arenoso da fazenda Sertãozinho, à profundidade média de $20 \mathrm{~cm}$. Valores médios de 5 repetições.

\begin{tabular}{lcccccccc} 
& \multicolumn{3}{c}{ Grade 1 } & \multicolumn{2}{c}{ Grade 2} & \multicolumn{2}{c}{ Grade 3 } & \multicolumn{2}{c}{ Grade 4 } \\
\hline \multicolumn{1}{c}{ Ferramentas } & $\theta_{\mathrm{s}} \%$ & $\mathrm{CV}$ & $\theta_{\mathrm{s}} \%$ & $\mathrm{CV}$ & $\theta_{\mathrm{s}} \%$ & $\mathrm{CV}$ & $\theta_{\mathrm{s}} \%$ & $\mathrm{CV}$ \\
\hline A-Trado Uhland & $17,5 \mathrm{~b}$ & 1,6 & $17,8 \mathrm{a}$ & 4,7 & $20,2 \mathrm{a}$ & 8,8 & $17,0 \mathrm{~b}$ & 5,0 \\
B-Anel Kopecky & $20,2 \mathrm{a}$ & 7,5 & $18,3 \mathrm{a}$ & 7,4 & $21,0 \mathrm{a}$ & 9,4 & $19,7 \mathrm{a}$ & 7,2 \\
C-Trado Soil Moisture & $17,4 \mathrm{~b}$ & 4,2 & $17,2 \mathrm{a}$ & 4,7 & $20,0 \mathrm{a}$ & 6,1 & $17,4 \mathrm{ab}$ & 8,8 \\
D-Trado Bravifer AI-50 & $18,9 \mathrm{ab}$ & 4,6 & $18,2 \mathrm{a}$ & 6,2 & $20,8 \mathrm{a}$ & 9,2 & $18,5 \mathrm{ab}$ & 9,9 \\
E-Trado Bravifer AI-100 & $18,2 \mathrm{~b}$ & 3,8 & $18,1 \mathrm{a}$ & 3,7 & $20,9 \mathrm{a}$ & 5,9 & $17,5 \mathrm{ab}$ & 5,8 \\
\hline \multicolumn{1}{c}{$\mathrm{F}$} & $11,884^{* *}$ & 1,033 n.s. & 0,663 n.s. & $3,385^{*}$ \\
Dms (5\%) & 1,50 & 2,04 & 2,44 & 2,61 \\
Dms (1\%) & 1,94 & 2,64 & 3,17 & 3,39 \\
CV(\%) & 6,22 & 2,56 & 2,13 & 5,92 \\
\hline
\end{tabular}

Médias seguidas de mesma letra e na mesma coluna, não diferem entre si (Tukey a 5\%).

$\mathrm{Na}$ Figura 19a, os valores mínimos e máximos da umidade volumétrica do solo $\left(\theta_{\mathrm{s}} \%\right)$, foram, respectivamente para as ferramentas na grade 1 : $\mathrm{A}(17,1$ e $17,8 \%)$, $B(18,7$ e $22,6 \%), C(16,2$ e $17,9 \%), D(18,1$ e $20,3 \%)$ e $E(17,2$ e $19,1 \%)$. Nesta grade, a ferramenta B, apresentou nas coordenadas $(10 ; 30),(30 ; 90),(50 ; 50)$ e $(90,70)$, os valores mais altos de umidade, obtendo a média $12,2 \%$ maior, que a média das outras quatro ferramentas.

Na Figura 19b, os valores mínimos e máximos da umidade volumétrica $\left(\theta_{\mathrm{s}} \%\right)$, foram, respectivamente para as ferramentas na grade 2: $\mathrm{A}(16,5$ e $18,6 \%), \mathrm{B}(16,7$ e $20,3 \%), C(15,9$ e $17,9 \%), D(16,3$ e 19,3\%) e $E(17,7$ e $19,3 \%)$. Nesta grade, a ferramenta B, coordenada $(50 ; 50)$, obteve o maior valor de umidade na grade $(20,2 \%)$, e a Ferramenta C, coordenada $(90 ; 10)$ o menor valor $(15,9 \%)$.

$\mathrm{Na}$ Figura $19 \mathrm{c}$, os valores mínimos e máximos de umidade volumétrica $\left(\theta_{\mathrm{s}} \%\right)$, foram, respectivamente para as ferramentas na grade 3: $\mathrm{A}(18,1$ e $22,4 \%), \mathrm{B}(18,7$ e $22,8 \%), \mathrm{C}(18,7$ e $21,6 \%), \mathrm{D}(18,9$ e $22,9 \%)$ e $\mathrm{E}(19,3$ e $22,5 \%)$.

$\mathrm{Na}$ Figura 19d, os valores mínimos e máximos obtidos, de umidade volumétrica $\left(\theta_{\mathrm{s}} \%\right)$, foram respectivamente para as ferramentas na grade $4: \mathrm{A}(15,7 \mathrm{e}$ 
$18,1 \%), \mathrm{B}(17,3$ e $21,0 \%), \mathrm{C}(15,1$ e $18,8 \%), \mathrm{D}(15,8$ e $20,4 \%)$ e $\mathrm{E}(16,3$ e $18,8 \%)$. A ferramenta $B$, apresentou os maiores valores de umidade $\left(\theta_{\mathrm{s}} \%\right)$, nas coordenadas $(10$; $30),(30 ; 90),(70 ; 10)$ e $(70 ; 70)$, enquanto a ferramenta $\mathrm{C}$, obteve o menor valor de $\left(\theta_{\mathrm{s}} \%\right)$, na coordenada $(30 ; 30)$, nesta grade de amostragem.
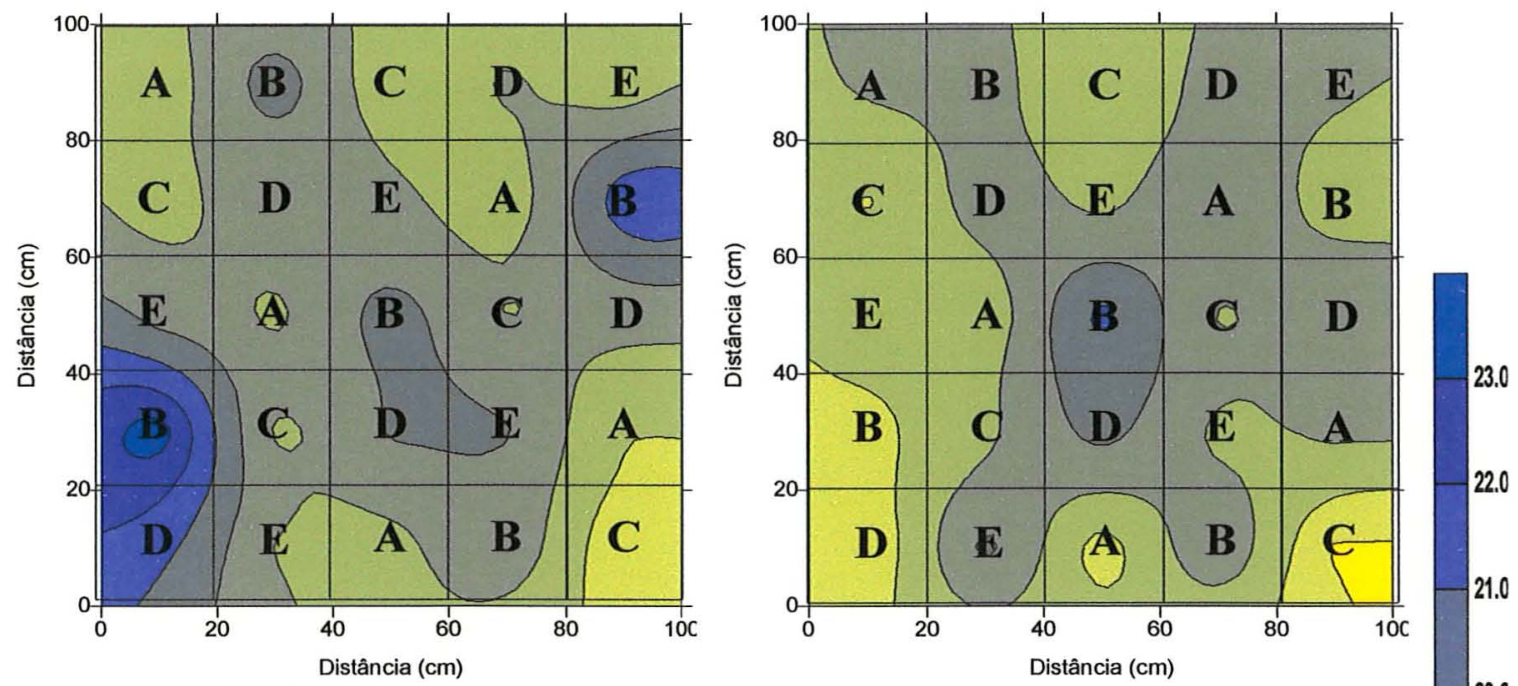

a) $\theta_{\mathrm{s}} \%\left(\mathrm{~cm}^{-3} \cdot \mathrm{cm}^{-3}\right)$ - grade amostragem 1

b) $\theta_{\mathrm{s}} \%\left(\mathrm{~cm}^{-3} \cdot \mathrm{cm}^{-3}\right)$ - grade amostragem 2
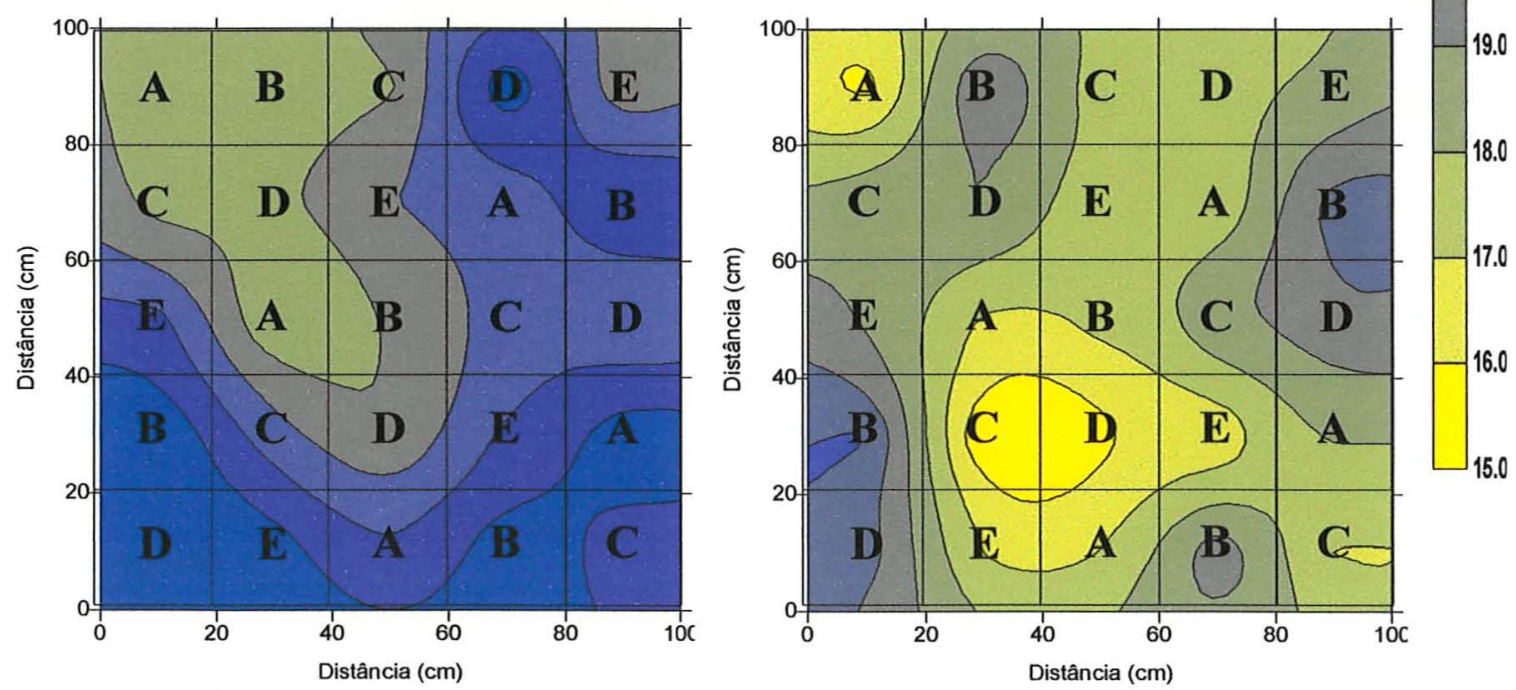

c) $\theta_{\mathrm{s}} \%\left(\mathrm{~cm}^{-3} \cdot \mathrm{cm}^{-3}\right)$ - grade amostragem 3

d) $\theta_{\mathrm{s}} \%\left(\mathrm{~cm}^{-3} \cdot \mathrm{cm}^{-3}\right)$ - grade amostragem 4

Figura 19- Mapas de contorno das quatro grades de amostragem, com a distribuição espacial da umidade volumétrica do solo $\theta_{\mathrm{s}} \%\left(\mathrm{~cm}^{3} / \mathrm{cm}^{3}\right)$, no solo arenoso da fazenda Sertãozinho: a) grade 1, b) grade 2, c) grade 3 e d) grade 4.

As médias da umidade volumétrica $\theta_{\mathrm{s}} \%\left(\mathrm{~cm}^{3} \cdot \mathrm{cm}^{-3}\right)$, obtidas entre as 20 amostras coletadas nas quatro grades de amostragem, com cada ferramenta, e a geral, 
para o solo arenoso da fazenda Sertãozinho, foram: A(18,1\%), B(19,8\%), C(18,0\%), $\mathrm{D}(19,1 \%), \mathrm{E}(18,7 \%)$ e a média geral $(18,7 \%)$, e estão representadas na Figura 20.

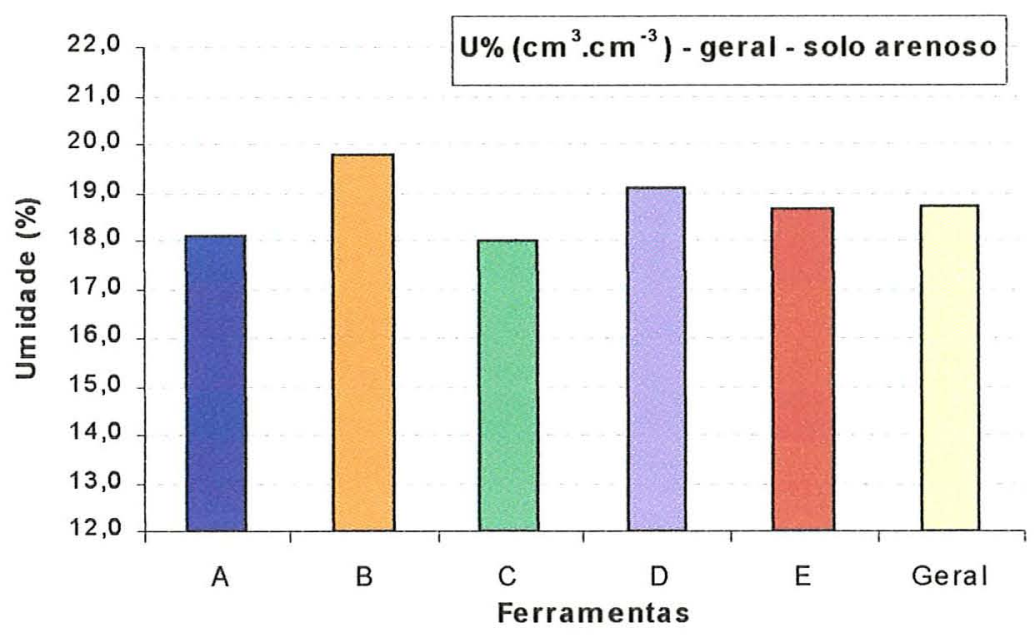

Figura 20- Médias da umidade volumétrica do solo $\theta_{\mathrm{s}} \%\left(\mathrm{~cm}^{3} \cdot \mathrm{cm}^{-3}\right)$, determinadas com as ferramentas A, B, C, D, E, e a geral, nas quatro grades amostradas no solo arenoso da fazenda Sertãozinho.

Os valores encontrados para a densidade do solo, foram maiores nas amostras coletadas com a ferramenta $\mathrm{B}$, em todas as grades de amostragem do solo arenoso. A umidade volumétrica, por utilizar este parâmetro na seu cálculo, apresentou valores maiores para a ferramenta $\mathrm{B}$, em todas as grades de amostragem, com pequena diferença ( $2 \%$ maior) entre seu valor e o da média das outras 4 ferramentas, nas grades 2 e 3 . Na grade 1 , os valores obtidos com a ferramenta $\mathrm{B}$, foram $12 \%$ maiores, e na grade 4 , foram $11,6 \%$ maiores, que a média obtida das outras 4 ferramentas.

Como para os solos arenosos, o coeficiente de determinação da equação de regressão (Figura 16), indicou o mesmo sentido entre os valores de umidade gravimétrica e da densidade do solo, observamos que, o fato dos valores da umidade gravimétrica serem maiores que os da densidade do solo, fez com que os mapas de contorno da umidade volumétrica $\left(\theta_{\mathrm{s}} \%\right)$ na Figura 19 , ficassem mais parecidos com os mapas de contorno da umidade gravimétrica (U\%) na Figura 10, do que com o da densidade do solo (Ds) na Figura 13, com um pequeno aumento de valores nos pontos amostrados com a ferramenta $\mathrm{B}$, que apresentou maiores valores de densidade do solo que as outras ferramentas em todas as grades de amostragem. 


\subsection{Porosidade total}

A porosidade total, foi determinada por dois métodos, o método indireto que é calculado com base nos valores das densidades do solo e de partículas, e pelo método direto, onde se determina utilizando a mesa de tensão.

\subsubsection{Porosidade total determinado pelo método indireto.}

Com os valores encontrados para densidade do solo e densidade de partículas, utilizando a eq. (5), determinamos a porosidade total para as amostras coletadas em cada ponto.

\subsubsection{Solos argilosos amostrados na fazenda Areão}

Os valores médios da porosidade total determinada pelo método indireto, são apresentados na Tabela 11, com os respectivos coeficientes de variação, obtidos para cada ferramenta nas grades de amostragem, junto aos testes de significância $F$, diferenças mínimas significativas de Tukey a $5 \%$ e 1\%, e o coeficiente de variação entre as ferramentas.

Tabela 11 - Porosidade total do solo (\%), determinada pelo método indireto, através dos dados obtidos com as diferentes ferramentas no solo argiloso da fazenda Areão, à profundidade média de $20 \mathrm{~cm}$. Valores médios de 5 repetições.

\begin{tabular}{lcccccccc} 
& \multicolumn{2}{c}{ Grade 1 } & \multicolumn{2}{c}{ Grade 2 } & \multicolumn{2}{c}{ Grade 3 } & \multicolumn{2}{c}{ Grade 4 } \\
\hline \multicolumn{1}{c}{ Ferramentas } & $\mathrm{Pt}(\%)$ & $\mathrm{CV}$ & $\mathrm{Pt}(\%)$ & $\mathrm{CV}$ & $\mathrm{Pt}(\%)$ & $\mathrm{CV}$ & $\mathrm{Pt}(\%)$ & $\mathrm{CV}$ \\
\hline A-Trado Uhland & $45,8 \mathrm{a}$ & 4,6 & $40,7 \mathrm{a}$ & 7,8 & $41,2 \mathrm{ab}$ & 7,2 & $42,1 \mathrm{a}$ & 6,8 \\
B-Anel Kopecky & $38,4 \mathrm{~b}$ & 1,9 & $34,6 \mathrm{c}$ & 2,5 & $37,4 \mathrm{c}$ & 3,6 & $37,4 \mathrm{c}$ & 7,0 \\
C-Trado Soil Moisture & $45,7 \mathrm{a}$ & 4,1 & $39,9 \mathrm{ab}$ & 3,6 & $42,0 \mathrm{a}$ & 6,2 & $40,6 \mathrm{ab}$ & 4,9 \\
D-Trado Bravifer AI-50 & $45,2 \mathrm{a}$ & 4,1 & $34,5 \mathrm{c}$ & 3,1 & $40,9 \mathrm{ab}$ & 5,0 & $41,7 \mathrm{a}$ & 9,7 \\
E-Trado Bravifer AI-100 & $45,3 \mathrm{a}$ & 6,1 & $36,4 \mathrm{bc}$ & 6,2 & $39,1 \mathrm{bc}$ & 4,1 & $38,8 \mathrm{bc}$ & 5,2 \\
\hline F & $16,24 * *$ & $10,07^{* *}$ & $4,472 *$ & $3,93 *$ \\
Dms (5\%) & 3,54 & 4,16 & 2,60 & 2,43 \\
Dms (1\%) & 4,58 & 5,39 & 3,87 & 3,15 \\
CV(\%) & 7,6 & 9,0 & 6,6 & 7,9 \\
\hline
\end{tabular}

Médias seguidas de mesma letra e na mesma coluna, não diferem entre si (Tukey a $5 \%$ ). 
A análise estatística entre as médias obtidas de porosidade total, apresentou diferenças significativas a (1\%) para as grades de amostragem 1 e 2 , e a (5\%) para as grades 3 e 4, no solo argiloso da fazenda Areão.

$\mathrm{Na}$ Figura $21 \mathrm{a}$, os valores mínimos e máximos de porosidade total, foram, respectivamente para as ferramentas na grade 1: $\mathrm{A}(43,8$ e $47,7 \%), \mathrm{B}(37,4$ e $39,2 \%)$, $\mathrm{C}(43,1$ e $47,6 \%), \mathrm{D}(42,7$ e $46,9 \%)$ e $\mathrm{E}(43,0$ e $49,1 \%)$. A ferramenta B, apresentou nas coordenadas $(10 ; 30),(30 ; 90),(50 ; 50),(70 ; 10)$ e $(90,70)$, os valores mais baixos de porosidade total, obtendo uma média $18,5 \%$ menor, que a média das outras quatro ferramentas nesta grade.

$\mathrm{Na}$ Figura $21 \mathrm{~b}$, os valores mínimos e máximos de porosidade total, foram, respectivamente para as ferramentas na grade 2 : $\mathrm{A}(38,4$ e $45,9 \%), \mathrm{B}(33,9$ e $35,0 \%)$, $\mathrm{C}(38,8$ e $42,1 \%), \mathrm{D}(32,9$ e $36,4 \%)$ e $\mathrm{E}(33,5$ e $39,6 \%)$. A ferramenta $\mathrm{A}$, coordenada (30; 50 ), apresentou o maior valor de porosidade total $(45,9 \%)$, e a Ferramenta D, coordenada $(90 ; 50)$ o menor valor de porosidade $(32,9 \%)$ nesta grade.

$\mathrm{Na}$ Figura 21c, os valores mínimos e máximos de porosidade total, foram, respectivamente para as ferramentas na grade $3: \mathrm{A}(38,0$ e $45,9 \%), \mathrm{B}(36,2$ e $39,6 \%)$, $C(39,5$ e $45,9 \%), D(37,9$ e $44,3 \%)$ e $E(37,5$ e $41,7 \%)$. Nesta grade, as ferramentas que apresentaram os maiores valores de porosidade total foram A, coordenadas (10; 90); C coordenadas $(10 ; 70)$ e a $\mathrm{D}$, coordenadas $(10 ; 10)$, que coincidem com os pontos que obtiveram os maiores valores de umidade gravimétrica (Figura 8) e os menores valores de densidade do solo (Figura 12). A ferramenta B, obteve os menores valores para porosidade total em 4 amostras, nas coordenadas $(10 ; 30),(50 ; 50),(70 ; 10)$ e $(90 ; 70)$, e, consequentemente, a menor média entre as ferramentas nesta grade de amostragem.

Na Figura 21d, os valores mínimos e máximos obtidos de porosidade total, foram respectivamente para as ferramentas na grade 4: $\mathrm{A}(39,6$ e $46,8 \%), \mathrm{B}(33,9$ e $40,1 \%), C(38,6$ e $43,3 \%), D(38,2$ e $48,7 \%)$ e $E(37,3$ e $42,1 \%)$. As ferramentas $A$, coordenadas $(70 ; 70)$ e $\mathrm{D}$, coordenadas $(70 ; 90)$, apresentaram os maiores valores de porosidade total, e a ferramenta $\mathrm{B}$, nas coordenadas $(10 ; 30)$, obteve o menor valor desta propriedade no solo argiloso da fazenda Areão. 


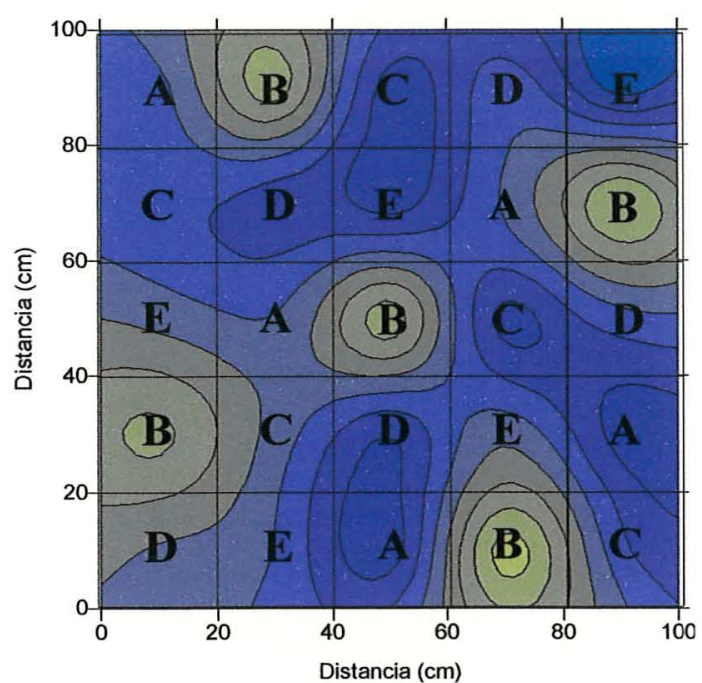

a) Pt (\%) - grade amostragem 1

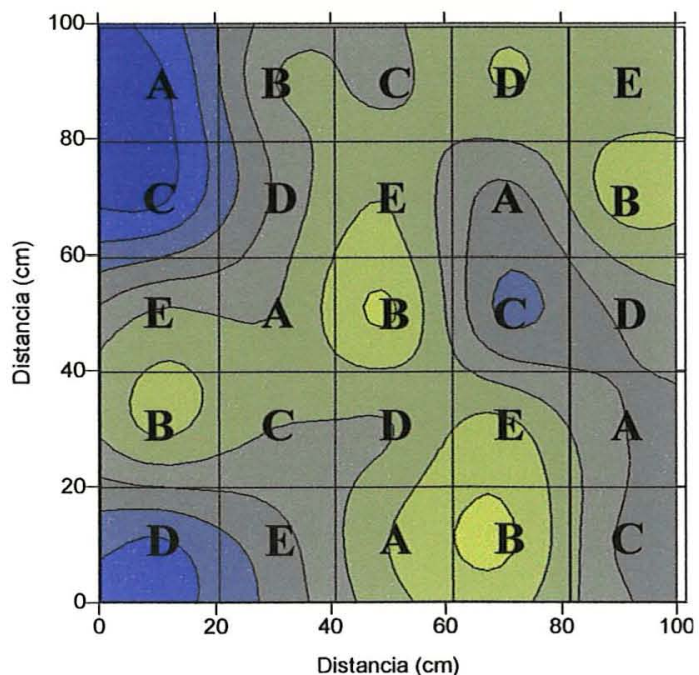

c) Pt (\%) - grade amostragem 3

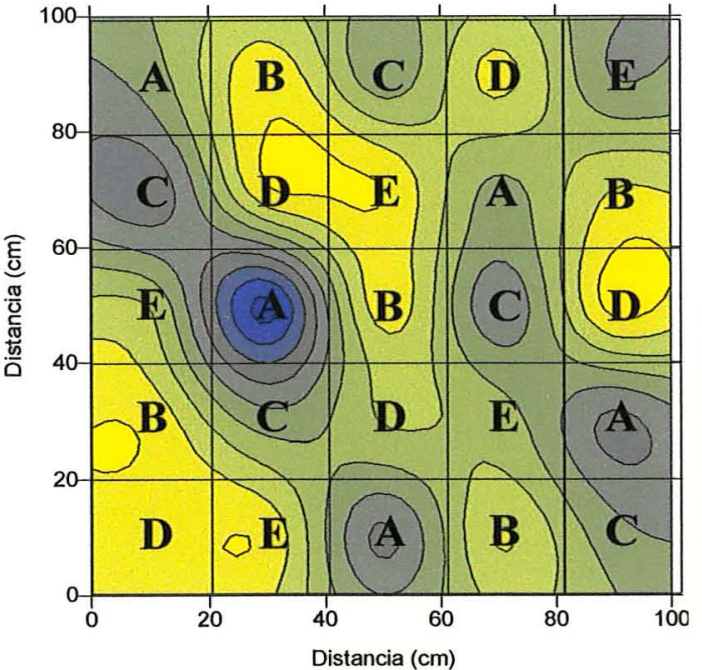

b) Pt (\%) - grade amostragem 2

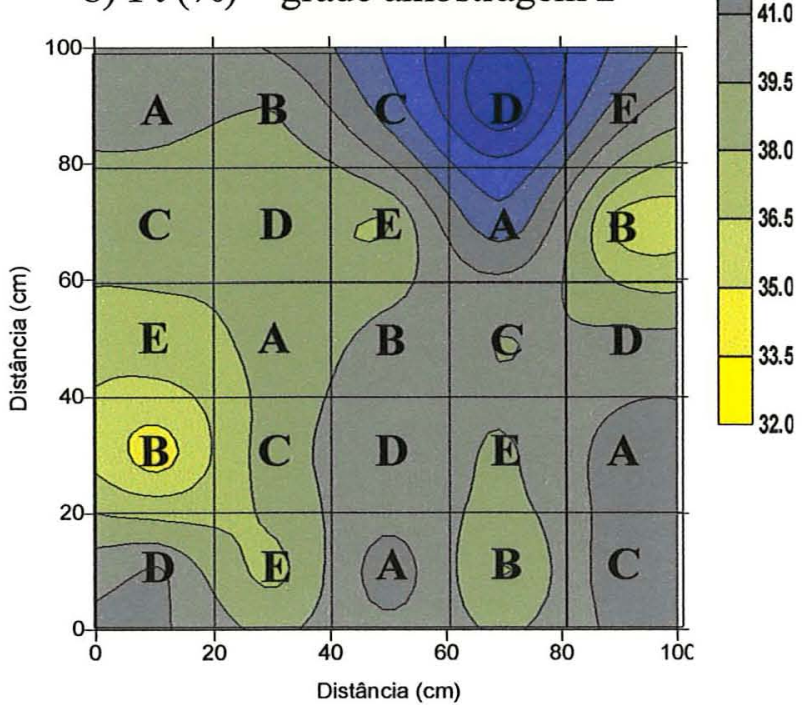

d) Pt (\%) - grade amostragem 4

Figura 21- Mapas de contorno das quatro grades de amostragem, com a distribuição espacial da porosidade total determinada pelo método indireto no solo argiloso da fazenda Areão: a) grade 1, b) grade 2, c) grade 3 e d) grade 4.

As médias da porosidade total obtidas pelo método indireto, determinadas com as 20 amostras coletadas com cada ferramenta, nas quatro grades amostradas, foram: $\mathrm{A}(42,4 \%), \mathrm{B}(36,9 \%), \mathrm{C}(42,0 \%), \mathrm{D}(40,4 \%), \mathrm{E}(39,9 \%)$, e a geral (40,3\%), obtida com as 100 amostras coletadas no solo argiloso, estão representadas na Figura 22. 


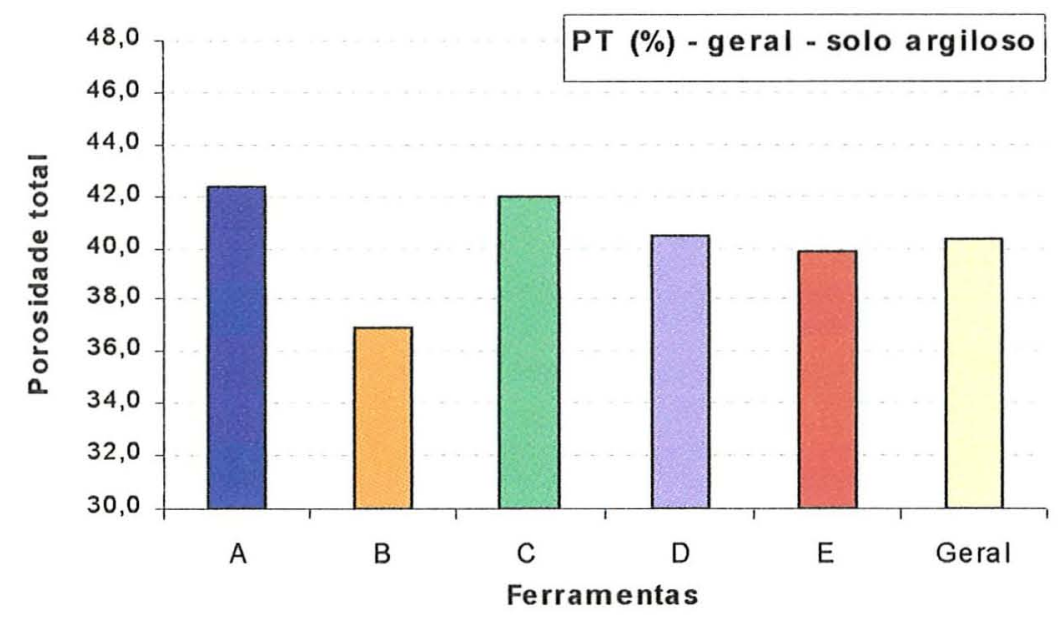

Figura 22- Médias da porosidade total do solo, determinadas pelo método indireto, com as ferramentas A, B, C, D, E, e a geral nas quatro grades de coletadas no solo argiloso da fazenda Areão.

A porosidade total, foi calculada através dos valores da densidade do solo, e, de forma inversamente proporcional, isto é, quanto maior a densidade do solo, menor a porosidade total, este fato pode ser confirmado, observando e comparando a Figura 21 com a Figura 12.

\subsubsection{Amostras coletadas no solo arenoso da fazenda Sertãozinho.}

Os valores médios da porosidade total determinada pelo método indireto, são apresentadas na Tabela 12, com os respectivos coeficientes de variação, obtidos para cada ferramenta nas grades de amostragem, junto aos testes de significância $\mathrm{F}$, diferença mínima significativa de Tukey a 5\% e 1\%, e o coeficiente de variação entre as ferramentas.

A análise estatística apresentou diferenças significativas entre as médias obtidas com as ferramentas, em 3 grades de amostragem, sendo que: para a grade 1, a diferença foi a (1\%) e para as grades 2 e 3 a diferença foi a (5\%). A grade 4 não apresentou diferenças significativas. 
Tabela 12- Porosidade total do solo (\%), determinada pelo método indireto, através dos dados obtidos com as diferentes ferramentas no solo arenoso da fazenda Sertãozinho, à profundidade média de $20 \mathrm{~cm}$. Valores médios de 5 repetições.

\begin{tabular}{|c|c|c|c|c|c|c|c|c|}
\hline & \multicolumn{2}{|c|}{ Grade 1} & \multicolumn{2}{|c|}{ Grade 2} & \multicolumn{2}{|c|}{ Grade 3} & \multicolumn{2}{|c|}{ Grade 4} \\
\hline Ferramentas & $\mathrm{Pt}(\%)$ & $\mathrm{CV}$ & $\mathrm{Pt}(\%)$ & $\mathrm{CV}$ & $\mathrm{Pt}(\%)$ & $\mathrm{CV}$ & $\mathrm{Pt}(\%)$ & CV \\
\hline A-Trado Uhland & $34,9 \mathrm{ab}$ & 2,4 & $35,1 \mathrm{a}$ & 2,6 & $32,1 \mathrm{ab}$ & 4,1 & 36,4 a & 6,3 \\
\hline B-Anel Kopecky & $31,9 \mathrm{c}$ & 7,0 & $32,7 \mathrm{~b}$ & 3,8 & $32,2 \mathrm{ab}$ & 2,6 & $33,9 \mathrm{a}$ & 3,8 \\
\hline C-Trado Soil Moisture & $36,2 \mathrm{a}$ & 4,7 & $34,9 \mathrm{ab}$ & 2,7 & $33,1 \mathrm{a}$ & 2,6 & $36,0 \mathrm{a}$ & 4,2 \\
\hline D-Trado Bravifer AI-50 & $33,0 \mathrm{bc}$ & 5,9 & $33,7 \mathrm{ab}$ & 5,6 & $32,2 \mathrm{ab}$ & 2,0 & $34,8 \mathrm{a}$ & 3,1 \\
\hline E-Trado Bravifer AI-100 & $34,9 \mathrm{ab}$ & 5,1 & $34,2 \mathrm{ab}$ & 4,0 & $31,3 \mathrm{~b}$ & 4,5 & $35,6 \mathrm{a}$ & 2,9 \\
\hline $\mathrm{F}$ & 11,82 & & 3,72 & & 4,22 & & 1,81 & \\
\hline Dms $(5 \%)$ & 2,2 & & 2,2 & & 1,37 & & 3,2 & \\
\hline Dms $(1 \%)$ & 2,8 & & 2,9 & & 1,78 & & 4,2 & \\
\hline $\mathrm{CV}(\%)$ & 4,9 & & 2,8 & & 1,9 & & 2,7 & \\
\hline
\end{tabular}

Médias seguidas de mesma letra e na mesma coluna, não diferem entre si. (Tukey a 5\%)

Na Figura 23a, os valores mínimos e máximos de porosidade total, foram, respectivamente para as ferramentas na grade 1 : $\mathrm{A}(33,9$ e $35,8 \%), \mathrm{B}(28,2$ e $34,7 \%)$, $C(34,6$ e $38,5 \%), D(30,7$ e $35,0 \%)$ e $E(32,2$ e $37,0 \%)$.

$\mathrm{Na}$ Figura 23b, os valores mínimos e máximos de porosidade total, foram, respectivamente para as ferramentas na grade 2 : $\mathrm{A}(34,5$ e $36,7 \%), \mathrm{B}(31,2$ e $34,0 \%)$, $C(34,2$ e $36,6 \%), D(30,7$ e $35,8 \%)$ e $E(32,5$ e $36,0 \%)$.

$\mathrm{Na}$ Figura 23c, os valores mínimos e máximos de porosidade total, foram, respectivamente para as ferramentas na grade 3 : $\mathrm{A}(31,1$ e $34,4 \%), \mathrm{B}(31,3$ e $33,1 \%)$, $C(32,3$ e $34,3 \%), D(31,6$ e $33,2 \%)$ e $E(29,3$ e $32,6 \%)$.

$\mathrm{Na}$ Figura 23d, os valores mínimos e máximos obtidos de porosidade total, foram, respectivamente para as ferramentas na grade 4 : $\mathrm{A}(34,0$ e $40,2 \%), \mathrm{B}(32,4$ e $35,9 \%), C(33,8$ e $37,9 \%), D(33,6$ e $36,4 \%)$ e $E(34,4$ e $36,9 \%)$.

A influência da densidade do solo nos valores da porosidade total determinada pelo método indireto, também fica demonstrada, na semelhança em forma inversa dos valores, quando comparamos os mapas de contorno de porosidade total (Figura 23) e o de densidade do solo (Figura 14). 


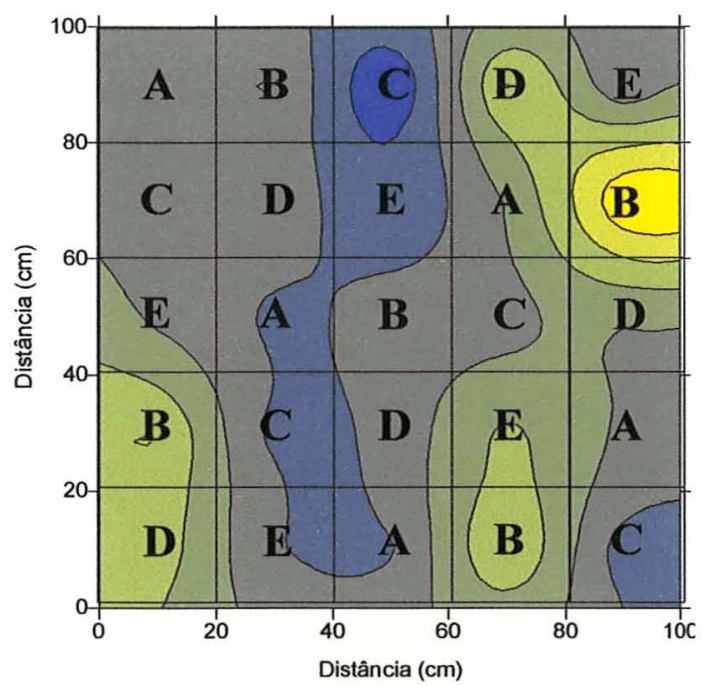

a) Pt (\%) - grade amostragem 1

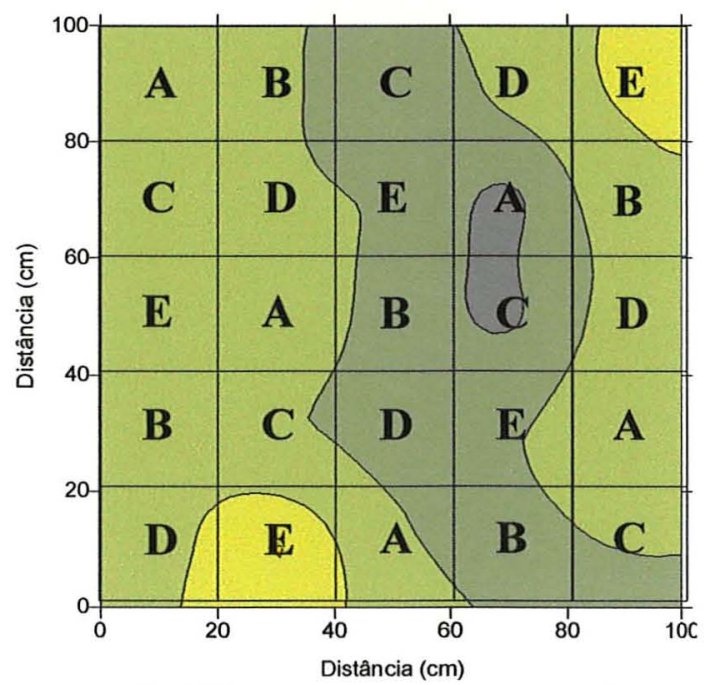

c) Pt (\%) - grade amostragem 3

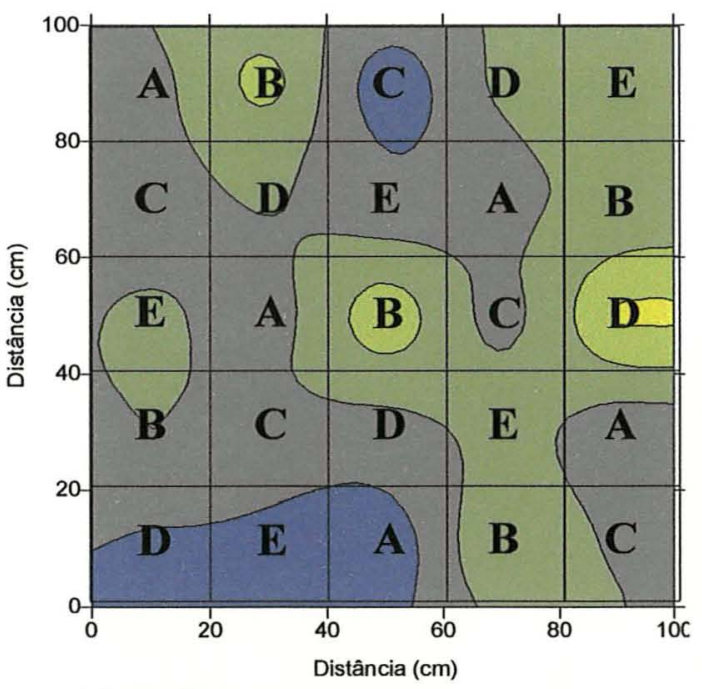

b) Pt (\%) - grade amostragem 2

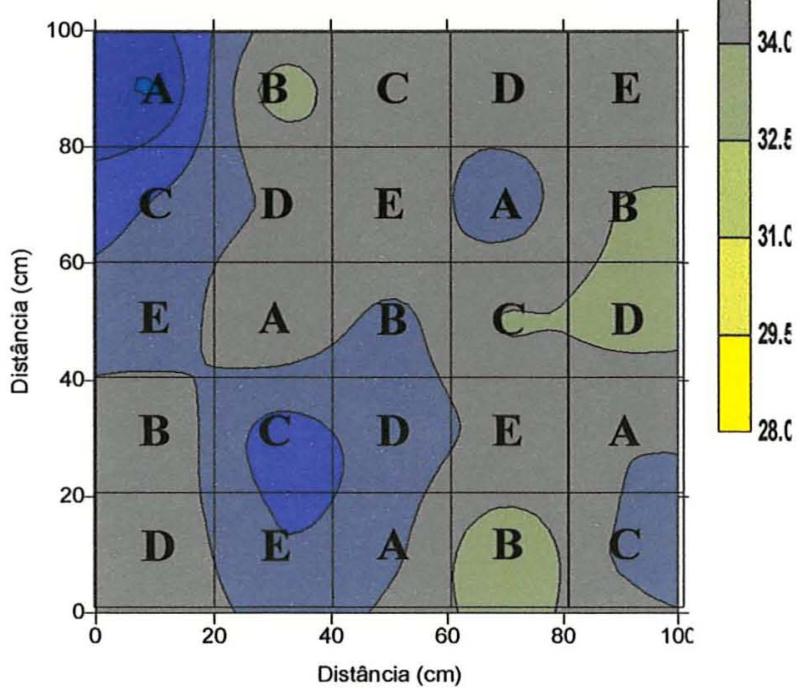

d) Pt (\%) - grade amostragem 4

Figura 23- Mapas de contorno, da distribuição espacial da porosidade total do solo determinada pelo método indireto, nas quatro grades de amostragem do solo arenoso da fazenda Sertãozinho: a) grade 1, b) grade 2, c) grade 3 e d) grade 4.

As médias da porosidade total pelo método indireto, determinadas pelas 20 amostras coletadas com cada ferramenta, nas quatro grades amostradas, foram: $\mathrm{A}(34,7 \%), \mathrm{B}(32,4 \%), \mathrm{C}(34,7 \%), \mathrm{D}(33,6 \%), \mathrm{E}(34,3 \%)$, e a geral $(33,9 \%)$, obtida pelas 100 amostras coletadas no solo arenoso, estão representadas na Figura 24. 


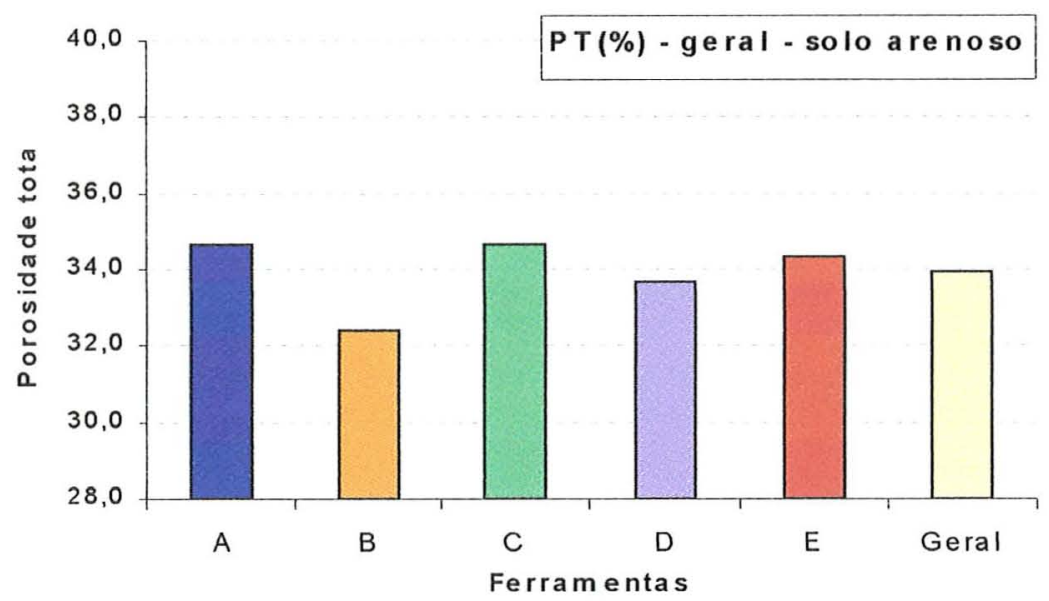

Figura 24- Médias da porosidade total do solo, determinadas pelo método indireto com as ferramentas A, B, C, D, E, e a geral, nas quatro grades amostradas no solo arenoso da fazenda Sertãozinho.

\subsubsection{Porosidade total determinada pelo método direto.}

Utilizando a metodologia recomendada pela EMBRAPA (1979) e Kiehl (1979), utilizando a eq. (2), determinamos o valor da porosidade total, para todas as amostras coletadas.

\subsubsection{Solos argilosos amostrados na fazenda Areão}

Os valores médios da porosidade total determinada pelo método direto, com os respectivos coeficientes de variação, obtidos para cada ferramenta nas grades de amostragem, junto com os testes de significância $\mathrm{F}$, diferença mínima significativa de Tukey a $5 \%$ e $1 \%$, e o coeficiente de variação entre as ferramentas, são apresentadas na Tabela 13.

A análise estatística apresentou entre as médias obtidas com as diferentes ferramentas, diferenças significativas a $(1 \%)$ apenas para a grade 3 , onde apenas a ferramenta D- trado Bravifer AI-50, obteve um valor mais alto para a média de porosidade total, que a diferenciou das demais. Todas as ferramentas apresentaram coeficientes de variação abaixo de $8 \%$. 
Tabela 13- Porosidade total do solo (\%), determinada pelo método direto, através dos dados obtidos com as diferentes ferramentas no solo argiloso da fazenda Areão, à profundidade média de $20 \mathrm{~cm}$. Valores médios de 5 repetições.

\begin{tabular}{lcccccccc} 
& \multicolumn{1}{c}{ Grade 1 } & \multicolumn{2}{c}{ Grade 2 } & \multicolumn{2}{c}{ Grade 3 } & \multicolumn{2}{c}{ Grade 4 } \\
\hline \multicolumn{1}{c}{ Ferramentas } & Pt (\%) & $\mathrm{CV}$ & $\mathrm{Pt}(\%)$ & $\mathrm{CV}$ & $\mathrm{Pt}(\%)$ & $\mathrm{CV}$ & $\mathrm{Pt}(\%)$ & $\mathrm{CV}$ \\
\hline A-Trado Uhland & $42,6 \mathrm{a}$ & 6,1 & $40,4 \mathrm{a}$ & 7,1 & $40,4 \mathrm{~b}$ & 3,8 & $41,8 \mathrm{a}$ & 7,7 \\
B-Anel Kopecky & $40,4 \mathrm{a}$ & 1,7 & $38,1 \mathrm{a}$ & 3,3 & $40,7 \mathrm{~b}$ & 2,3 & $39,9 \mathrm{a}$ & 5,6 \\
C-Trado Soil Moisture & $43,2 \mathrm{a}$ & 2,8 & $39,3 \mathrm{a}$ & 2,1 & $40,8 \mathrm{~b}$ & 5,8 & $38,8 \mathrm{a}$ & 5,0 \\
D-Trado Bravifer AI-50 & $43,6 \mathrm{a}$ & 3,5 & $39,0 \mathrm{a}$ & 4,5 & $44,3 \mathrm{a}$ & 5,6 & $41,8 \mathrm{a}$ & 7,4 \\
E-Trado Bravifer AI-100 & $42,2 \mathrm{a}$ & 6,7 & $37,0 \mathrm{a}$ & 3,5 & $39,1 \mathrm{~b}$ & 5,2 & $38,1 \mathrm{a}$ & 6,6 \\
\hline \multicolumn{1}{c}{ F } & 2,610 n.s. & 2,150 n.s. & 11,719 & $* *$ & 2,357 n.s. \\
\multicolumn{1}{c}{ Dms (5\%) } & 3,42 & 3,98 & 2,51 & 4,11 \\
Dms (1\%) & 4,42 & 5,16 & 3,25 & 5,32 \\
CV(\%) & 5,0 & 5,1 & 6,1 & 6,9 \\
\hline
\end{tabular}

Médias seguidas de mesma letra e na mesma coluna, não diferem entre si (Tukey a 5\%).

Na Figura 25a, os valores mínimos e máximos de porosidade total, foram, respectivamente para as ferramentas na grade 1: $\mathrm{A}(39,6$ e $46,1 \%), \mathrm{B}(39,4$ e $41,1 \%)$, $C(41,7$ e $43,9 \%)$, $D(41,8$ e $46,0 \%)$ e $E(39,6$ e $45,7 \%)$.

$\mathrm{Na}$ Figura 25b, os valores mínimos e máximos de porosidade total, foram, respectivamente para as ferramentas na grade 2 : $\mathrm{A}(38,3$ e $45,4 \%), \mathrm{B}(36,4$ e $39,4 \%)$, $\mathrm{C}(38,0$ e $40,0 \%), \mathrm{D}(36,2$ e $40,8 \%)$ e $\mathrm{E}(35,5$ e $38,4 \%)$. A ferramenta $\mathrm{A}$, coordenadas ( 30 ; 50), apresentou o maior valor de porosidade total $(45,4 \%)$, e a Ferramenta E, coordenadas $(30 ; 10)$ e $(70 ; 30)$, obtive os menores valores de porosidade total nesta grade, respectivamente $(35,5$ e $35,7 \%)$.

$\mathrm{Na}$ Figura 25c, os valores mínimos e máximos de porosidade total, foram, respectivamente para as ferramentas na grade 3: $\mathrm{A}(38,9$ e $43,0 \%), \mathrm{B}(39,7$ e $42,1 \%)$, $C(38,6$ e $44,7 \%), D(41,9$ e $48,3 \%)$ e $E(36,7$ e $42,1 \%)$. Nesta grade, a ferramenta $D$, coordenadas $(10 ; 10)$ foi a que apresentou o maior valor de porosidade total, e a ferramenta $\mathrm{E}$, coordenada $(70 ; 30)$, o menor valor de porosidade nesta grade.

$\mathrm{Na}$ Figura $25 \mathrm{~d}$, os valores mínimos e máximos obtidos de porosidade total, foram, respectivamente para as ferramentas na grade 4: $\mathrm{A}(36,9$ e $45,1 \%), \mathrm{B}(37,1$ e $43,3 \%), C(36,4$ e $41,3 \%), D(39,6$ e $47,1 \%)$ e $E(36,1$ e $42,4 \%)$. A ferramenta $A$, 
coordenadas $(70 ; 90)$, apresentou o maior valor de porosidade total, e a ferramenta B, na coordenada $(10 ; 30)$, obteve o menor valor nesta grade de amostragem.

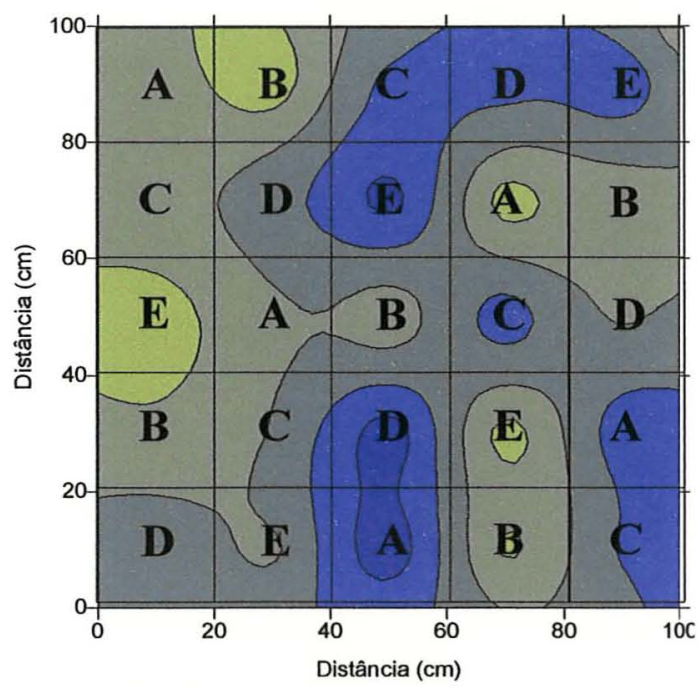

a) Pt (\%) - grade amostragem 1

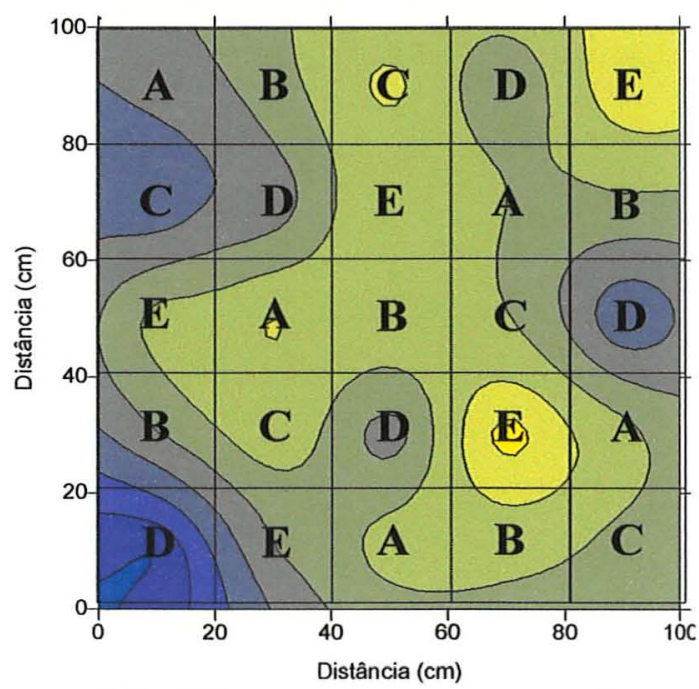

c) Pt (\%) - grade amostragem 3

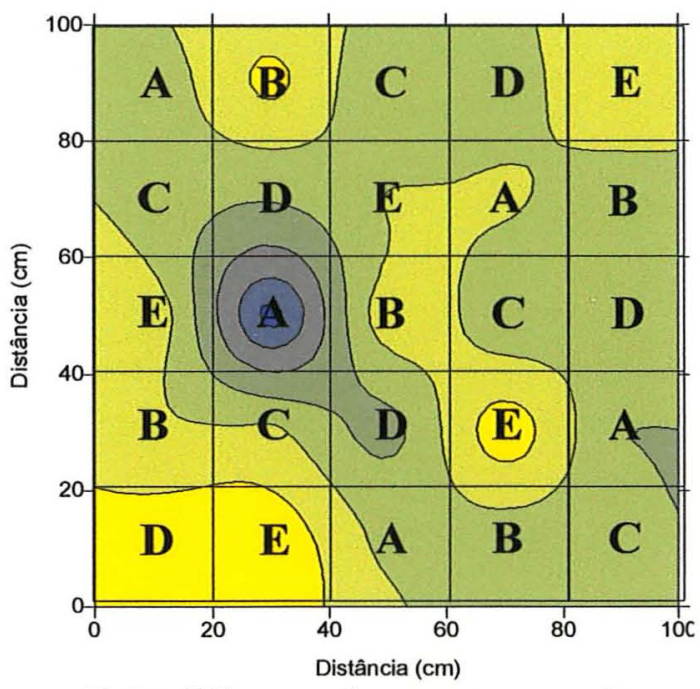

b) Pt (\%) - grade amostragem 2

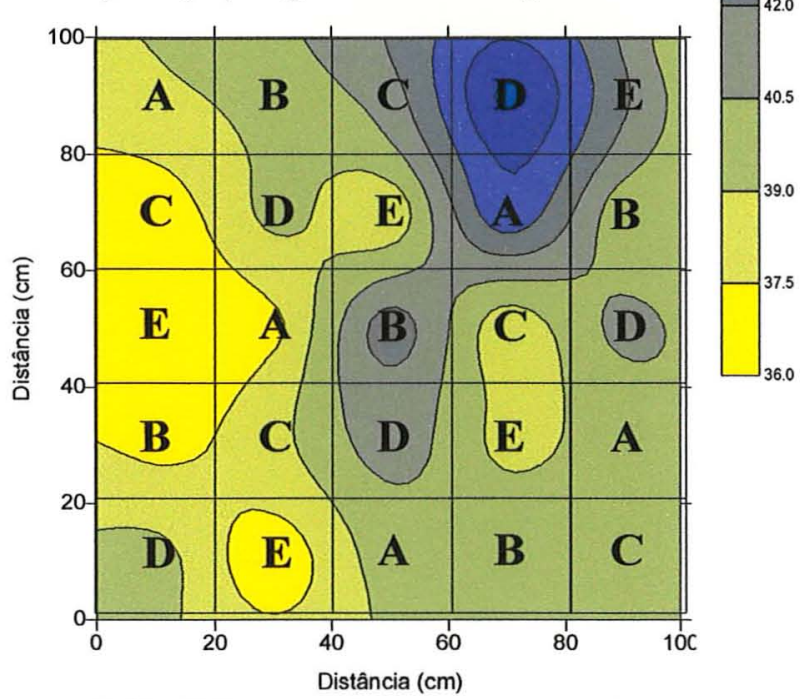

d) Pt (\%) - grade amostragem 4

Figura 25- Mapas de contorno, da distribuição espacial da porosidade total do solo determinada pelo método direto, nas quatro grades de amostragem do solo argiloso da fazenda Areão: a) grade 1, b) grade 2, c) grade 3 e d) grade 4.

As médias da porosidade total, determinadas pelo método direto, pelas 20 amostras coletadas com cada ferramenta, nas quatro grades amostradas, foram: 
$\mathrm{A}(40,9 \%), \mathrm{B}(39,8 \%), \mathrm{C}(40,5 \%), \mathrm{D}(42,2 \%), \mathrm{E}(39,1 \%)$, e a geral $(40,5 \%)$, obtida pelas 100 amostras coletadas no solo argiloso, estão representadas na Figura 26.

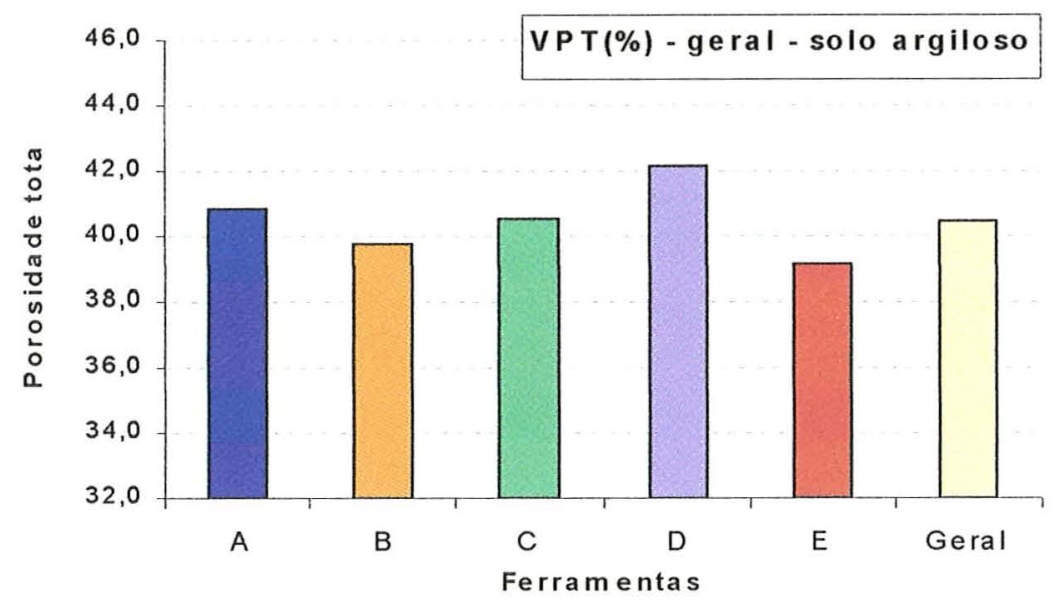

Figura 26- Médias da porosidade total do solo, determinadas pelo método direto com as ferramentas A, B, C, D, E, e a geral, nas quatro grades amostradas no solo argiloso da fazenda Areão.

Comparando os mapas de contorno de porosidade total determinada pelo método indireto (Figura 21), com o determinado pelo método direto(Figura 25), observamos que eles possuem características semelhantes, mas se compararmos as médias obtidas por esses métodos, respectivamente na Figura 22 e na Figura 26, encontraremos valores distintos para essas mesmas ferramentas.

\subsubsection{Amostras coletadas no solo arenoso da Fazenda Sertãozinho}

Os valores médios da porosidade total determinada pelo método direto, com os respectivos coeficientes de variação, obtidos para cada ferramenta nas grades de amostragem, junto com os testes de significância $F$, diferença mínima significativa de Tukey a $5 \%$ e $1 \%$, e o coeficiente de variação entre as ferramentas, são apresentadas na Tabela 14

A análise estatística entre as médias de porosidade total, determinadas pelo método direto com as ferramentas no solo arenoso, apresentou, nas grades 1,2 e 3 , diferenças significativas a ( $1 \%)$, e na grade 4 , a diferença significativa foi a $(5 \%)$. 
Tabela 14- Porosidade total do solo (\%) obtida pelo método direto, com as amostras coletadas pelas diferentes ferramentas no solo argiloso da fazenda Sertãozinho, à profundidade média de $20 \mathrm{~cm}$. Valores médios de 5 repetições.

\begin{tabular}{|c|c|c|c|c|c|c|c|c|}
\hline & \multicolumn{2}{|c|}{ Grade 1} & \multicolumn{2}{|c|}{ Grade 2} & \multicolumn{2}{|c|}{ Grade 3} & \multicolumn{2}{|c|}{ Grade 4} \\
\hline Ferramentas & $\mathrm{Pt}(\%)$ & $\mathrm{CV}$ & $\mathrm{Pt}(\%)$ & $\mathrm{CV}$ & $\operatorname{Pt}(\%)$ & $\mathrm{CV}$ & $\mathrm{Pt}(\%)$ & $\mathrm{CV}$ \\
\hline A-Trado Uhland & $29,5 \mathrm{~b}$ & 3,9 & $29,3 \mathrm{c}$ & 0,8 & $28,6 \mathrm{bc}$ & 4,4 & $29,3 \mathrm{~b}$ & 4,2 \\
\hline B-Anel Kopecky & $31,0 \mathrm{~b}$ & 4,1 & $32,1 \mathrm{ab}$ & 3,8 & $30,3 \mathrm{ab}$ & 1,6 & $30,8 \mathrm{ab}$ & 4,7 \\
\hline C-Trado Soil Moisture & $31,2 \mathrm{ab}$ & 5,2 & $30,8 \mathrm{bc}$ & 0,5 & $29,1 \mathrm{bc}$ & 2,7 & $30,4 \mathrm{ab}$ & 7,0 \\
\hline D-Trado Bravifer AI-50 & $32,8 \mathrm{a}$ & 5,7 & $33,5 \mathrm{a}$ & 4,1 & $32,0 \mathrm{a}$ & 4,0 & $32,8 \mathrm{a}$ & 5,2 \\
\hline E-Trado Bravifer AI-100 & $29,5 \mathrm{~b}$ & 4,1 & $30,3 \mathrm{bc}$ & 3,4 & $28,5 \mathrm{c}$ & 3,7 & $29,2 \mathrm{~b}$ & 4,4 \\
\hline $\mathrm{F}$ & 13,020 & & 14,828 & & 14,926 & & 4,48 & \\
\hline Dms $(5 \%)$ & 1,7 & & 1,9 & & 1,7 & & 3,1 & \\
\hline Dms (1\%) & 2,2 & & 2,4 & & 2,2 & & 4,0 & \\
\hline $\mathrm{CV}(\%)$ & 4,5 & & 5,2 & & 5,0 & & 4,7 & \\
\hline
\end{tabular}

Médias seguidas de mesma letra e na mesma coluna, não diferem entre si (Tukey a 5\%).

Os valores de porosidade total determinado pelo método indireto, apresentados foram maiores que os determinados pelo método direto, para todas as ferramentas, em todas as grades amostradas no solo arenoso. Os valores médios de porosidade total, determinados pelos dois métodos com a ferramenta $\mathrm{D}$, foram os mais próximos em todas as grades do solo arenoso.

A ferramenta $\mathrm{D}$, obteve os maiores valores de porosidade total determinada pelo método direto, em todas as grades amostradas no solo arenoso da fazenda Sertãozinho, que podem ser visualizados na Figura 27.

Na Figura 27a, os valores mínimos e máximos de porosidade total, foram, respectivamente para as ferramentas na grade 1: $\mathrm{A}(27,9$ e $30,9 \%), \mathrm{B}(29,4$ e $32,5 \%)$, $\mathrm{C}(29,6$ e $33,4 \%), \mathrm{D}(31,0$ e $35,5 \%)$ e $\mathrm{E}(27,9$ e $30,9 \%)$.

$\mathrm{Na}$ Figura 27b, os valores mínimos e máximos de porosidade total, foram, respectivamente para as ferramentas na grade 2 : $\mathrm{A}(29,1$ e $29,6 \%), \mathrm{B}(30,9$ e $33,8 \%)$, $\mathrm{C}(30,6$ e $31,0 \%), \mathrm{D}(31,8$ e $34,8 \%)$ e $\mathrm{E}(29,1$ e $31,7 \%)$.

$\mathrm{Na}$ Figura 27c, os valores mínimos e máximos de porosidade total, foram, respectivamente para as ferramentas na grade $3: \mathrm{A}(27,4$ e $30,3 \%), \mathrm{B}(29,6$ e $30,8 \%)$, $C(27,7$ e $29,8 \%), D(30,4$ e $33,7 \%)$ e $E(26,7$ e $29,3 \%)$. 
Na Figura 27d, os valores mínimos e máximos obtidos de porosidade total, foram, respectivamente para as ferramentas na grade 4: $\mathrm{A}(27,8$ e $31,2 \%), \mathrm{B}(29,0$ e $32,4 \%), C(28,0$ e $33,7 \%), D(31,1$ e $35,5 \%)$ e $\mathrm{E}(28,3$ e $31,5 \%)$.

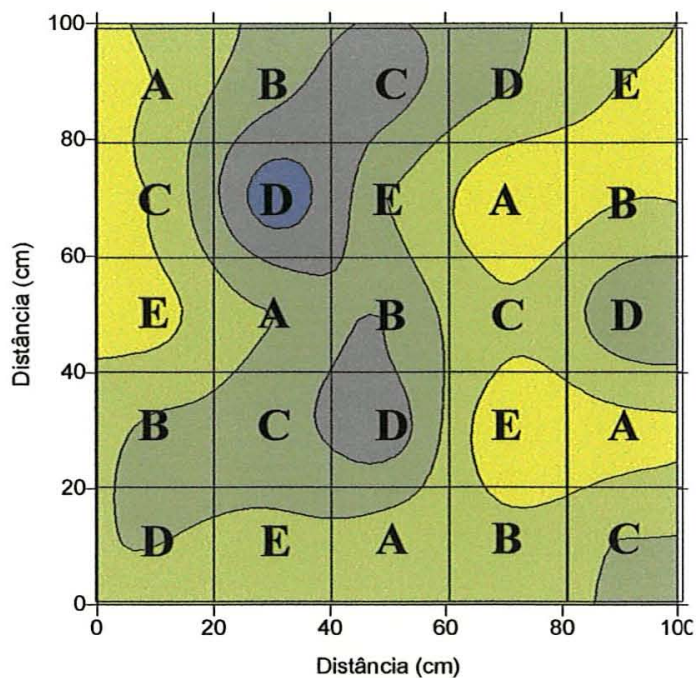

a) Pt (\%) - grade amostragem 1

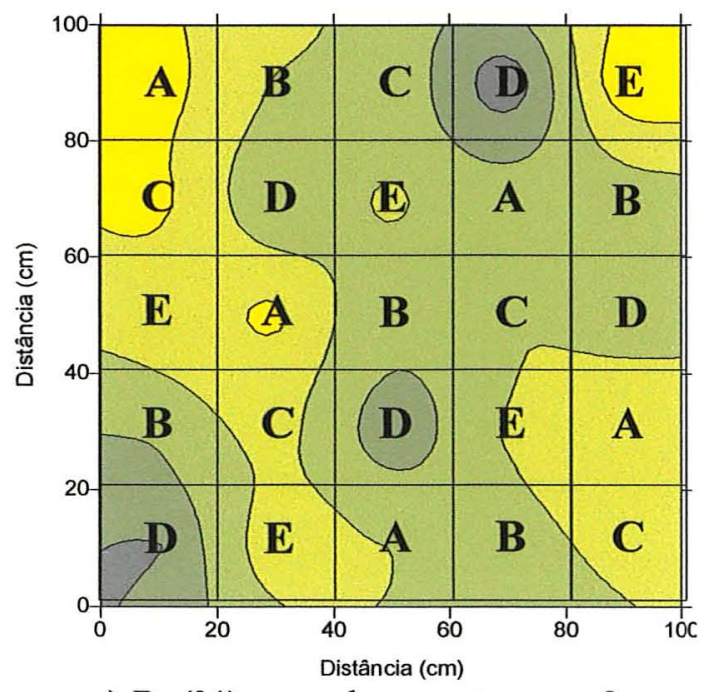

c) Pt (\%) - grade amostragem 3

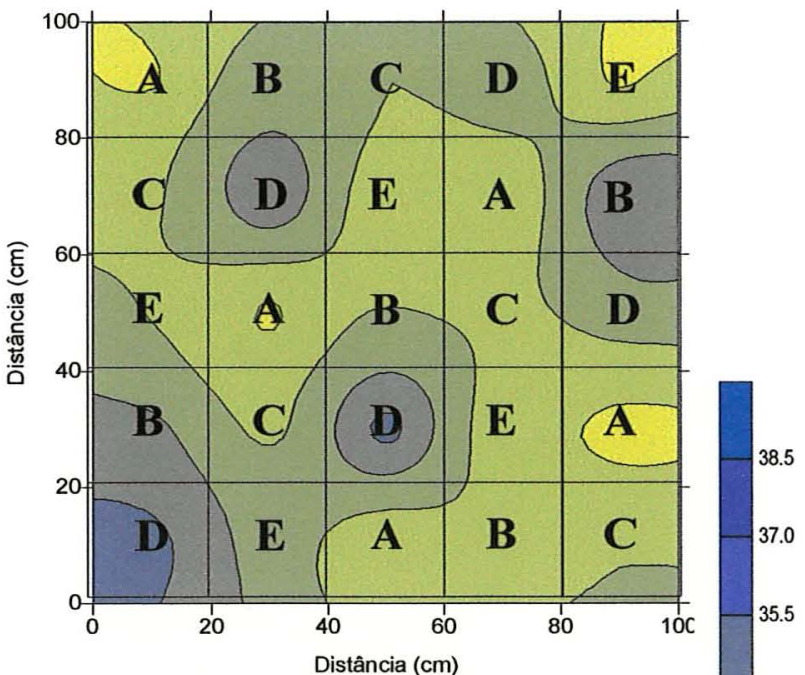

b) $\mathrm{Pt}(\%)$ - grade amostragem 2

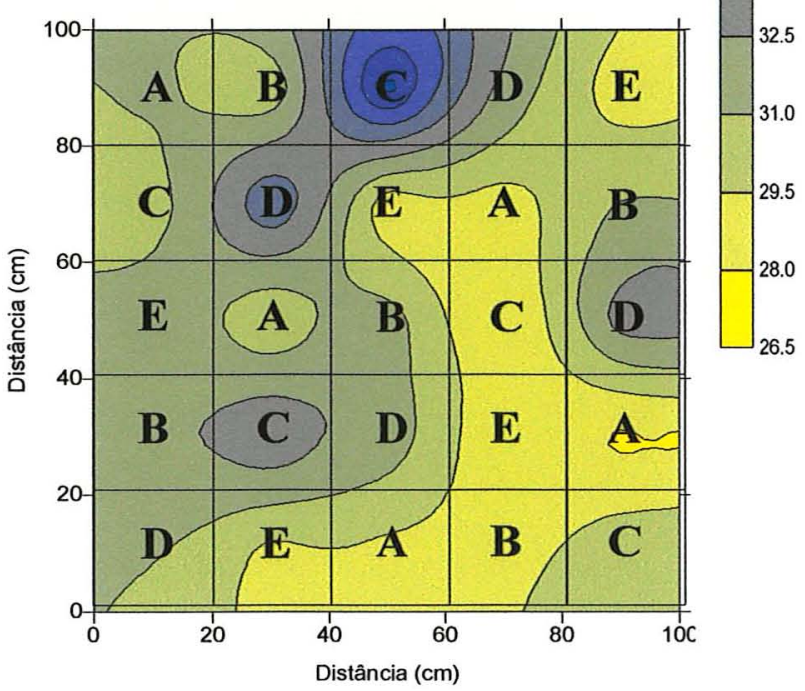

d) Pt (\%) - grade amostragem 4

Figura 27- Mapas de contorno, da distribuição espacial da porosidade total do solo determinada pelo método direto, nas quatro grades de amostragem do solo arenoso da fazenda Sertãozinho: a) grade 1, b) grade 2, c) grade 3 e d) grade 4. 
As médias da porosidade total, determinadas pelo método direto, pelas 20 amostras coletadas com cada ferramenta, nas quatro grades amostradas, foram: $\mathrm{A}(29,3 \%), \mathrm{B}(31,0 \%), \mathrm{C}(30,6 \%), \mathrm{D}(32,4 \%), \mathrm{E}(29,2 \%)$, e a geral $(30,5 \%)$, obtida pelas 100 amostras coletadas no solo arenoso, estão representadas na Figura 28.

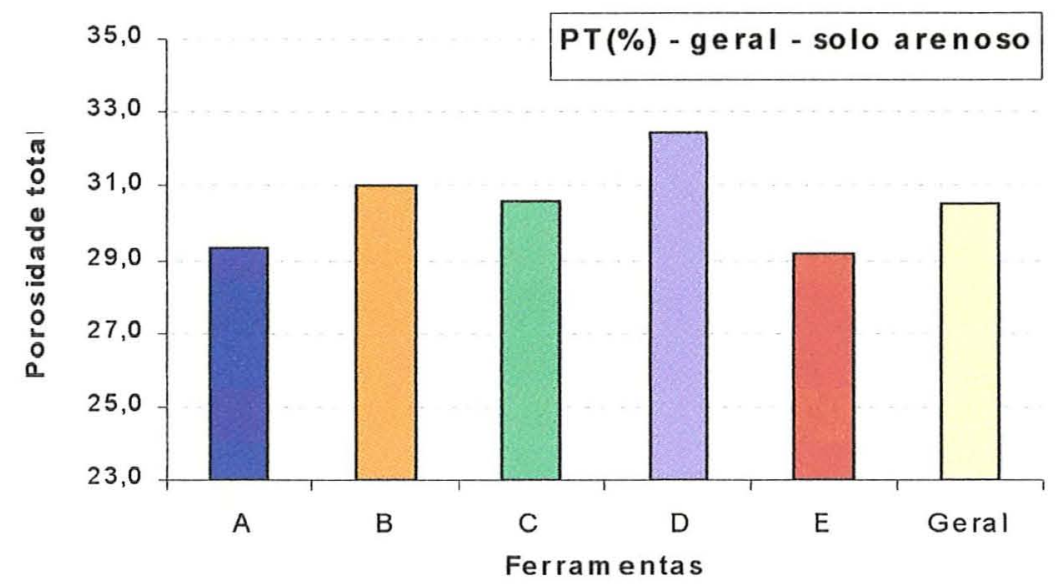

Figura 28- Médias da porosidade total do solo, determinadas pelo método direto com as ferramentas A, B, C, D, E, e a geral, nas quatro grades amostradas no solo arenoso da fazenda Sertãozinho.

\subsection{Macroporosidade}

Utilizando a metodologia recomendada pela EMBRAPA (1979) e Kiehl (1979), utilizando a eq. (3), determinamos o valor da macroporosidade para todas as amostras coletadas.

\subsubsection{Solos argilosos amostrados na fazenda Areão}

Os valores médios da macroporosidade do solo, com os respectivos coeficientes de variação, obtidos para cada ferramenta nas grades de amostragem, junto com os testes de significância $\mathrm{F}$, diferença mínima significativa de Tukey a 5\% e 1\%, e o coeficiente de variação entre as ferramentas, são apresentadas na Tabela 15.

A análise estatística, entre as médias de macroporosidade, obtidas com as ferramentas, no solo argiloso, apresentou diferenças significativas a (1\%) nas grades de amostragem 2, 3 e 4, e na grade 1, a diferença significativa foi a (5\%). 
Tabela 15- Macroporosidades do solo (\%), obtidas com as amostras coletadas com as diferentes ferramentas no solo argiloso da fazenda Areão, à profundidade média de $20 \mathrm{~cm}$. Valores médios de 5 repetições.

\begin{tabular}{lcccccccc} 
& \multicolumn{2}{c}{ Grade 1 } & \multicolumn{2}{c}{ Grade 2 } & \multicolumn{2}{c}{ Grade 3 } & \multicolumn{2}{c}{ Grade 4 } \\
\hline \multicolumn{1}{c}{ Ferramentas } & Ma (\%) & CV & Ma (\%) & CV & Ma(\%) & CV & Ma(\%) CV \\
\hline A-Trado Uhland & $13,2 \mathrm{a}$ & 21,8 & $10,8 \mathrm{a}$ & 36,0 & $9,6 \mathrm{a}$ & 22,5 & $7,1 \mathrm{ab}$ & 18,2 \\
B-Anel Kopecky & $6,5 \mathrm{~b}$ & 6,8 & $5,9 \mathrm{~b}$ & 11,6 & $6,1 \mathrm{~b}$ & 29,1 & $3,8 \mathrm{c}$ & 42,0 \\
C-Trado Soil Moisture & $12,7 \mathrm{a}$ & 15,2 & $7,4 \mathrm{ab}$ & 16,8 & $7,4 \mathrm{ab}$ & 17,3 & $7,1 \mathrm{ab}$ & 15,0 \\
D-Trado Bravifer AI-50 & $12,5 \mathrm{a}$ & 17,0 & $6,1 \mathrm{~b}$ & 11,3 & $9,9 \mathrm{a}$ & 17,1 & $8,8 \mathrm{a}$ & 23,9 \\
E-Trado Bravifer AI-100 & $11,9 \mathrm{ab}$ & 24,5 & $4,9 \mathrm{~b}$ & 17,3 & $6,6 \mathrm{~b}$ & 23,0 & $5,6 \mathrm{bc}$ & 8,1 \\
\hline \multicolumn{1}{c}{ F } & $4,485^{*}$ & $7,150^{* *}$ & $7,746^{* *}$ & $11,809^{* *}$ \\
Dms (5\%) & 5,81 & 3,86 & 2,81 & 2,49 \\
Dms (1\%) & 7,53 & 4,99 & 3,64 & 3,23 \\
CV(\%) & 28,8 & & 38,9 & 28,1 & 33,4 \\
\hline
\end{tabular}

Médias seguidas de mesma letra e na mesma coluna, não diferem entre si (Tukey a 5\%).

Na Figura 29a, os valores mínimos e máximos de macroporosidade, foram, respectivamente para as ferramentas na grade 1 : $\mathrm{A}(10,4$ e $17,2 \%), \mathrm{B}(6,1$ e $7,0 \%), \mathrm{C}(11,1$ e $14,9 \%), D(9,8$ e $15,0 \%)$ e $E(9,1$ e $16,2 \%)$. A ferramenta $B$, obteve os mais baixos valores de macroporosidade nesta grade, sendo que o seu maior valor encontrado, foi inferior aos menores valores encontrados com as outras ferramentas.

$\mathrm{Na}$ Figura 29b, os valores mínimos e máximos de macroporosidade, foram, respectivamente para as ferramentas na grade 2: $\mathrm{A}(8,5$ e 17,7\%), $\mathrm{B}(5,2$ e $6,9 \%), \mathrm{C}(5,6 \mathrm{e}$ $9,1 \%), D(5,2$ e $7,0 \%)$ e $E(3,9$ e $6,0 \%)$. A ferramenta $A$, coordenadas $(30 ; 50)$, apresentou o valor de macroporosidade $(17,7 \%)$, muito acima da média dos outros quatro valores $(9,1 \%)$, elevando o valor da sua média $(10,8 \%)$ e do coeficiente de variação $(36,02 \%)$.

$\mathrm{Na}$ Figura 29c, os valores mínimos e máximos de macroporosidade, foram, respectivamente para as ferramentas na grade 3: $\mathrm{A}(7,4$ e $12,9 \%), \mathrm{B}(4,6$ e 8,9\%), $\mathrm{C}(5,5$ e $8,5 \%), \mathrm{D}(7,1$ e $11,2 \%)$ e $\mathrm{E}(4,5$ e $8,6 \%)$. A ferramenta $\mathrm{A}$, coordenadas $(10 ; 90)$, apresentou o maior valor de macroporosidade nesta grade, tendo também obtido neste ponto, alto valor de umidade gravimétrica (Figura 8), e baixo valor de densidade do solo (Figura 12). 
Na Figura 29d, os valores mínimos e máximos obtidos de macroporosidade, foram, respectivamente para as ferramentas na grade $4: \mathrm{A}(5,8$ e 9,1\%), $\mathrm{B}(1,7$ e 5,3\%), $\mathrm{C}(6,3$ e $8,6 \%), \mathrm{D}(7,1$ e $11,9 \%)$ e $\mathrm{E}(5,1$ e $6,2 \%)$. A ferramenta $\mathrm{B}$, obteve em todos os pontos desta grade, valores baixos de macroporosidade, e a ferramenta $\mathrm{D}$, os valores mais altos em 3 pontos nesta grade.

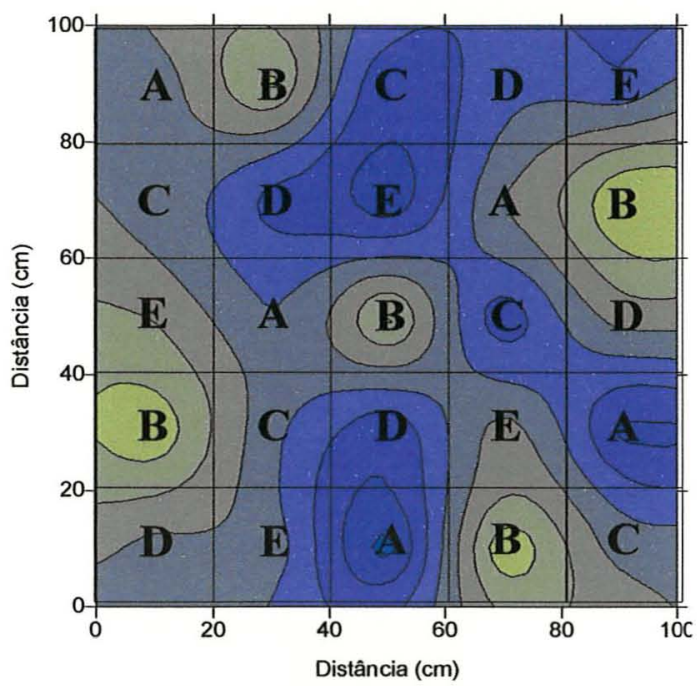

a) $\mathrm{Ma}(\%)$ - grade amostragem 1

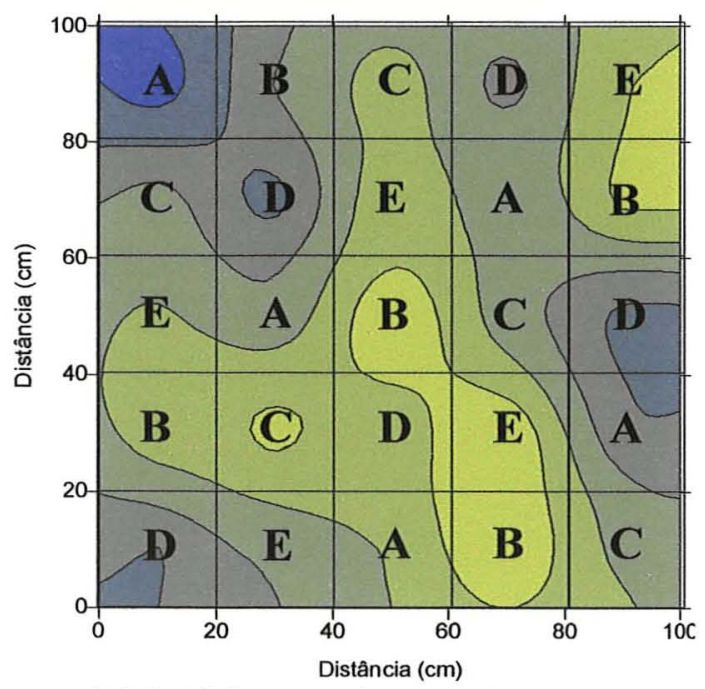

c) Ma (\%) - grade amostragem 3

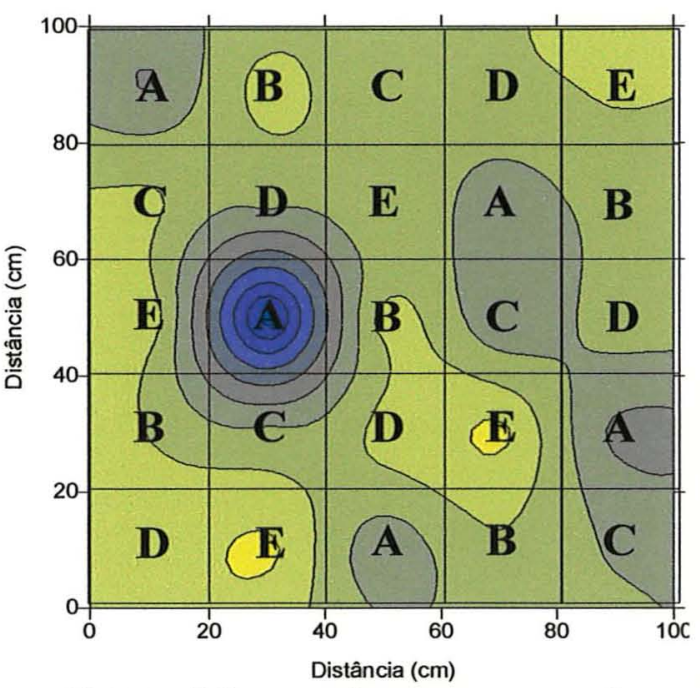

b) $\mathrm{Ma}(\%)$ - grade amostragem 2

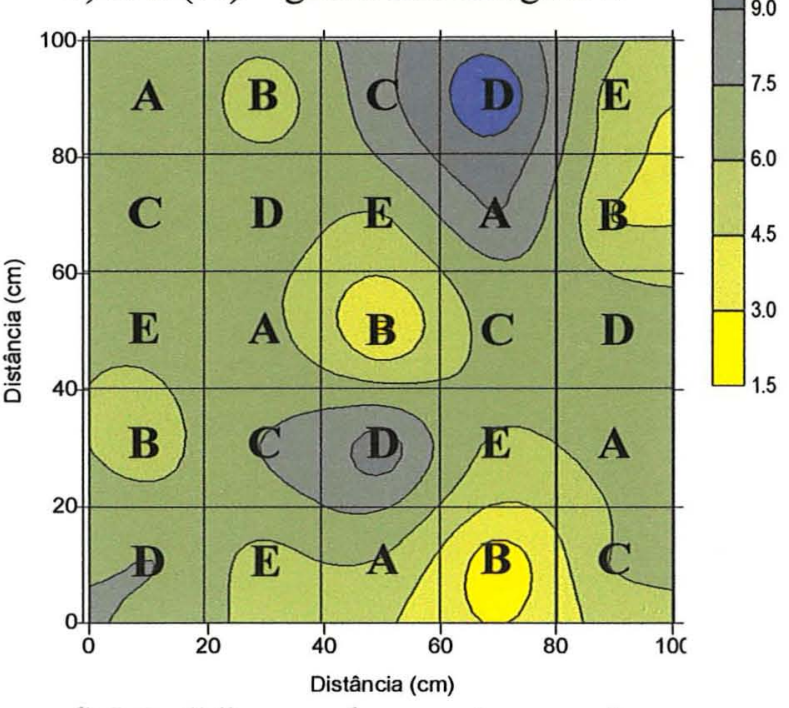

d) $\mathrm{Ma}(\%)$ - grade amostragem 4

Figura 29- Mapas de contorno, da distribuição espacial da macroporosidade do solo, nas quatro grades de amostragem do solo argiloso da fazenda Areão: a) grade 1, b) grade 2, c) grade 3 e d) grade 4. 
As médias da macroporosidade, obtidas pelas 20 amostras coletadas com cada ferramenta, nas quatro grades amostradas, foram: $\mathrm{A}(10,2 \%), \mathrm{B}(5,5 \%), \mathrm{C}(8,6 \%)$, $\mathrm{D}(9,7 \%), \mathrm{E}(7,3 \%)$, e a geral $(8,3 \%)$, obtida pelas 100 amostras coletadas no solo argiloso, estão representadas na Figura 30.

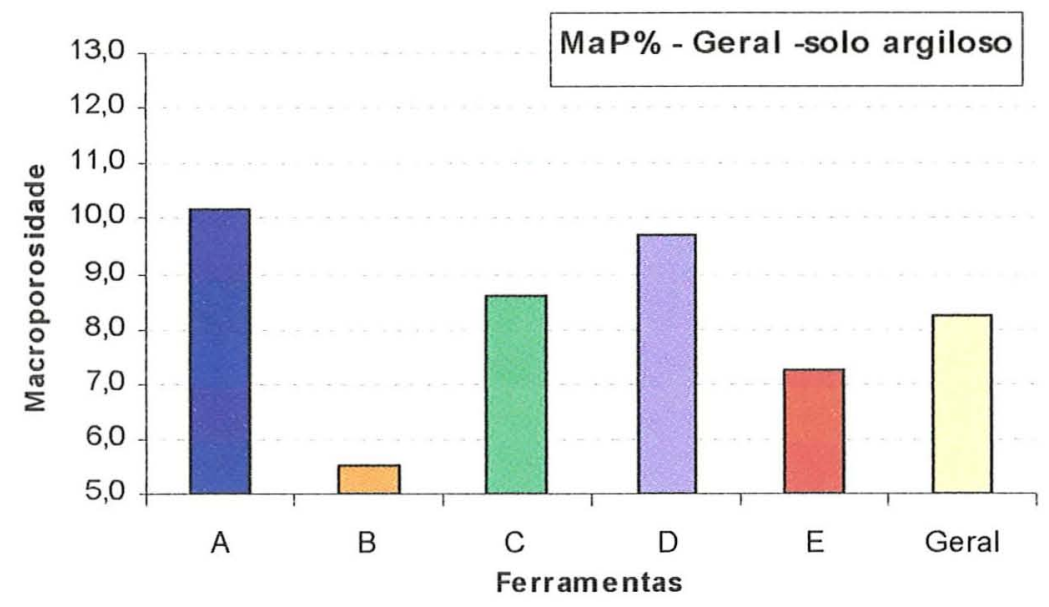

Figura 30- Médias da macroporosidade do solo, determinadas com as ferramentas A, B, $\mathrm{C}, \mathrm{D}, \mathrm{E}$, e a geral, nas quatro grades amostradas no solo argiloso da fazenda Areão.

\subsubsection{Amostras coletadas no solo arenoso da Fazenda Sertãozinho}

Os valores médios da macroporosidade, com os respectivos coeficientes de variação, obtidos para cada ferramenta nas grades de amostragem, junto com os testes de significância $\mathrm{F}$, diferença mínima significativa de Tukey a 5\% e 1\%, e o coeficiente de variação entre as ferramentas, são apresentados na Tabela 16.

A análise estatística, entre as médias de macroporosidade, obtidas com as ferramentas, no solo arenoso, apresentou diferenças significativas a (1\%) nas grades de amostragem 1,2 e 3. A grade 4 não apresentou diferenças significativas. 
Tabela 16- Macroporosidades do solo (\%), obtidas com as amostras coletadas pelas ferramentas no solo arenoso da fazenda Sertãozinho, à profundidade média de $20 \mathrm{~cm}$. Valores médios de 5 repetições.

\begin{tabular}{lcccccccc} 
& \multicolumn{2}{c}{ Grade 1 } & \multicolumn{2}{c}{ Grade 2 } & \multicolumn{2}{c}{ Grade 3 } & \multicolumn{2}{c}{ Grade 4 } \\
\hline \multicolumn{1}{c}{ Ferramentas } & Ma (\%) & $\mathrm{CV}$ & $\mathrm{Ma}(\%)$ & $\mathrm{CV}$ & $\mathrm{Ma}(\%)$ & $\mathrm{CV}$ & $\mathrm{Ma} \mathrm{( \% )} \mathrm{CV}$ \\
\hline A-Trado Uhland & $7,5 \mathrm{c}$ & 7,5 & $7,5 \mathrm{~b}$ & 18,0 & $6,9 \mathrm{~b}$ & 23,8 & $9,6 \mathrm{a}$ & 18,5 \\
B-Anel Kopecky & $7,5 \mathrm{c}$ & 25,4 & $9,3 \mathrm{ab}$ & 21,0 & $7,6 \mathrm{ab}$ & 22,7 & $7,3 \mathrm{a}$ & 20,1 \\
C-Trado Soil Moisture & $10,0 \mathrm{ab}$ & 17,1 & $9,3 \mathrm{ab}$ & 9,7 & $7,1 \mathrm{~b}$ & 14,6 & $9,8 \mathrm{a}$ & 31,0 \\
D-Trado Bravifer AI-50 & $11,4 \mathrm{a}$ & 19,4 & $11,6 \mathrm{a}$ & 13,5 & $9,4 \mathrm{a}$ & 22,4 & $10,4 \mathrm{a}$ & 21,5 \\
E-Trado Bravifer AI-100 & $8,4 \mathrm{bc}$ & 16,7 & $8,4 \mathrm{~b}$ & 9,2 & $6,4 \mathrm{~b}$ & 16,8 & $8,3 \mathrm{a}$ & 5,6 \\
\hline \multicolumn{1}{c}{ F } & $13,020^{* *}$ & $7,071 * *$ & $6,487 * *$ & $1,607 \mathrm{n} . \mathrm{s}$. \\
Dms (5\%) & 2,26 & 2,61 & 2,07 & 4,44 \\
Dms (1\%) & 2,93 & 3,38 & 2,69 & 5,75 \\
CV(\%) & 18,93 & 16,74 & 15,69 & 13,80 \\
\hline
\end{tabular}

Médias seguidas de mesma letra e na mesma coluna, não diferem entre si (Tukey a 5\%).

Na Figura 31a, os valores mínimos e máximos obtidos de macroporosidade, foram, respectivamente para as ferramentas na grade 1: $\mathrm{A}(6,6$ e 8,0\%), B(5,6 e 9,9\%), $\mathrm{C}(8,2$ e $12,4 \%), \mathrm{D}(8,1$ e $14,1 \%)$ e $\mathrm{E}(6,4$ e $9,7 \%)$.

$\mathrm{Na}$ Figura $31 \mathrm{~b}$, os valores mínimos e máximos obtidos de macroporosidade, foram, respectivamente para as ferramentas na grade 2 : $\mathrm{A}(6,3$ e $9,5 \%), \mathrm{B}(7,8$ e $11,7 \%)$, $C(8,3$ e $10,6 \%), D(10,0$ e $13,8 \%)$ e $E(7,1$ e $9,1 \%)$.

$\mathrm{Na}$ Figura 31c, os valores mínimos e máximos obtidos de macroporosidade, foram, respectivamente para as ferramentas na grade 3 : $\mathrm{A}(4,8$ e $8,6 \%), \mathrm{B}(6,3$ e 10,3\%), $\mathrm{C}(5,7$ e $8,5 \%), \mathrm{D}(6,8$ e $11,7 \%)$ e $\mathrm{E}(4,9$ e $7,8 \%)$.

$\mathrm{Na}$ Figura 31d, os valores mínimos e máximos obtidos de macroporosidade, foram, respectivamente para as ferramentas na grade $4: \mathrm{A}(7,4$ e $12,3 \%), \mathrm{B}(5,8$ e $9,8 \%)$, $C(6,3$ e $14,5 \%), D(6,9$ e $12,3 \%)$ e $E(7,8$ e $9,0 \%)$. Nesta grade uma das amostras coletadas com a ferramenta A, coordenada $(10 ; 90)$, apresentou um valor mais alto de macroporosidade $(12,3 \%)$, que a média das outras 4 repetições $(8,8 \%)$, e a ferramenta $\mathrm{D}$, coordenada $(10 ; 10)$, apresentou um valor mais baixo $(6,9 \%)$, que a média das outras 4 $(11,2 \%)$, diminuindo a sua média de macroporosidade para $(10,3 \%)$. 


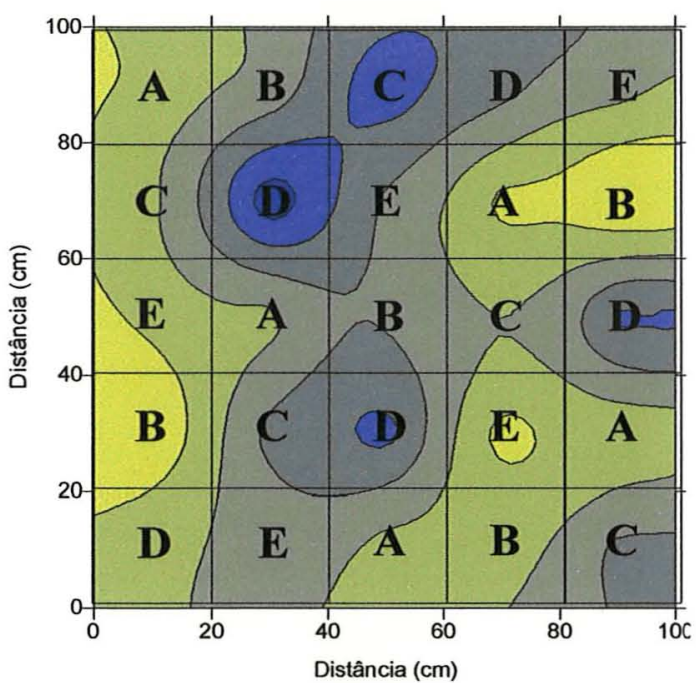

a) $\mathrm{Ma}(\%)$ - grade amostragem 1

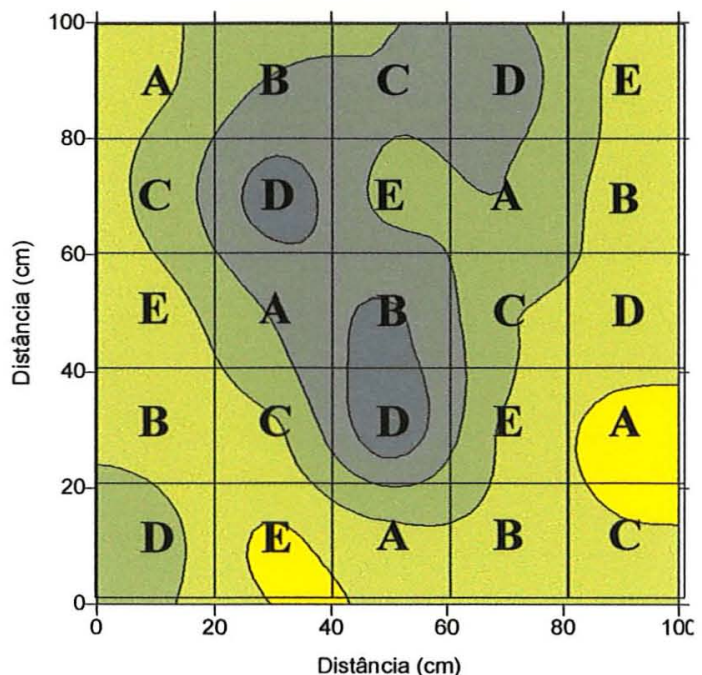

c) Ma (\%) - grade amostragem 3

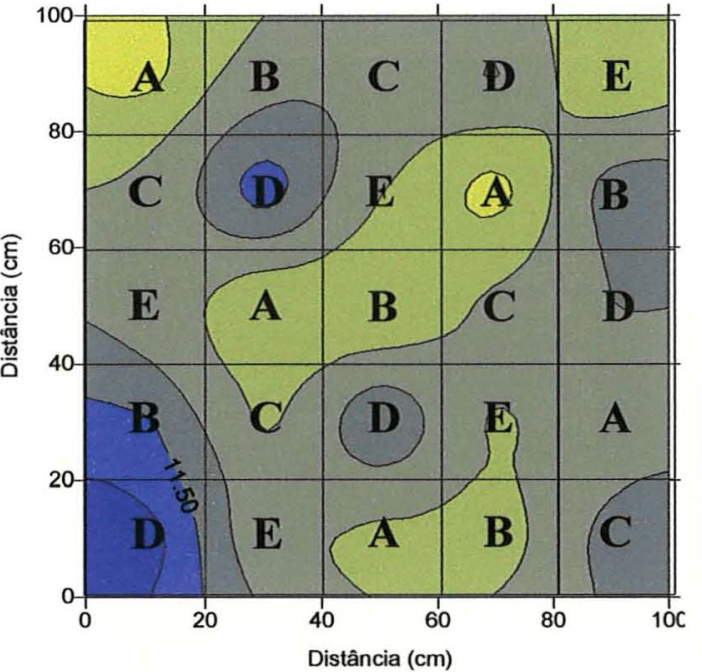

b) $\mathrm{Ma}(\%)$ - grade amostragem 2

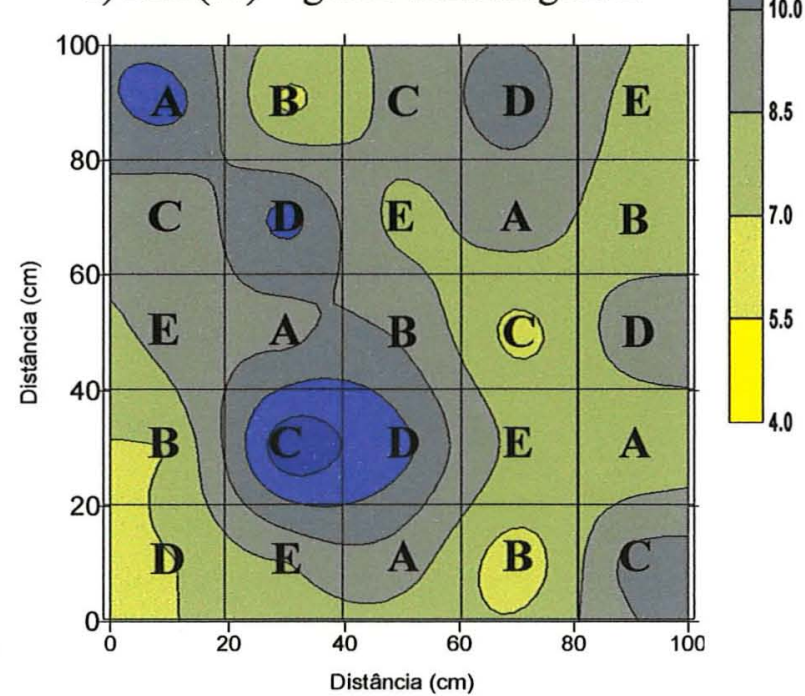

d) $\mathrm{Ma}(\%)$ - grade amostragem 4

Figura 31- Mapas de contorno, da distribuição espacial da macroporosidade, nas quatro grades de amostragem do solo arenoso da fazenda Sertãozinho: a) grade 1, b) grade 2, c) grade 3 e d) grade 4 .

As médias da macroporosidade, obtidas pelas 20 amostras coletadas com cada ferramenta, nas quatro grades amostradas, foram: $\mathrm{A}(7,8 \%), \mathrm{B}(7,9 \%), \mathrm{C}(9,0 \%)$, $\mathrm{D}(10,7 \%), \mathrm{E}(7,8 \%)$, e a geral $(8,7 \%)$, obtida pelas 100 amostras coletadas no solo arenoso, estão representadas na Figura 32. 


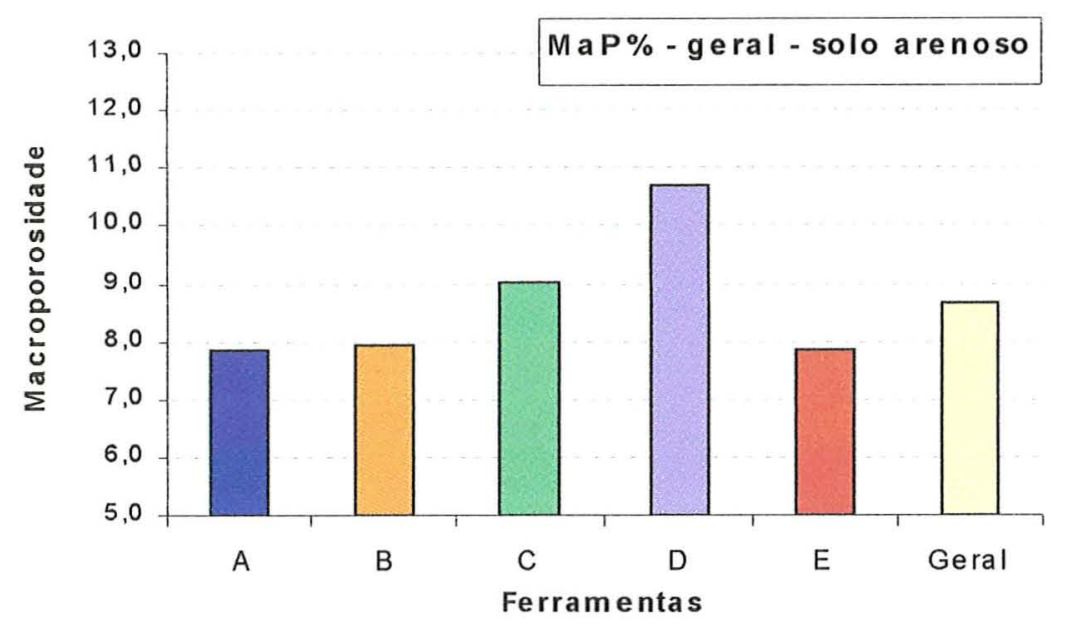

Figura 32- Médias da macroporosidade do solo, determinadas com as ferramentas A, B, C, D, E, e a geral, nas quatro grades amostradas no solo arenoso da fazenda Sertãozinho.

A ferramenta D- trado Bravifer AI-50, foi a que apresentou os valores médios mais altos para esta propriedade, nas quatro grades de amostragem no solo arenoso da fazenda Sertãozinho.

\subsection{Microporosidade}

Utilizando a metodologia recomendada pela EMBRAPA (1979) e Kiehl (1979), utilizando a eq. (4), determinamos o valor da microporosidade para todas as amostras coletadas.

\subsubsection{Solos argilosos amostrados na fazenda Areão}

Os valores médios da microporosidade do solo, com os respectivos coeficientes de variação, obtidos para cada ferramenta nas grades de amostragem, junto com os testes de significância $\mathrm{F}$, diferença mínima significativa de Tukey a $5 \%$ e $1 \%$, e o coeficiente de variação entre as ferramentas, são apresentados na Tabela 17.

A análise estatística, entre as médias de microporosidade, obtidas com as diferentes ferramentas, no solo argiloso, apresentou diferenças significativas a (1\%) nas grades de amostragem 1,2 e 3 , e diferenças significativas a (5\%) para a grade 4 . 
Tabela 17- Microporosidades do solo (\%), obtidas com as amostras coletadas pelas ferramentas no solo argiloso da fazenda Areão, à profundidade média de $20 \mathrm{~cm}$. Valores médios de 5 repetições.

\begin{tabular}{|c|c|c|c|c|c|c|c|c|}
\hline & \multicolumn{2}{|c|}{ Grade 1} & \multicolumn{2}{|c|}{ Grade 2} & \multicolumn{2}{|c|}{ Grade 3} & \multicolumn{2}{|c|}{ Grade 4} \\
\hline Ferramentas & $\mathrm{Mi}(\%)$ & $\mathrm{CV}$ & Mi (\%) & $\mathrm{CV}$ & $\mathrm{Mi}(\%)$ & $\mathrm{CV}$ & $\operatorname{Mi}(\%)$ & $\mathrm{CV}$ \\
\hline A-Trado Uhland & $29,4 \mathrm{c}$ & 1,5 & $29,6 \mathrm{~b}$ & 3,8 & $30,9 \mathrm{~b}$ & 4,1 & $33,0 a b$ & 6,8 \\
\hline B-Anel Kopecky & $34,0 \mathrm{a}$ & 2,9 & $32,2 \mathrm{a}$ & 2,5 & $34,7 \mathrm{a}$ & 4,0 & $36,2 \mathrm{a}$ & 9,8 \\
\hline C-Trado Soil Moisture & $30,5 \mathrm{bc}$ & 4,4 & $32,0 \mathbf{a}$ & 3,6 & 33,5 a & 5,7 & $31,7 \mathrm{~b}$ & 4,8 \\
\hline D-Trado Bravifer AI-50 & $31,1 \mathrm{~b}$ & 4,1 & $32,9 \mathrm{a}$ & 4,4 & $34,4 \mathrm{a}$ & 7,1 & $33,0 \mathrm{ab}$ & 4,9 \\
\hline E-Trado Bravifer AI- 100 & $30,4 b c$ & 2,4 & $32,1 \mathrm{a}$ & 1,1 & $32,6 \mathrm{ab}$ & 1,9 & $32,5 \mathrm{ab}$ & 8,7 \\
\hline $\mathrm{F}$ & 23,67 & & 7,421 & & 8,311 & & 3,409 & \\
\hline Dms $(5 \%$ & 1,6 & & $2,0^{\circ}-x-20$ & & 2,38 & & 4,16 & \\
\hline Dms (1\%) & 2,1 & & 2,68 & & 3,0 & & 5,35 & \\
\hline $\mathrm{CV}(\%)$ & 5,9 & & 4,8 & & 6,2 & & 8,2 & \\
\hline
\end{tabular}

$\mathrm{Na}$ Figura 33a, os valores mínimos e máximos obtidos de microporosidade, foram, respectivamente para as ferramentas na grade 1 : $\mathrm{A}(28,9$ e $30,0 \%), \mathrm{B}(32,4$ e $35,0 \%), \mathrm{C}(28,9$ e $32,5 \%), \mathrm{D}(29,0$ e $32,1 \%)$ e $\mathrm{E}(29,5$ e $31,3 \%)$. Nesta grade a ferramenta $\mathrm{B}$, obteve em todos os pontos amostrados os maiores valores de microporosidade.

$\mathrm{Na}$ Figura 33b, os valores mínimos e máximos obtidos de microporosidade, foram, respectivamente para as ferramentas na grade 2: $\mathrm{A}(27,6$ e $30,6 \%), \mathrm{B}(31,1$ e $33,4 \%), C(30,7$ e $33,4 \%), D(30,9$ e $35,4 \%)$ e $E(31,5$ e $32,4 \%)$. Nesta grade, o menor valor de microporosidade foi obtido com a ferramenta $A$, na coordenada $(30 ; 50)$.

$\mathrm{Na}$ Figura 33c, os valores mínimos e máximos obtidos de microporosidade, foram, respectivamente para as ferramentas na grade 3: $\mathrm{A}(29,7$ e $32,5 \%), \mathrm{B}(32,2$ e $35,5 \%), \mathrm{C}(31,9$ e $36,5 \%), \mathrm{D}(32,0$ e $37,7 \%)$ e $\mathrm{E}(31,8$ e $33,5 \%)$. Nesta grade, os valores mais altos de microporosidade, encontrados com as ferramentas B, coordenadas (10; $30),(50 ; 50),(70,10),(70 ; 70)$, ferramenta $C$, coordenadas $(10 ; 70)$ e ferramenta $D$, coordenadas $(10 ; 10)$ são os mesmos de alto valor de umidade gravimétrica na Figura 8c.

Na Figura 33d, os valores mínimos e máximos obtidos de microporosidade, foram, respectivamente para as ferramentas na grade 4: $\mathrm{A}(30,4$ e $36,0 \%), \mathrm{B}(31,9$ e $40,8 \%), C(30,2$ e $33,9 \%), D(31,2$ e $35,2 \%)$ e $E(30,4$ e $37,3 \%)$. Os pontos onde os 
valores de microporosidade foram mais elevados, obtidos com as ferramentas B, coordenadas $(50 ; 50),(70 ; 10)$ e E, coordenadas $(90 ; 90)$, coincidem com os pontos que apresentaram os valores elevados de umidade gravimétrica (Figura 8d).

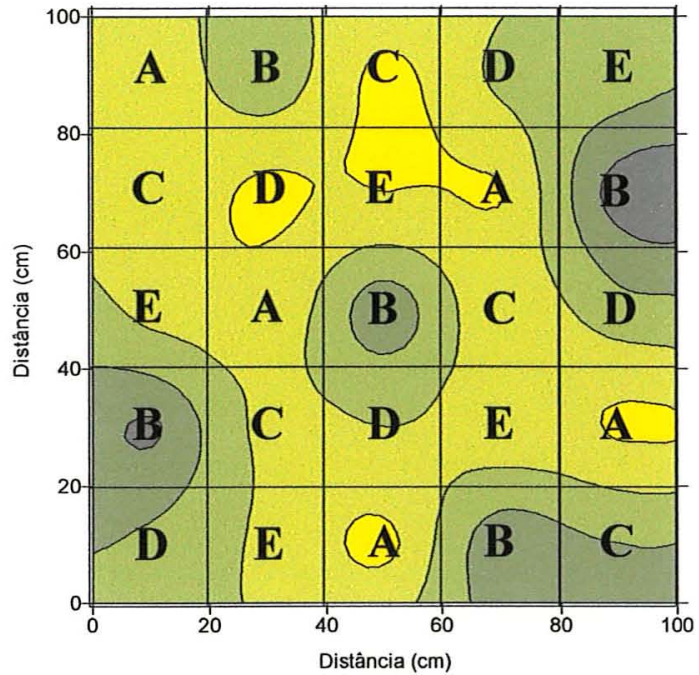

a) Mi (\%) - grade amostragem 1

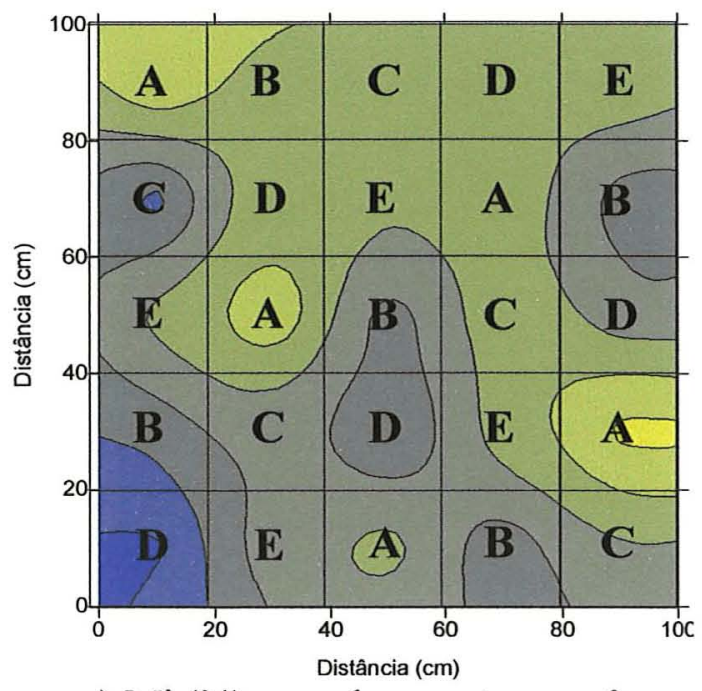

c) Mi (\%) - grade amostragem 3

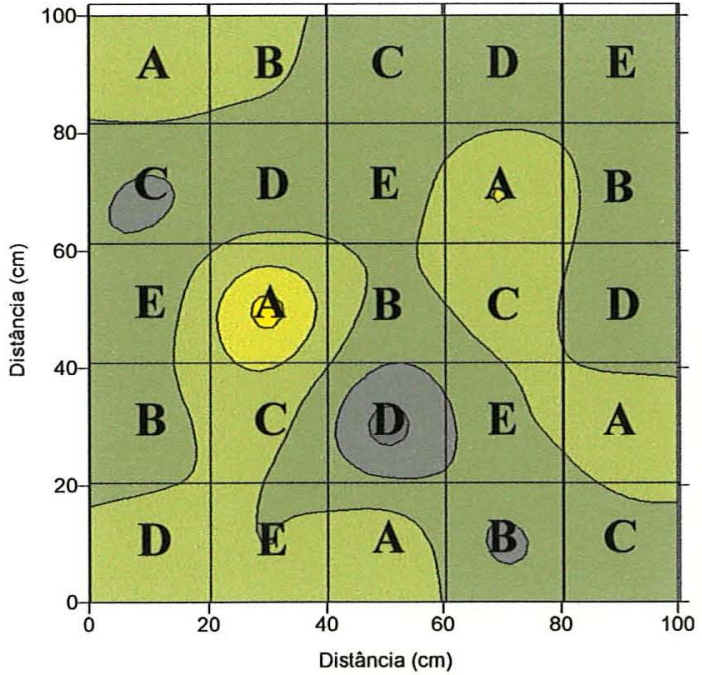

b) Mi (\%) - grade amostragem 2

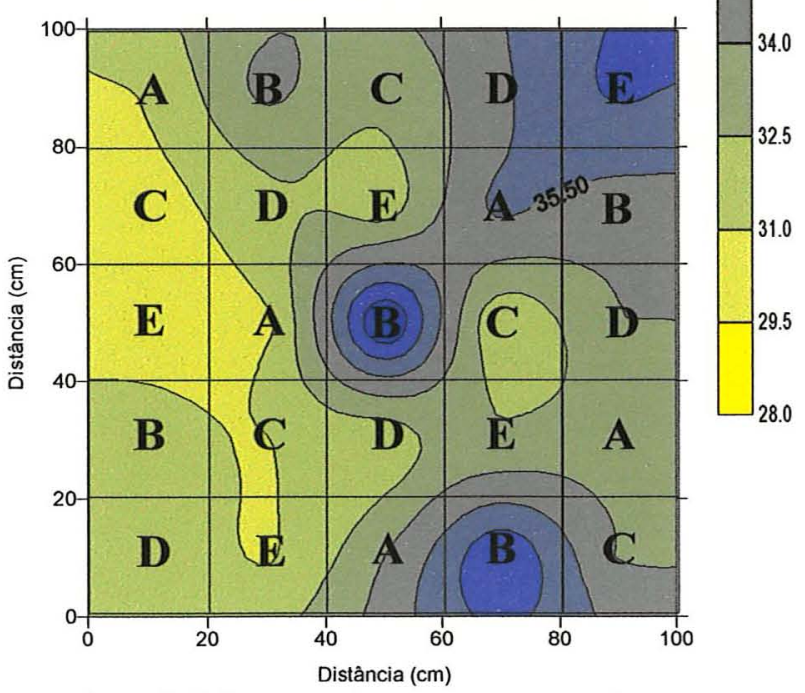

d) Mi (\%) - grade amostragem 4

Figura 33- Mapas de contorno das quatro grades de amostragem, com a distribuição espacial da microporosidade do solo argiloso na fazenda Areão: a) grade 1, b) grade 2, c) grade 3 e d) grade 4 .

As médias da microporosidade, obtidas pelas 20 amostras coletadas com cada ferramenta, nas quatro grades amostradas, foram: $\mathrm{A}(30,7 \%), \mathrm{B}(34,2 \%), \mathrm{C}(31,9 \%)$, 
$\mathrm{D}(32,8 \%), \mathrm{E}(31,9 \%)$, e a geral $(32,3 \%)$, obtida pelas 100 amostras coletadas no solo argiloso, estão representadas na Figura 34.

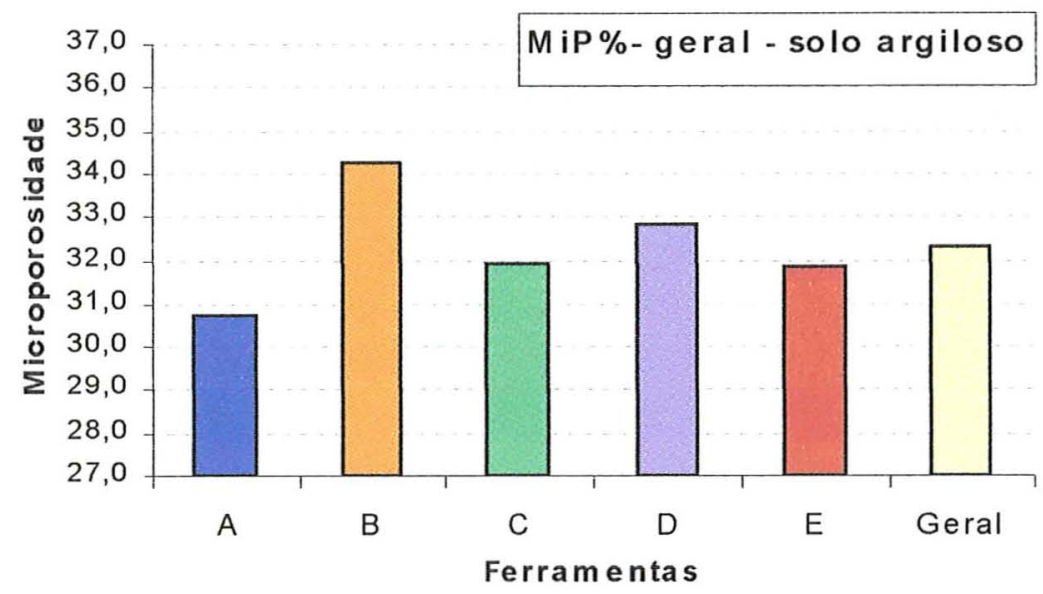

Figura 34- Médias da microporosidade do solo, determinadas com as ferramentas A, B, $\mathrm{C}, \mathrm{D}, \mathrm{E}$, e a geral, nas quatro grades amostradas no solo argiloso da fazenda Areão.

Na Figura 33 (a, c e d), visualizamos, os pontos onde a ferramenta B- anel de Kopecky, obteve altos valores de microporosidade, que coincidem com os de alta densidade do solo Ds $\left(\mathrm{g} . \mathrm{cm}^{-3}\right)$, na Figura 12 (a, c e d), e os de baixa porosidade total (Pt\%) na Figura 21 (a, c e d), e macroporosidades (Ma\%) na Figura 29 (a, c e d), fato que caracteriza estar ocorrendo compactação do solo nas amostras coletadas com este equipamento. Verificamos também, que com a ferramenta A- trado Uhland, ocorreu o contrário, os baixos valores de microporosidades e densidades do solo, e os altos valores de macroporosidades, demonstram a presença de espaços vazios no interior das amostras, fato detectado pela diferença dos pesos das amostras secas nos anéis coletados com este equipamento.

\subsubsection{Amostras coletadas no solo arenoso da Fazenda Sertãozinho}

Os valores médios da microporosidade, com os respectivos coeficientes de variação, obtidos para cada ferramenta nas grades de amostragem, junto com os testes de significância $\mathrm{F}$, diferença mínima significativa de Tukey a $5 \%$ e $1 \%$, e o coeficiente de variação entre as ferramentas, são apresentados na Tabela 18. 
A análise estatística, entre as médias de microporosidade, obtidas com as ferramentas, no solo arenoso, apresentou diferenças significativas a (1\%) nas grades de amostragem 1 e 4 . As grades 2 e 3 não apresentaram diferenças significativas.

Tabela 18- Microporosidades do solo (\%), obtidas com as amostras coletadas pelas diferentes ferramentas no solo arenoso da fazenda Sertãozinho, à profundidade média de $20 \mathrm{~cm}$. Valores médios de 5 repetições.

\begin{tabular}{lcccccccc} 
& \multicolumn{3}{c}{ Grade 1 } & \multicolumn{2}{c}{ Grade 2 } & \multicolumn{2}{c}{ Grade 3 } & \multicolumn{2}{c}{ Grade 4 } \\
\hline \multicolumn{1}{c}{ Ferramenta } & Mi $(\%)$ & CV & Mi (\%) & CV & Mi (\%) & CV & Mi (\%) & CV \\
\hline A-Trado Uhland & $22,0 \mathrm{~b}$ & 3,2 & $21,8 \mathrm{a}$ & 6,6 & $21,7 \mathrm{a}$ & 8,5 & $19,8 \mathrm{c}$ & 3,2 \\
B-Anel Kopecky & $23,5 \mathrm{a}$ & 6,0 & $22,9 \mathrm{a}$ & 4,4 & $22,7 \mathrm{a}$ & 7,7 & $23,5 \mathrm{a}$ & 5,2 \\
C-Trado Soil Moisture & $21,2 \mathrm{~b}$ & 1,5 & $21,5 \mathrm{a}$ & 3,5 & $22,0 \mathrm{a}$ & 5,5 & $20,6 \mathrm{bc}$ & 5,7 \\
D-Trado Bravifer AI-50 & $21,4 \mathrm{~b}$ & 4,2 & $21,8 \mathrm{a}$ & 4,0 & $22,6 \mathrm{a}$ & 10,1 & $22,5 \mathrm{ab}$ & 8,1 \\
E-Trado Bravifer AI-100 & $21,1 \mathrm{~b}$ & 2,2 & $21,9 \mathrm{a}$ & 3,1 & $22,1 \mathrm{a}$ & 6,1 & $20,9 \mathrm{bc}$ & 4,3 \\
\hline \multicolumn{1}{c}{ F } & $10,042 * *$ & 1,122 & n.s. & 0,423 n.s. & $10,490 * *$ \\
Dms (5\%) & 1,41 & 2,16 & 2,89 & 2,12 \\
Dms (1\%) & 1,82 & 2,79 & & 3,74 & 2,74 \\
CV(\%) & 4,53 & 2,30 & & 1,88 & 7,08 \\
\hline
\end{tabular}

Médias seguidas de mesma letra e na mesma coluna, não diferem entre si (Tukey a 5\%).

$\mathrm{Na}$ Figura 35, podemos visualizar que os pontos que apresentaram os maiores e menores valores de microporosidade, coincidem com os de maiores e menores valores de umidade gravimétrica, encontrados na Figura 10.

$\mathrm{Na}$ Figura $35 \mathrm{a}$, os valores mínimos e máximos obtidos de microporosidade, foram, respectivamente para as ferramentas na grade 1: $\mathrm{A}(28,9$ e $30,0 \%), \mathrm{B}(32,4$ e $35,0 \%), \mathrm{C}(28,9$ e $32,5 \%), \mathrm{D}(29,0$ e $32,1 \%)$ e $\mathrm{E}(29,5$ e $31,3 \%)$. Nesta grade a ferramenta B obteve, nos pontos de coordenadas $(10 ; 30),(30 ; 90),(50 ; 50)$ e $(90 ; 70)$, os maiores valores de microporosidade.

$\mathrm{Na}$ Figura 35b, os valores mínimos e máximos obtidos de microporosidade, foram, respectivamente para as ferramentas na grade 2: $\mathrm{A}(27,6$ e $30,6 \%), \mathrm{B}(31,1$ e $33,4 \%), C(30,7$ e $33,4 \%), D(30,9$ e $35,4 \%)$ e $E(31,5$ e $32,4 \%)$. Nesta grade, o maior valor de microporosidade foi obtido com a ferramenta $B$ na coordenada $(50 ; 50)$, e o menor valor, foi obtido com a ferramenta $\mathrm{C}$ na coordenada $(90 ; 10)$. 
Na Figura 35c, os valores mínimos e máximos obtidos de microporosidade, foram, respectivamente para as ferramentas na grade 3: $\mathrm{A}(29,7$ e $32,5 \%), \mathrm{B}(32,2$ e $35,5 \%), C(31,9$ e $36,5 \%), D(32,0$ e $37,7 \%)$ e $\mathrm{E}(31,8$ e $33,5 \%)$. Nesta grade, o maior valor de microporosidade foi determinado com a ferramenta $\mathrm{D}$, coordenadas $(10 ; 10)$, e o menor valor, determinado com a ferramenta $\mathrm{A}$, coordenadas $(30 ; 50)$.

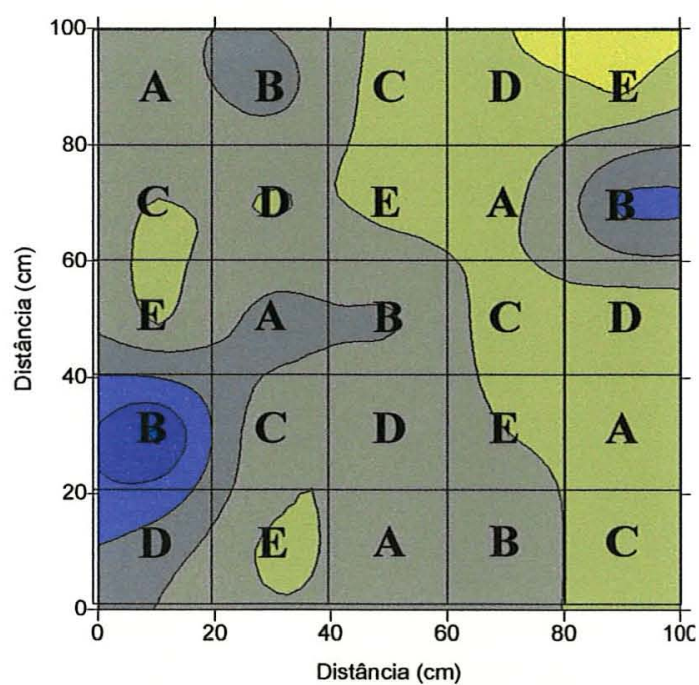

a) $\mathrm{Mi}(\%)$ - grade amostragem 1

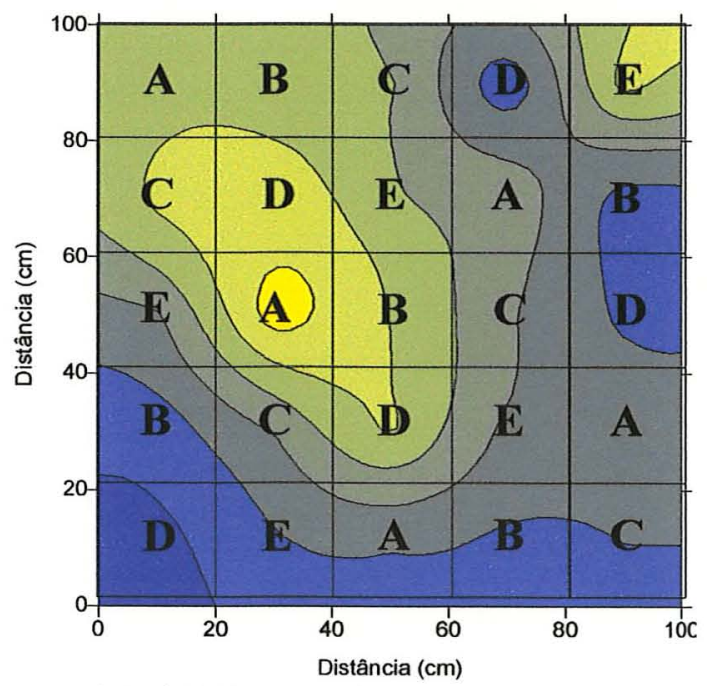

c) Mi (\%) - grade amostragem 3

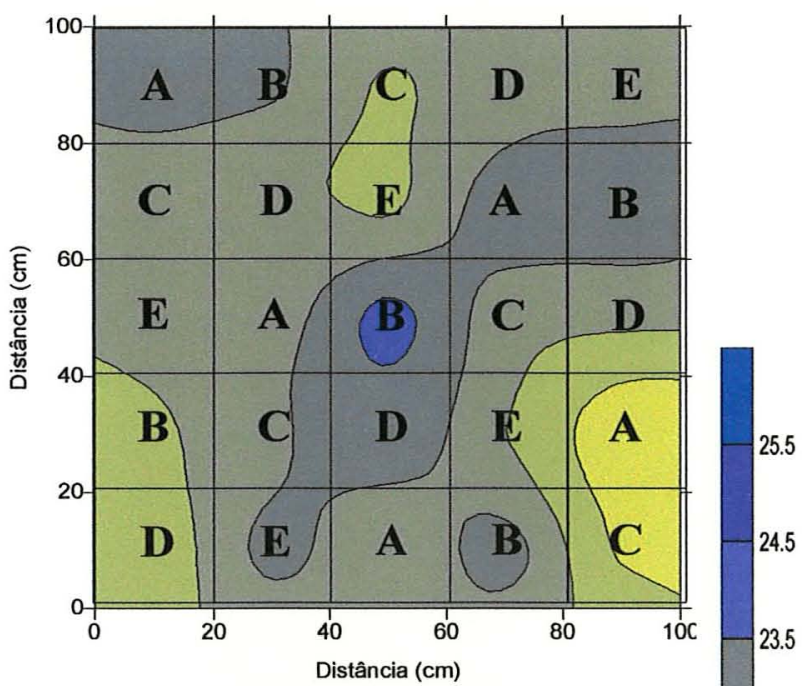

b) Mi (\%) - grade amostragem 2

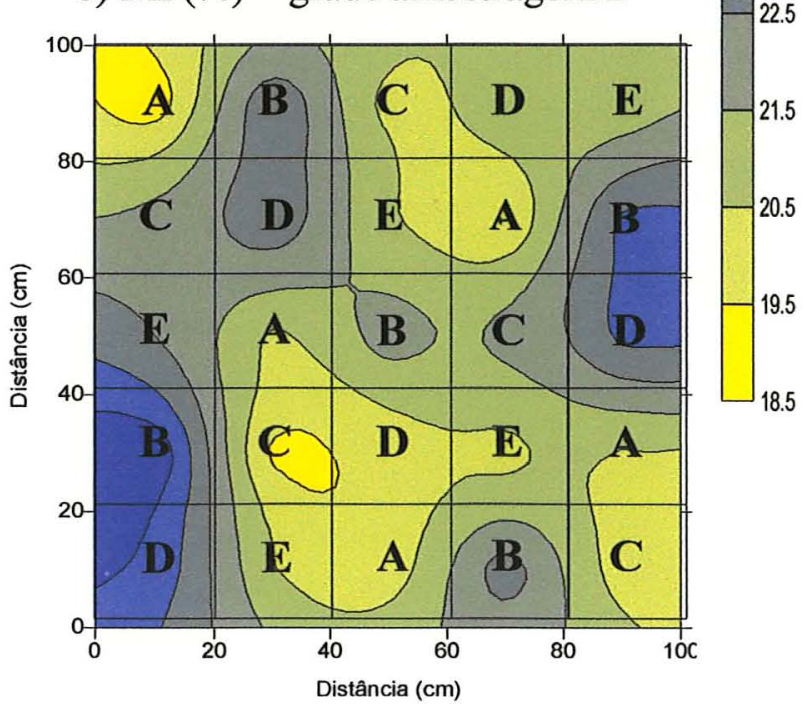

d) Mi (\%) - grade amostragem 4

Figura 35- Mapas de contorno das quatro grades de amostragem, com a distribuição espacial da microporosidade do solo arenoso na fazenda Sertãozinho: a) grade 1, b) grade 2, c) grade 3 e d) grade 4. 
Na Figura 35d, os valores mínimos e máximos obtidos de microporosidade, foram, respectivamente para as ferramentas na grade 4: $\mathrm{A}(30,4$ e 36,0\%), $\mathrm{B}(31,9$ e $40,8 \%), C(30,2$ e $33,9 \%), D(31,2$ e $35,2 \%)$ e $E(30,4$ e $37,3 \%)$. Nesta grade, a ferramenta B obteve o maior valor de microporosidade nas coordenadas $(10 ; 30)$, e o menor valor foi determinado com a ferramenta $\mathrm{C}$, coordenadas $(30 ; 30)$.

As médias da microporosidade, obtidas pelas 20 amostras coletadas com cada ferramenta, nas quatro grades amostradas, foram: $\mathrm{A}(21,3 \%), \mathrm{B}(23,1 \%), \mathrm{C}(21,3 \%)$, $\mathrm{D}(22,1 \%), \mathrm{E}(21,5 \%)$, e a geral $(21,9 \%)$, obtida pelas 100 amostras coletadas no solo arenoso, estão representadas na Figura 36.

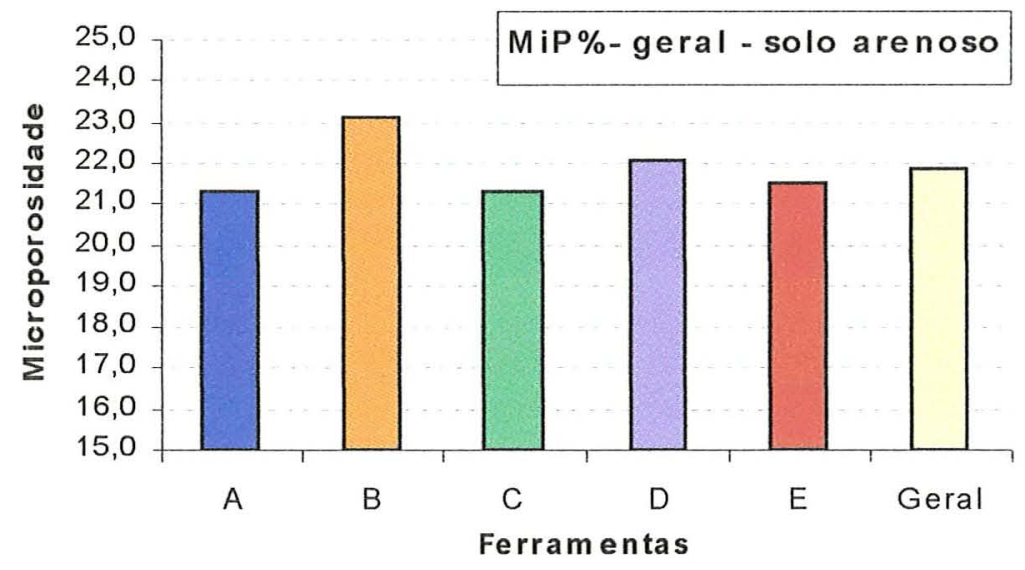

Figura 36- Médias da microporosidade do solo, determinadas com as ferramentas A, B, $\mathrm{C}, \mathrm{D}, \mathrm{E}$, e a geral, nas quatro grades amostradas no solo arenoso da fazenda Sertãozinho.

\subsection{Energia consumida na operação de coleta de amostras.}

A amostragem, por ser uma operação que exige muita precisão, torna-se cansativa, diminuindo a atenção do operador, influenciando na qualidade das amostras que são enviadas aos laboratórios, para determinação das propriedades do solo.

As ferramentas foram avaliadas apenas pela energia consumida para a operação de coleta [eq. (1)], não sendo avaliados, os desgastes físicos provocados no operador, pelo transporte dos equipamentos de uma grade a outra no decorrer da amostragem. 
A energia consumida para a realização da retirada das amostras com cada ferramenta utilizada neste trabalho, foi determinada pela média obtida de vinte operações em cada tipo de solo, e o resultado encontrado para os dois solos, pode ser visualizado na Figura 37.

$\mathrm{O}$ consumo de energia da ferramenta $\mathrm{A}$, foi bem maior que as outras nos dois tipos de solo estudados, no solo argiloso a sua média de consumo de energia (1080J) foi 7,5 vezes maior que a média das outras ferramentas $(143,5 \mathrm{~J})$, e para o solo arenoso, seu consumo (970J), foi 12,4 vezes maior que a média consumida nas outras ferramentas $(78,2 \mathrm{~J})$.

Os consumos médios de energia de cada ferramenta, foram para os solos argilosos: A (1080 J), B (38 J), C (239 J), D (117 J), E (180 J) e para os solos arenosos: A (970 J), B (36 J), C (210 J), D (64 J) e E (113 J).

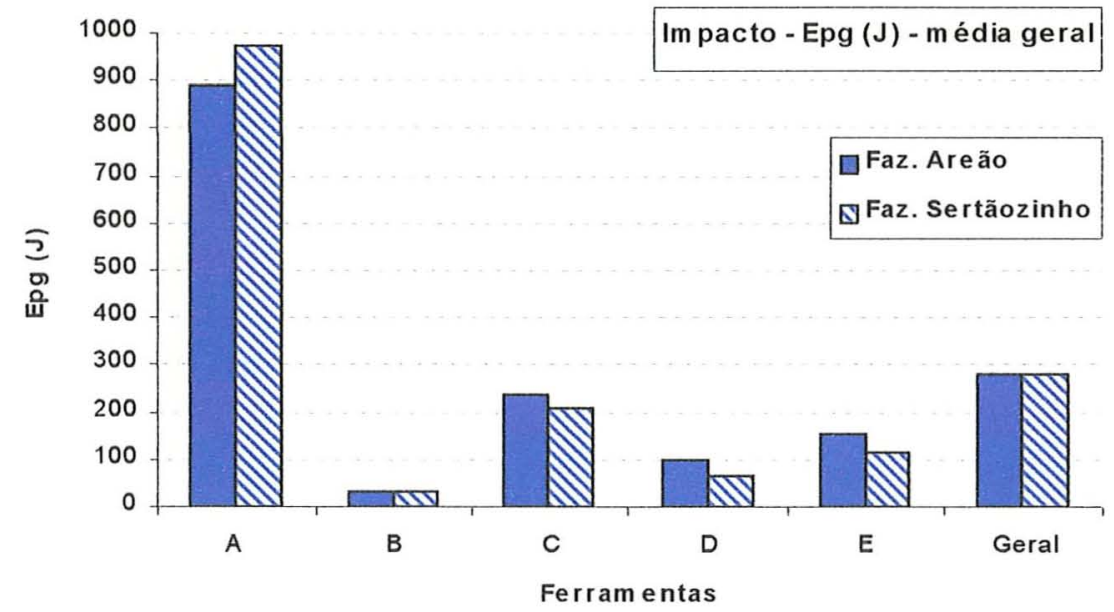

Figura 37- Médias da energia potencial gravitacional consumida na operação de coleta de amostras, com as ferramentas, no solo argiloso da fazenda Areão e no solo arenoso da fazenda Sertãozinho, num total de 20 amostras para cada ferramenta.

\subsubsection{Solos argilosos amostrados na fazenda Areão}

Os valores médios da energia consumida e os respectivos coeficientes de variação encontrados para cada ferramenta, podem ser visualizados na Tabela 19. 
Tabela 19- Energia potencial gravitacional consumida pelas ferramentas, para coletar as amostras, em cada grade de amostragem no solo argiloso da fazenda Areão, à profundidade média de $20 \mathrm{~cm}$. Valores médios de 5 repetições.

\begin{tabular}{lrrrrrrrr} 
& \multicolumn{1}{c}{ Grade 1 } & \multicolumn{2}{c}{ Grade 2 } & \multicolumn{3}{c}{ Grade 3 } & \multicolumn{3}{c}{ Grade 4 } \\
\hline Ferramentas & \multicolumn{1}{c}{ Ep $(\mathrm{J})$} & CV & Ep $(\mathrm{J})$ & CV & Ep (J) & CV & Ep (J) & CV \\
\hline A-Trado Uhland & 882 & 20,5 & $\mathbf{8 8 2}$ & 9,5 & 728 & 23,6 & 1830 & 14,0 \\
B-Anel Kopecky & 46 & 14,8 & 41 & 10,7 & 31 & 7,7 & 36 & 15,4 \\
C-Trado Soil Moisture & 274 & 22,9 & 137 & 11,0 & 202 & 16,4 & 347 & 17,6 \\
D-Trado Bravifer AI-50 & 92 & 20,2 & 106 & 11,8 & 78 & 14,7 & 191 & 18,7 \\
E-Trado Bravifer AI-100 & 219 & 26,2 & 127 & 15,7 & 113 & 15,3 & 254 & 12,4 \\
\hline
\end{tabular}

Os valores mínimos e máximos de energia potencial gravitácional, obtidos com cada ferramenta no solo argiloso, foram, respectivamente, grade 1: A(750 e 1191J), $\mathrm{B}(36$ e $51 \mathrm{~J}), \mathrm{C}(234$ e $387 \mathrm{~J}), \mathrm{D}(64$ e $113 \mathrm{~J})$ e $\mathrm{E}(155$ e 296J); na grade 2: $\mathrm{A}(772$ e $992 \mathrm{~J})$, $B(36$ e 46J), $C(121$ e 153J), $D(92$ e 127J) e $E(106$ e 155J); na grade 3: $A(551$ e 926J), $B(25$ e $31 \mathrm{~J}), C(145$ e $234 \mathrm{~J}), \mathrm{D}(64$ e $92 \mathrm{~J})$ e $\mathrm{E}(99$ e $145 \mathrm{~J})$ e, na grade $4: \mathrm{A}(1477$ e $2161 \mathrm{~J})$, $B(31$ e $46 J), C(258$ e $427 J), D(155$ e $240 J)$ e $E(233$ e $310 J)$.

\subsubsection{Amostras coletadas no solo arenoso da Fazenda Sertãozinho}

Os valores médios da energia consumida e os respectivos coeficientes de variação encontrados para cada ferramenta, podem ser visualizados na Tabela 20.

Tabela 20- Energia potencial gravitacional consumida pelas ferramentas, para coletar as amostras em cada grade de amostragem no solo arenoso da fazenda Sertãozinho, à profundidade média de $20 \mathrm{~cm}$. Valores médios de 5 repetições.

\begin{tabular}{lrrrrrrrr} 
& \multicolumn{2}{c}{ Grade 1 } & \multicolumn{2}{c}{ Grade 2 } & \multicolumn{2}{c}{ Grade 3 } & \multicolumn{2}{c}{ Grade 4 } \\
\hline \multicolumn{1}{c}{ Ferramentas } & \multicolumn{1}{c}{ Ep $(\mathrm{J})$} & \multicolumn{1}{c}{ CV } & \multicolumn{1}{c}{ Ep (J) } & CV & \multicolumn{1}{c}{ Ep (J) } & CV & Ep (J) & CV \\
\hline A-Trado Uhland & 992 & 11,0 & 992 & 7,6 & 970 & 12,5 & 926 & 6,5 \\
B-Anel Kopecky & 36 & 11,6 & 36 & 15,4 & 36 & 10,1 & 31 & 17,8 \\
C-Trado Soil Moisture & 210 & 9,8 & 218 & 7,6 & 202 & 18,4 & 202 & 13,4 \\
D-Trado Bravifer AI-50 & 56 & 10,2 & 64 & 16,1 & 71 & 16,1 & 71 & 16,1 \\
E-Trado Bravifer AI-100 & 106 & 8,2 & 120 & 17,4 & 127 & 9,0 & 113 & 12,6 \\
\hline
\end{tabular}


Os valores mínimos e máximos de energia potencial gravitácional, obtidos com cada ferramenta no solo arenoso, foram, respectivamente, grade 1: A(860 e 1147J), $\mathrm{B}(31$ e $41 \mathrm{~J}), \mathrm{C}(177$ e $218 \mathrm{~J}), \mathrm{D}(49$ e $64 \mathrm{~J})$ e $\mathrm{E}(99$ e $120 \mathrm{~J})$; na grade 2: $\mathrm{A}(926$ e 1125J), $\mathrm{B}(31$ e $46 \mathrm{~J}), \mathrm{C}(193$ e $234 \mathrm{~J}), \mathrm{D}(56$ e $85 \mathrm{~J})$ e $\mathrm{E}(99$ e $148 \mathrm{~J})$; na grade 3: $\mathrm{A}(860$ e $1103 \mathrm{~J})$, $\mathrm{B}(31$ e $41 \mathrm{~J}), \mathrm{C}(161$ e $258 \mathrm{~J}), \mathrm{D}(64$ e $85 \mathrm{~J})$ e $\mathrm{E}(113$ e $141 \mathrm{~J})$ e, na grade $4: \mathrm{A}(860$ e $1014 \mathrm{~J})$, $\mathrm{B}(25$ e $41 \mathrm{~J}), \mathrm{C}(161$ e $234 \mathrm{~J}), \mathrm{D}(64$ e $92 \mathrm{~J})$ e $\mathrm{E}(99$ e $134 \mathrm{~J})$.

\subsection{Tempo de operação de coleta.}

O tempo gasto em segundos para a realização da retirada das amostras com cada ferramenta foi determinado pela média obtida de vinte operações em cada tipo de solo, e o resultado encontrado para os dois solos, pode ser visualizado na Figura 38.

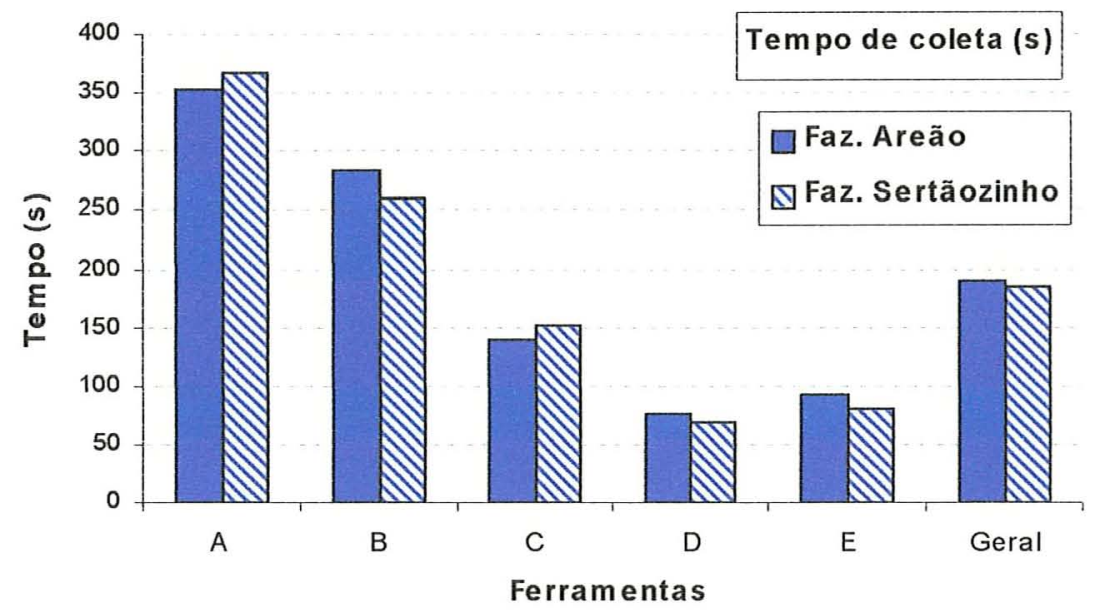

Figura 38- Médias do tempo de operação das coletas de amostras, obtidas com as ferramentas no solo argiloso da fazenda Areão e no solo arenoso da fazenda Sertãozinho, num total de 20 amostras para cada ferramenta em cada tipo de solo.

Os tempos consumidos na coleta das amostras com cada ferramenta, foram muito parecidos para os dois tipos de solos estudados, como o ocorrido com a energia consumida, demonstrando que o tipo de solo não influi nesses resultados.

$\mathrm{O}$ alto tempo cronometrado para a amostragem com a ferramenta A, é conseqüente, não só da dificuldade de penetração no solo (Figura 37), mas também por ser necessário a abertura de trincheiras para a sua retirada, bem como os cuidados 
exigidos na remoção do anel do interior do corpo da ferramenta, para evitar danos na amostra.

A ferramenta B, apesar de necessitar de pouca energia para sua introdução no solo (Figura 37), também exige abertura de trincheira para a sua retirada, e uma atenção ainda maior que a ferramenta anterior, pelo fato do anel estar diretamente em contato com o solo, sendo necessário a utilização de espátulas para retirar o solo em volta do anel, e cortar a terra uns $2 \mathrm{~cm}$ abaixo do mesmo, para não danificar a amostra, operação que consome bastante tempo e atenção.

A ferramenta $\mathrm{C}$, apresentou em alguns pontos dificuldades para soltar a rosca do corpo onde fica o anel, da base da ferramenta, além da atenção, na retirada da ferramenta do solo pela formação de sucção no orificio, que puxava a amostra de dentro do anel, aumentando assim, o tempo de operação.

As ferramentas D- trado Bravifer AI-50 e a E- Bravifer AI-100, foram as mais rápidas, consumindo pouco tempo e energia para a operação de coleta, exigindo apenas atenção quanto ao controle da profundidade.

\subsubsection{Solos argilosos amostrados na fazenda Areão}

Os tempos médios obtidos e os respectivos coeficientes de variação para as ferramentas em cada grade de amostragem, podem ser visualizados na Tabela 21.

Tabela 21 - Tempos médios consumidos pelas ferramentas, para coletar as amostras em cada grade de amostragem no solo argiloso da fazenda Areão à profundidade média de $20 \mathrm{~cm}$. Valores médios de 5 repetições.

\begin{tabular}{lrrrrrrrr} 
& \multicolumn{2}{c}{ Grade 1 } & \multicolumn{2}{c}{ Grade 2 } & \multicolumn{2}{c}{ Grade 3 } & \multicolumn{2}{c}{ Grade 4 } \\
\hline \multicolumn{1}{c}{ Ferramenta } & \multicolumn{1}{c}{ T $(\mathrm{s})$} & \multicolumn{1}{c}{ CV } & \multicolumn{1}{c}{ T (s) } & CV & \multicolumn{1}{c}{ T (s) } & CV & T(s) & CV \\
\hline A-Trado Uhland & 232 & 11,1 & 273 & 9,0 & 426 & 18,3 & 482 & 27,0 \\
B-Anel Kopecky & 243 & 7,2 & 212 & 23,1 & 290 & 10,3 & 394 & 16,6 \\
C-Trado Soil Moisture & 189 & 15,8 & 71 & 15,6 & 117 & 30,9 & 181 & 8,5 \\
D-Trado Bravifer AI-50 & 88 & 16,5 & 66 & 17,3 & 50 & 10,3 & 101 & 18,1 \\
E-Trado Bravifer AI-100 & 120 & 20,2 & 65 & 5,7 & 56 & 19,8 & 128 & 8,0 \\
\hline
\end{tabular}


Os tempos em segundos (s), mínimos e máximos, consumidos com cada ferramenta no solo argiloso, foram, respectivamente, grade 1: A(200 e 270 s), B(220 e 260 s), C(137 e 214 s), D(70 e 108 s) e E(85 e 150 s); na grade 2: A(245 e 310 s), B(131 e $260 \mathrm{~s}), \mathrm{C}(59$ e $84 \mathrm{~s}), \mathrm{D}(55$ e $85 \mathrm{~s})$ e $\mathrm{E}(60$ e $80 \mathrm{~s})$; na grade 3 : $\mathrm{A}(310$ e $517 \mathrm{~s}), \mathrm{B}(255$ e 330 s), C(86 e 178 s), D(44 e 58 s) e E(43 e 70 s) e, na grade 4: A(267 e 608 s), B(320 e $480 \mathrm{~s}), \mathrm{C}(156$ e $195 \mathrm{~s}), \mathrm{D}(84$ e $130 \mathrm{~s})$ e E(117 e $142 \mathrm{~s})$.

\subsubsection{Amostras coletadas no solo arenoso da Fazenda Sertãozinho}

Os tempos médios e o coeficiente de variação obtidos para cada ferramenta, podem ser visualizados na Tabela 22.

Tabela 22- Tempos médios consumidos pelas ferramentas, para coletar as amostras em cada grade de amostragem no solo arenoso da fazenda Sertãozinho à profundidade média de $20 \mathrm{~cm}$. Valores médios de 5 repetições.

\begin{tabular}{lrrrrrrrr} 
& \multicolumn{2}{c}{ Grade 1 } & \multicolumn{2}{c}{ Grade 2 } & \multicolumn{2}{c}{ Grade 3 } & \multicolumn{2}{c}{ Grade 4 } \\
\hline \multicolumn{1}{c}{ Ferramentas } & \multicolumn{1}{c}{ T (s) } & \multicolumn{1}{c}{ CV } & \multicolumn{1}{c}{ T (s) } & \multicolumn{1}{c}{ CV } & \multicolumn{1}{c}{ T (s) } & \multicolumn{1}{c}{ CV } & \multicolumn{1}{c}{ T (s) } & CV \\
\hline A-Trado Uhland & 320 & 16,8 & 339 & 9,0 & 434 & 10,0 & 369 & 10,3 \\
B-Anel Kopecky & 267 & \multicolumn{1}{c}{4,3} & 220 & 3,4 & 289 & 2,9 & 263 & 3,9 \\
C-Trado Soil Moisture & 169 & 12,7 & 139 & 10,3 & 146 & 8,9 & 152 & 7,6 \\
D-Trado Bravifer AI-50 & 66 & 3,1 & 68 & 10,8 & 69 & 10,1 & 69 & 7,6 \\
E-Trado Bravifer AI-100 & 78 & 6,1 & 78 & 3,1 & 79 & 13,8 & 84 & 27,5 \\
\hline
\end{tabular}

Os tempos em segundos (s), mínimos e máximos, consumidos com cada ferramenta no solo arenoso, foram, respectivamente, grade 1: A(265 e $405 \mathrm{~s}), \mathrm{B}(253 \mathrm{e}$ 279 s), C(144 e 196 s), D(63 e 68 s) e E(73 e 85 s); na grade 2: A(315 e 390 s), B(210 e 227 s), C(125 e 155 s), D(62 e 80 s) e E(75 e 81 s); na grade 3: A(382 e 485 s), B(278 e 298 s), C(137 e 169 s), D(63 e 81 s) e E(67 e 93 s) e, na grade 4: A(325 e 425 s), B(250 e $275 \mathrm{~s}), \mathrm{C}(135$ e $165 \mathrm{~s}), \mathrm{D}(63$ e $75 \mathrm{~s})$ e $\mathrm{E}(73$ e $125 \mathrm{~s})$. 


\subsection{Avaliação das técnicas utilizadas.}

A experiência da utilização desses métodos de amostragem, permitiram uma comparação na eficiência das diversas ferramentas.

\subsubsection{A- trado de Uhland.}

Dentre as ferramentas utilizadas neste trabalho, foi a que apresentou maior dificuldade de operação, consumindo bastante energia para sua penetração no solo, cuidados com a profundidade para não compactar a amostra dentro do equipamento $\mathrm{e}$ abertura de trincheiras para a sua retirada do solo. Por exigir um numero muito grande de impactos com a massa de $4,5 \mathrm{~kg}$, provocou deformidades nas bordas do corpo da ferramenta, apresentando dificuldades para colocação, e, principalmente, para a retirada dos cilindros, que se prendiam fazendo com que a terra saísse de dentro deles. Também apresentou dificuldades no manuseio das amostras, que devido aos fortes impactos, apresentavam fissuras e esboroamento. Outro fator importante, é a limitação de profundidade, pois a haste onde corre o peso, permite coletar amostras apenas até $40 \mathrm{~cm}$ de profundidade sem a abertura de trincheiras para a sua colocação no solo. Esta ferramenta não é adequada para coleta de amostras no sentido horizontal, no interior de trincheiras, para determinação de condutividade hidráulica para fins de drenagem.

\subsubsection{B- anel de Kopecky}

Esse método é o mais utilizado, por ser o de menor custo, pois só exige a compra dos anéis, um martelo, e a construção de um castelo de madeira para não bater diretamente na borda do anel. Tem como desvantagem a dificuldade de colocação e, principalmente, de retirada das amostras no sentido vertical, quando da coleta em profundidades maiores que $20 \mathrm{~cm}$, exigindo abertura de trincheiras.

É uma ferramenta bastante prática para coleta de amostras em trincheiras, no sentido horizontal, pois necessita de pouco espaço para sua operação.

Os resultados das análises físicas deste trabalho, demonstraram que este método provoca a compactação da amostra dentro do anel, superestimando os valores da densidade do solo e microporosidade, e subestimando a porosidade total e a 
macroporosidade do solo. Os resultados obtidos com esta ferramenta, que é a mais utilizada no Brasil, preocupam, pelo fato dessas propriedades serem utilizadas no cálculo do volume de água disponível do solo, empregado no manejo e controle do consumo de água nas áreas irrigadas.

\subsubsection{C- trado modelo Soil Moisture}

É uma ferramenta leve e exige pouca energia para penetrar no solo, possui um limitador de profundidade, que elimina a preocupação com a compactação da amostra por excesso de terra. Apresentou alguns problemas pelo fato do corpo que envolve o cilindro, ser rosqueado na base da ferramenta, onde a presença de terra provoca o travamento da rosca, dificultando a retirada do cilindro. O sistema de martelo, no decorrer do serviço também provoca alguma perda de tempo. Esta ferramenta apresenta também a limitação de profundidade de coleta, pois seu cabo possuí apenas $35 \mathrm{~cm}$, o que exige abertura de trincheiras para coletar amostras em maiores profundidades. Esta ferramenta é adequada para coletar amostras no sentido horizontal, desde que se utilize um martelo comum em substituição ao peso utilizado normalmente para introduzi-lo no solo.

\subsubsection{D- trado Bravifer AI-50.}

Das ferramentas utilizadas foi a que exigiu menor esforço na amostragem. É uma ferramenta leve, que exige pouca energia para penetrar no solo e possuí um sistema rápido e preciso para a retirada do anel do interior da ferramenta. Permite coletar amostras até $1 \mathrm{~m}$ de profundidade, porém, pela facilidade de enterrar no solo, e não possuir um limitador de profundidade, exige atenção para não compactar as amostras por excesso de terra no interior da ferramenta. O cabo dividido em hastes com roscas, permite que se acople um sistema de batedor, para a utilização de martelo de borracha ou madeira, na operação de coleta das amostras, tanto no sentido vertical quanto no sentido horizontal, quando no interior de trincheiras. 


\subsubsection{E- trado Bravifer AI-100.}

A diferença entre a ferramenta $E$, e a ferramenta $D$, está no tamanho do anel utilizado, que por ser maior exige mesmo em profundidades menores, atenção para não compactar as amostras no seu interior como ocorreu em algumas amostras coletadas no presente trabalho.

O fato de termos alterado o sistema de operação deste equipamento, utilizando uma massa de $1,6 \mathrm{~kg}$, caindo de uma altura de $40 \mathrm{~cm}$ no lugar da marreta de ferro e borracha, usado originalmente, pode ter dificultado o controle da profundidade de coleta, provocando a compactação da amostra na parte superior do amostrador. 


\section{CONCLUSÕES}

Com os resultados obtidos nas análises, podemos concluir que:

a) As técnicas de amostragem influem nas determinações das propriedades fisicohídricas: densidade do solo, umidade volumétrica, porosidade total, macroporosidade e microporosidade.

b) $\mathrm{O}$ efeito conjunto da umidade do solo no momento da coleta e o equipamento/tamanho do cilindro, interferem nos resultados das propriedades fisico-hídricas do solo, com maior intensidade nos solos argilosos.

c) As ferramentas que apresentaram menores tempos e energia consumida durante o processo de coleta de amostras, para os dois solos estudados, foram na seguinte ordem: trado Bravifer AI-50, trado Bravifer AI-100, trado Soil Moisture, anel de Kopecky e trado Uhland.

d) As ferramentas que afetaram menos a estrutura do solo no interior do cilindro e que consumiram menos tempo e energia na operação de coleta, foram o trado Bravifer AI-50, Trado Bravifer AI-100 e trado Soil Moisture.

e) A ferramenta anel de Kopecky, superestimou as propriedades: densidade do solo, umidade volumétrica e microporosidade, e subestimou as propriedades: porosidade total calculada, porosidade total determinada e a macroporosidade do solo, caracterizando estar compactando a amostra no interior do cilindro. 


\section{REFERÊNCIAS BIBLIOGRÁFICAS}

ANDREWS, C.A.; BROADFOOT, W.M. The San Dimas Soil Core Sampler. Soil Science, v.85, n.6, p.297-301, 1958.

ARRUDA, F.B.; ZULLO JR, J.; OLIVEIRA J.B. de Parâmetros de solo para o cálculo da água disponível com base na textura do solo. Revista Brasileira de Ciência de Solo, v.11, p.11-15, 1987.

BABALOLA, O. Spatial variability of soil water properties in tropical soils of Nigeria. Soil Science, Baltimore, v.126, n.5, p.269-279, 1978.

BELTRAME. L.F.C.; GONDIM, L.A.; TAYLOR. J.C. Estrutura e compactação na permeabilidade de solos do Rio Grande do Sul. Revista da Sociedade Brasileira de Ciência do Solo,v.5, p.145-149, 1981.

BERG, M. van der; KLAMT, E. Variabilidade espacial de características de solos na região do planalto médio, RS: I. Análise da variância por amostragem aninhada. Viçosa, Revista Brasileira de Ciência de Solo, v.21, p.393-399, 1997.

BERNER, P.G.M.; VIEIRA, S.R.; LIMA, E.; ANJOS, L.H.C. Variabilidade espacial das propriedades fisicas e químicas de um cambissolo sob sistemas de manejo de cana-de-açúcar. In: CONGRESSO BRASILEIRO DE CIÊNCIA DO SOLO, 25: Viçosa, 1995. Resumos expandidos. Viçosa: SBCS/UFV, 1995. v.1, p.147-149. 
BLAKE, G. R. Bulk density. In: Black, C. A (Ed.). Methods of Soil analysis. Part I... Madison. ASA, 1965. p. $383-390$

BLAKE, G. R.; HARTGE, K.H. Bulk density, 363-375. In Methods of Soil Analysis.- I- Physical and Mineralogical Methods, 2.Ed., n.9. Madison, ASA, 1986, $1188 \mathrm{p}$.

BLAKE, G.R.; HARTGE, K. H. Particle Density,- In Methods of Soil Analysis - IPhysical and Mineralogical Methods; 2Ed., n.9. Madison, ASA, 1986, 1188 p.

BUCKMAN, H.O.; BRADY, N.C. Natureza e propriedades dos solos. Rio de Janeiro: Freitas Barros S.A., 1966, 594 p.

BURGESS, T.M.; WEBSTER, R. Optimal interpolation and isarithmic mapping of soil properties. I. the semivariogram and punctual kriging. Journal of Soil Science, v.31, p.315-331, 1980.

CONSTANTINI, A. Soil Sampling Bulk Density in The Coastal Lowlands of SouthEast Queensland. Australian Journal of Soil Research, v.33,11-18, 1993.

DEMOLON, A. Principles D'Agronomie , 5.ed.Tome 1 - Dynamique du Sol, Paris: Dunod, $1952,522 \mathrm{p}$.

DIAS JUNIOR, M. de S.; PIERCE, F.J. O processo de compactação do solo e sua modelagem. Revista Brasileira de Ciência do Solo, v.20, p.175-182, 1996.

FERNANDES, B.; GALLOWAY, H.M.; BRONSON, R.D.; MANNERING, J.V. Efeito de três sistemas de preparo do solo na densidade aparente, na porosidade total e na distribuição dos poros, em dois solos (Typic Argiaquoll e Typic Hapludalf). Revista Brasileira de Ciência do Solo, v.7: p.329-333, 1983. 
FIETZ, C.R. Variabilidade espacial do armazenamento de água no solo, visando o manejo de irrigação por aspersão. Piracicaba, 1998. 97p. Tese (Doutorado) - Escola Superior de Agricultura "Luiz de Queiroz", Universidade de São Paulo.

FOALE, M.A.; UPCHURCH, D.R. Soil coring method for sites with restricted acess. Agronomy Journal, v.74: p.761-763, 1982.

FOLEGATTI, M.V. Estabilidade temporal e variabilidade espacial da umidade e do armazenamento de água em solo siltoso. Piracicaba, 1996. 84p. Tese (Livre Docência) - Escola Superior de Agricultura "Luiz de Queiroz", Universidade de São Paulo.

FOX, W.E.; PAGE-HANIFY, D.S. A method of determining bulk density of soil. Soil Science, v.88, n.3: p.168-171, 1959.

FREIRE, J.C.; SCARDUA, R. Curvas características de retenção de água de um latossolo roxo distrófico do município de Lavras, Minas Gerais. Revista Brasileira de Ciência do Solo, v.2: p.95-98, 1978.

GINN, L.H.; HEATHERLY, L.G.; RUSSELL, W.J. Assembly for mounting hydraulic soil core sampler on tractor front. Agronomy Journal, v.70, p.512-514, 1978.

GOMES, A.S.; PATELlA, J.P.; PAULlETTO, E.A. Efeitos de sistemas e tempo de cultivo sobre a estrutura de um solo podzólico vermelho amarelo. Revista Brasileira de Ciência de Solo, v.2, p.17-21, 1978.

GONÇALVES, A.C.A. Variabilidade espacial de propriedades físicas do solo para fins de manejo da irrigação. Piracicaba, 1997. 118p. Tese (Doutorado) - Escola Superior de Agricultura "Luiz de Queiroz", Universidade de São Paulo. 
JACKSON, D. A. Description of a manually operated soil core sampler. In: Soil Science Plant Anal, v.18, n.7, p.781-787, 1987.

JAMISON, V.C.; WEAVER, H.H.; REED, I.F. A hammer-driving soil core sampler. Soil Science, v.69: p.487-496, 1950.

KIEHL, E.J. Manual de Edafologia - Relações solo-plantas, São Paulo: Agronômica Ceres, 1979, $262 \mathrm{p}$.

KLEIN, V.A. Propriedades físico-hídrico-mecânicas de um latossolo roxo, sob diferentes sistemas de uso e manejo. Piracicaba, 1998. 150p. Tese (Doutorado) Escola Superior de Agricultura "Luiz de Queiroz", Universidade de São Paulo.

LEITE, G.R.; BROWN, I.F.; AMARAL, E.F. Estudo do impacto do uso da terra sobre as propriedades físicas dos solos em diferentes ecossistemas no Acre. In: CONGRESSO BRASILEIRO DE CIÊNCIA DO SOLO, 25: Viçosa- MG, 1995. Resumos Expandidos. Viçosa: SBCS/ UFV, 1995, v.1, p.165-167

LI, D.; LAKE, L.W. A moving window semivariance estimator. Water Resources Research. Washington, v.30, n.5, p. 1479-89, 1994.

LIBARDI, P.L.; MANFRON, P.A.; MORAES, S.O.; TUON, R.L. Variabilidade espacial e temporal da umidade de um solo hidromórfico. Revista Brasileira de Ciência do Solo, v.20, p.1-12, 1996.

LUTZ, J.F. Apparatus for collecting undisturbed soil samples. Soil Science, v.64, p.399-401. 1947. 
MACEDO, J.R.; OTONNI FILHO, T.B.; MENEGUELLI, N.A. Estudo de variabilidade espacial das características físicas, químicas e físico-hídricas em solo podzólico vermelho-amarelo de Seropédica/RJ. In: CONGRESSO BRASILEIRO DE CIÊNCIA DO SOLO, 25: Viçosa, 1995. Resumos expandidos. Viçosa: SBCS/UFV, 1995. v.1, p.162-164.

MACHADO, R.V. Variabilidade espacial dos atributos físico-hídricos em uma hidroseqüência de solos bem a muito mal drenados. Lavras, 1994. 88p. Dissertação (M.S.) - ESAL.

MEDINA, B.F.; OLIVEIRA JUNIOR, R.C. Relações entre capacidade de campo determinada in situ e em laboratório em latossolo amarelo muito argiloso. Revista Brasileira de Ciência do Solo, v.11, p.91-95, 1987.

MIELKE, L.N. Encasing undisturbed soil cores inplastic. Soil Science Society American Proceedings, v.37, p.325-326, 1973.

MIELKE L.N.; WILHELM, W.W. Mast anchore for Hydraulic soil-sampling machines. Soil Science Society American Journal, v.47, p.1263-1264, 1983.

MORAES, S.O. Heterogeneidade hidráulica de uma terra roxa estruturada. Piracicaba, 1991. 141p. Tese (Doutorado) - Escola Superior de Agricultura "Luiz de Queiroz", Universidade de São Paulo.

MORAES, S.O.; LIBARDI, P.L. \& DOURADO NETO, D. Problemas metodológicos na obtenção da curva de retenção da água no solo. Sciencia Agricola. Piracicaba, v.50, n.3, p.338-392, out./dez., 1993. 
NESMITH, D.S.; HARGROVE, W.L.; TOLLNER, E.W.; RADCLIFFE, D.E. A comparison of three soil surface moisture and bulk density sampling techniques. Transactions of the ASAE, v.29, n.5, p.1297-1299, 1986.

PEDROTTI, A.; PAULETTO, E.A.; TURATTI, A.L. Eficiência do método hidráulico de amostragem indeformada de solo. In: CONGRESSO BRASILEIRO DE CIENCIA DO SOLO, 25: Viçosa, 1995. Resumos expandidos. Viçosa: SBCS/ UFV, 1995. v.1, p.6-8.

PIMENTEL GOMES, F. Curso de estatística experimental, Piracicaba: Nobel. 1990, $468 \mathrm{p}$.

PREVEDELLO, C.L. Física do solo com problemas resolvidos. Curitiba. SAEAFS. 1996, 446p.

RAIJ, B. van, Avaliação da fertilidade do solo. Piracicaba. POTAFOS, 1987, 142p.

REICHARDT, K.; VIEIRA, S.R.; LIBARDI, P.L. Variabilidade espacial de solos e experimentação de campo. Campinas. Revista Brasileira de Ciência de Solo. V.10, p.1-6, 1986.

REMORTEL, R.D.V.; SHIELDS, D.A. Comparison of clode and core methods for determinations of soil bulk density. Communicatiom Soil Science and Plant Analysis..v.24, n.17-18, p.2517-2528, 1993.

REVUT, I.B.; RODE, A.A. Experimental methods studying soil structure. Published for United States Department of Agriculture, Washington, D.C., 1969. 
RIBEIRO JUNIOR, P.J. Métodos geoestatísticos no estudo da variabilidade espacial de parâmetros do solo. Piracicaba, SP. 1995. 99p. (dissertação de mestrado) ESALQ/USP.

SARAIVA, O.F.; ALVAREZ, V.H.; da COSTA, L.M. Variabilidade de algumas características físicas e químicas de um podzólico vermelho-amarelo câmbicp distrófico. Revista Ceres, v.39, n.226, p.529-541, 1992.

SEIXAS, F. Compactação do solo devido á mecanização florestal: causa, efeitos e práticas de controle. Piracicaba: IPEF, 1988, 10p. (Circular Técnica,IPEF,163).

SHARMA, P. K.; De DATTA, S. K. A core sampler for puddled soils. Soil Science Society American Journal,v.49: 1069-1070, 1985.

SILVA, A. P. Variabilidade espacial de atributos físicos do solo. Piracicaba, 1988. 98p. Tese (Doutorado) - ESALQ/USP.

SILVA, A.P.; LIBARDI, P.L.; VIEIRA, S.R. Variabilidade espacial da resistência à penetração de um latossolo vermelho-escuro ao longo de uma transeção. Campinas. Revista Brasileira de Ciência de Solo, v.13, p.1-5,1989.

SINIDRAS, N.; VIEIRA, S. R.; ROTH, C. H. Determinação de algumas características físicas de um latossolo roxo distrófico sob plantio direto e preparo convencional. Revista Brasileira de Ciência de Solo, v.8, p.265-268, 1984.

SOUTO, J.S.; MIRANDA, J.R.P. de; FREIRE, A.L.O.; SOUZA, A.A.; ROLIM Jr., S.S. \& MOURA, O.N. Efeito da compactação artificial do solo sobre a penetração de raízes de Algaroba (prosopis juliflora) e alguns parâmetros de crescimento. In: CONGRESSO BRASILEIRO DE CIÊNCIA DO SOLO, 25: Viçosa, 1995. Resumos expandidos. Viçosa: SBCS/UFV, 1995. v.4, p.1945-1947. 
SOUZA, L. da S.; COGO, N.P.; VIEIRA, S.R. Variabilidade de propriedades físicas e químicas do solo em um pomar cítrico. Viçosa, Revista Brasileira de Ciência de Solo, v.21, p.367-372, 1997.

SRIVASTAVA, A.K.; SMUCKER, A.J.M; McBURNEY, S.L.Na Improved mechanical soil-root sampler. Transactions of the ASAE, v.25, n.4: p. 868-871, 1982.

TERRY, T.A.; CASSEL, D.K.; WOLLUM, A.G. Effects of soil sample size and included root and wood on bulk density in forest soils. Soil Science Society American Journal, v.45: 135-138, 1981.

TOGNON, A.A. Propriedades físico hídricas do latossolo roxo da região de Guaíra-SP sob diferentes sistemas de cultivo. Piracicaba, 1991. 67p. Dissertação (Mestrado) Escola Superior de Agricultura "Luiz de Queiroz", Universidade de São Paulo.

TORMENA, C.A. Caracterização e avaliação do intervalo hídrico ótimo de um latossolo roxo. Piracicaba, 1998. 106p. Tese (Doutorado) - Escola Superior de Agricultura "Luiz de Queiroz", Universidade de São Paulo.

TURATTI, A.L.; VILLAGRA, M.M.; PONCE, J.E.; BACCHI, O.O.S.; REICHARDT, K. Variabilidade espacial do solo e sua implicação na calibração de sondas de neutrons. Campinas, Revista Brasileira de Ciência de Solo, v.14, p.259-262, 1990.

TURNER, G. O. A device for obtaining uncontaminated and undisturbed soil samples. Down Earth, v.30, p.19-21, 1974.

TUTLE, C. L.; GOLDEN, M. S.; SIROIS, D. L. A portable tool for obtaining soil cores in clayey or rockey soils. Soil Science Society American Journal. v.48, p.1453$1455,1984$. 
UHLAND, R.E. Physical properties of soils as modified by crops and management. Soil Science Society American Proceedings, v.14, p.361-366, 1949.

VIEIRA, S.R. Uso da geoestatística em estudos de variabilidade espacial. In: Curso de atualização em conservação do solo. Campinas: IAC, 1995. 61 p.

VIEIRA, L.S. Manual da ciência do solo. São Paulo: Agronômica Ceres, 1975. 464p.

VILA NOVA, N.A. Dados agrometeorológicos do município de Piracicaba. Piracicaba: Departamento de física e meteorologia, 1989.

WELLS, C. B. Core sampler for soil profiles. Journal Agricultural. Engeenering. Research.. v.4: p.260-266. 1959. 